\title{
Endovascular Metal Devices for the Treatment of Cerebrovascular Diseases
}

\section{Zhu, Yueqi}

2019-02-22

Zhu , Y, Zhang , H , Zhang , Y, Wu , H, Wei , L , Zhou, G, Zhang , Y, Deng , L , Cheng , Y , Li , M , Almeida Santos , H \& Cui , W 2019 , ' Endovascular Metal Devices for the Treatment of Cerebrovascular Diseases ' , Advanced Materials , vol. 31 , no. 8 , 1805452 . https://doi.org/10.1002/ad

http://hdl.handle.net/10138/327347

https://doi.org/10.1002/adma.201805452

acceptedVersion

Downloaded from Helda, University of Helsinki institutional repository.

This is an electronic reprint of the original article.

This reprint may differ from the original in pagination and typographic detail.

Please cite the original version. 


\section{Advanced Materials}

\section{Endovascular Metal Devices for the Treatment of Cerebrovascular Diseases --Manuscript Draft--}

Manuscript Number:

Full Title:

Article Type:

\section{Section/Category:}

Keywords:

\section{Corresponding Author:}

Additional Information:

Question

Please submit a plain text version of your cover letter here.
adma.201805452R1

Endovascular Metal Devices for the Treatment of Cerebrovascular Diseases

Review

Cerebrovascular disease; metal-based stents; biodegradable; flexible endovascular devices; drug elution

Helder Santos, D.Sc. (Chem. Eng.)

University of Helsinki

Helsinki, Helsinki FINLAND

\section{Response}

Helsinki, 21 August 2018,

Dr. Jos Lenders

Advanced Materials, Editor

Dear Dr. Jos,

Please, find enclosed our revised manuscript entitled "Endovascular Metal Devices for the Treatment of Cerebrovascular Diseases" (Review, No. adma.201805452), which we hope to be considered for publication in AM.

I would like to thank the reviewer for the very valuable and detailed comments on our manuscript. We have revised the manuscript according to the reviewer's comments, and made major revisions to the main text.

Please, find the modified and revised parts marked with yellow color in the revised manuscript file. However, some grammar modifications have not been marked in the manuscript. We have also replied to all the questions of the reviewer, and responded to each point of the comments. These have been revised and improved along the comments.

In additional, we have requested permissions to reproduce all the figures, except the ones we have drawn ourselves.

We sincerely hope that our questions satisfy the reviewer's concerns.

We believe that the readership of Advanced Materials will find this review useful and interesting, and look forward to your final approval of its publication.

Thank You in advanced for your kind consideration!

Sincerely,

Hélder Santos

Associate Professor (tenure-track; Pharm. Nanotechnol.), Head of Division Head of the Division of Pharmaceutical Chemistry and Technology Head of the Nanomedicines and Biomedical Engineering Group Head of the Preclinical Drug Formulation and Analysis Group 


\section{Director of Doctoral Programme in Drug Research, University of Helsinki}

Drug Research Program, Faculty of Pharmacy, University of Helsinki, Finland

\&

Helsinki Institute of Life Science (HiLIFE), University of Helsinki, Finland

@: helder.santos@helsinki.fi

Do you or any of your co-authors have a

No. The authors declare no conflict of interest.

conflict of interest to declare?

Corresponding Author Secondary

Information:

Corresponding Author's Institution:

University of Helsinki

Corresponding Author's Secondary Institution:

First Author:

Yueqi Zhu

First Author Secondary Information:

Order of Authors:

Yueqi Zhu

Hongbo Zhang

Yiran Zhang

Huayin Wu

Liming Wei

Gen Zhou

Yuezhou Zhang

Lianfu Deng

Yingsheng Cheng

Minghua Li

Helder Santos, D.Sc. (Chem. Eng.)

Wenguo Cui

Order of Authors Secondary Information:

Abstract:

Cerebrovascular disease involves various medical disorders that obstruct brain blood vessels or deteriorate cerebral circulation, resulting in ischemic or hemorrhagic stroke. Platinum coils with or without biological modification have become routine embolization devices in the cerebral aneurysm sac to reduce the risk of bleeding. Many intracranial stents, flow diverters and stent retrievers have been invented with uniquely designed structures. To accelerate the translation of these devices into clinical usage, an indepth understanding of the mechanical and material performance of these metal-based devices is critical. However, considering the more distal location and tortuous anatomic characteristics of cerebral arteries, present devices still risk failing to arrive at target lesions. Consequently, more flexible endovascular devices and novel designs are under urgent demand to overcome the deficiencies of existing devices. Herein, we discuss the pros and cons of the current structural designs when these devices are applied to the treatment of diseases ranging broadly from hemorrhages to ischemic strokes, in order to encourage further development of such kind of devices and investigation of their use in the clinic. Moreover, novel biodegradable materials and drug elution techniques, and the design, safety and efficacy of personalized devices for further clinical applications in cerebral vasculature are discussed. 
DOI: 10.1002/adma. ((please add manuscript number))

Article type: ((Review))

\title{
Endovascular Metal Devices for the Treatment of Cerebrovascular Diseases
}

\author{
Yueqi Zhü, Hongbo Zhang, Yiran Zhang ${ }^{\#}$, Huayin Wu, Liming Wei, Gen Zhou, \\ Yuezhou Zhang, Lianfu Deng, Yingsheng Cheng*, Minghua Li*, Hélder A. Santos*, \\ Wenguo Cui*
}

Dr. Y. Zhu, Y, Zhang, L. Wei, G. Zhou, Prof. Y. Cheng and Prof. M. Li

Department of Radiology; Shanghai Jiao Tong University Affiliated Sixth People's Hospital; No. 600, Yishan Road; Shanghai, 200233, P.R.China

Email: chengyingshengradio@hotmail.com, liminghuaradio@hotmail.com

Dr H. Zhang, Prof. L. Deng and Prof. W. Cui

Shanghai Key Laboratory for Prevention and Treatment of Bone and Joint Diseases, Shanghai Institute of Traumatology and Orthopaedics, Ruijin Hospital, Shanghai Jiao Tong University School of Medicine, 197 Ruijin 2nd Road, Shanghai 200025, P.R.China.

Email:wgcui80@hotmail.com

Dr H. Zhang and Y. Zhang

Department of Pharmaceutical Sciences Laboratory, Åbo Akademi University, FI00520, Finland.

Turku Center for Biotechnology, University of Turku and Åbo Akademi University, FI-00520, Finland.

H. $\mathrm{Wu}$

Harvard John A. Paulson School of Engineering and Applied Sciences, Harvard University, Cambridge MA 02138, USA

Prof. H. Santos

Drug Research Program, Division of Pharmaceutical Chemistry and Technology, Faculty of Pharmacy, University of Helsinki, FI-00014, Helsinki, Finland.

Email: helder.santos@helsinki.fi

\# These authors contributed equally to this work. 


\begin{abstract}
Cerebrovascular disease involves various medical disorders that obstruct brain blood vessels or deteriorate cerebral circulation, resulting in ischemic or hemorrhagic stroke. Platinum coils with or without biological modification have become routine embolization devices in the cerebral aneurysm sac to reduce the risk of bleeding. Many intracranial stents, flow diverters and stent retrievers have been invented with uniquely designed structures. To accelerate the translation of these devices into clinical usage, an in-depth understanding of the mechanical and material performance of these metalbased devices is critical. However, considering the more distal location and tortuous anatomic characteristics of cerebral arteries, present devices still risk failing to arrive at target lesions. Consequently, more flexible endovascular devices and novel designs are under urgent demand to overcome the deficiencies of existing devices. Herein, we discuss the pros and cons of the current structural designs when these devices are applied to the treatment of diseases ranging broadly from hemorrhages to ischemic strokes, in order to encourage further development of such kind of devices and investigation of their use in the clinic. Moreover, novel biodegradable materials and drug elution techniques, and the design, safety and efficacy of personalized devices for further clinical applications in cerebral vasculature are discussed.
\end{abstract}

Keywords: Cerebrovascular disease; metal-based stents; biodegradable; flexible endovascular devices; drug elution. 


\section{Introduction}

Cerebrovascular diseases have been ranked the second leading cause of death after ischemic heart disease in a recent analysis of the burden of 135 diseases $^{[1]}$. In 2015, cerebrovascular diseases accounted for 6.2 million deaths worldwide, or $11.1 \%$ of all deaths $^{[2]}$. Cerebrovascular diseases can damage the brain by causing changes to its blood supply, thereby depriving brain cells of the oxygen they need for survival. The pathological basis for stroke is disturbance of cerebral blood circulation, which may either be ischemic or hemorrhagic in nature. Approximately $85 \%$ of strokes are ischemic in nature, leading to infarction of the tissue supplied by the occluded vessel ${ }^{[3]}$. Hemorrhagic stroke is mostly caused by hypertension, intracranial aneurysms due to widening and weakening of an artery, and vascular malformations such as tangled vessels. Although they account for only $13 \%$ of total strokes ${ }^{[4]}$, hemorrhagic strokes are responsible for about $40 \%$ of all stroke mortality ${ }^{[5]}$. In the past, open surgery might be the only option for cerebrovascular diseases and was mainly considered for hemorrhage related diseases but rarely applied in acute or chronic ischemic stroke due to the high risk of mortality and morbidity from this operation.

In 1971, Serbinenko pioneered endovascular therapy by using a detachable balloon to occlude a traumatic carotid cavernous fistula ${ }^{[6]}$. Another milestone was marked by Guglielmi's report of the neurointerventional approach for cerebrovascular disease treatment in $1991^{[7]}$. Later on, this proof-of-concept was further commercialized into an electrolytically detachable platinum coil apparatus (GDC, Boston Scientific). At present, endovascular treatment is of utmost importance for cerebrovascular diseases due to its minimal invasiveness and largely satisfactory outcomes. The success of endovascular treatment relies heavily on the device applied since any deficiency in the device can cause serious consequences in the clinic. Compared with peripheral vascular devices, the devices used in the cerebral vasculature possess unique requirements as 
follows: first, the materials used must be approved for endovascular implantation and should not cause any bio-toxicity to neuro cells; second, the devices are required to have excellent flexibility and mechanical performance to avoid any hemorrhaging or ischemic complications during their delivery or release. Cerebral devices are often introduced from the femoral artery and passed through the aortic and cervical arteries before entering the brain vasculature; therefore, flexibility is often the first consideration when developing a new cerebral device. Moreover, the diameter of intracranial arteries is only several millimeters wide and these arteries often pass through the bone channel at the skull base to form an extremely tortuous path. Although many metal alloys, ceramics and biopolymer materials have been approved for implantation in a human body, only a few metals or metal alloys meet the requirements of cerebrovascular devices, including platinum, nitinol alloy, Co alloy and 316L stainless alloy ${ }^{[8]}$. Besides liquid embolic agents such as ethylene vinyl alcohol copolymer (Onyx), almost all intracranial implanted devices used in clinical settings are metal-based. Thus, the development of intracranial devices has mainly focused on designing novel structures.

Intracranial implanted metal devices are roughly categorized into four sub-types: embolic devices (coils), stents, flow diverting devices and stent retrievers. As embolic devices are mostly used for aneurysm embolization, which requires excellent flexibility, the coils are typically made of platinum and their alloys are usually precontoured into a $2 \mathrm{D}$ or $3 \mathrm{D}$ shape to reduce the risk of aneurysm rupture during embolization ${ }^{[9]}$. For devices that need to provide intraluminal support, including stents, flow diverters or stent retrievers, a high compression rate is often needed to achieve a smaller profile for smooth delivery and good mechanical radial force is demanded to adapt to tortuous vessel wall after releasement. (Figure 1) Such devices are mainly made of nitinol, Co and 316L stainless alloys. Shape memory nitinol alloys with self-expanding properties 


\section{Coil devices}

\subsection{Overview}

Coils with either detachable or free designs were the first devices made of metal alloys to be used in clinical settings to treat cerebrovascular diseases. The most 
commonly used metals are, in order of increasing hardness, nitinol, platinum, nickel, iridium, and tungsten; these metals all have a proven record for patient safety and their alloys can be used to tune the mechanical properties. To create coils for aneurysm sac embolization, metal stock wires are precontoured into a 2D or 3D shape. In 1991, the first reported electrolytically detachable coils by Guglielmi (GDC, Boston Scientific) were platinum coils ${ }^{[7]}$; however, a platinum (92\%)/tungsten $(8 \%)$ alloy has since become the most popular material for coil design. Platinum-based materials are used in a variety of medical applications, because the chemical, physical and mechanical stability of platinum and its alloys make them ideal for permanent implantation in the body. They are inert and do not corrode in physiological environments or cause allergic reactions, unlike other metals such as nickel and copper. Since coils used in brain vasculature are tiny (a few millimeters wide) and have complicated multi-dimensional structures, only platinum and its alloys meet the requirements. Platinum rods or wires can be produced in sizes ranging from 0.125 " $(3.175 \mathrm{~mm})$ in diameter all the way down to $0.001 "(0.0254 \mathrm{~mm})^{[11]}$, while other metal alloys, such as Nitinol alloy, cannot be made into such tiny diameters while maintaining a similar mechanical strength. Another benefit of platinum is its radiopacity; being clearly visible in X-ray images is useful for coil insertion, adjustment or detachment during operation. Intracranial platinum coils are mainly used for embolization of cerebrovascular diseases such as aneurysms and arteriovenous fistulas. Because of the fragile nature of vessel walls under disease conditions and the tortuous shape of brain arteries, the embolic system must be soft and flexible enough to conform to the size and shape of the aneurysm sac yet minimize increases in intraluminal pressure to avoid aneurysm rupture. Meanwhile, the coil device should also have enough stiffness, acceptable packing density and a reasonable three-dimensional architecture to resist stress caused by blood flow, which may cause recanalization after embolism. Furthermore, the surface of the coil device should resist 
to clotting within the aneurysm sac during the initial adjustment period and have good biocompatibility for permanent implantation.

The platinum coil's configuration determines its ability to form a basket in the aneurysm sac and its packability, which can be predicted from its primary, secondary and tertiary structures. The primary structure is the "stock" wire with a diameter $\left(\mathrm{D}_{1}\right)$ that is usually between 0.00175 and 0.003 inch. It is wound around a mandrel to create the coiled secondary structure, which may vary in size along its length. The secondary structure diameter, $\mathrm{D}_{2}$, can range from approximately 0.010 inch to $0.015 \mathrm{inch}^{[8 \mathrm{~b}]}$. Finally, the secondary structure can be shaped into tertiary configurations, such as helices, spheres, and complex or irregular 3D structures, described by a particular loop diameter $\left(\mathrm{D}_{3}\right)$ and length $(\mathrm{L})$.

In the clinic, the coil stiffness and configuration are two fundamental considerations for coil selection from among the commercially available systems. During an embolization procedure, coils will be inserted until the aneurysm sac is sufficiently occluded; operators choose specific stiffnesses and configurations of coils to perform framing, packing and wind up. Stiffness is a critical determinant of a coil's mechanical strength and is directly related to the material properties as well as the coil structure. The metal strength is described by the shear modulus $(\mathrm{G})$ of the stock wire (Equation $1)$, defined as the ratio of the shear stress to the shear strain ${ }^{[8 b]}$, which describes the coefficient of elasticity under a shearing force. A thinner stock wire diameter (D1) will make a softer coil while the secondary structure diameter (D2) and the spacing between turns influence both stiffness and packing. Lastly, the tertiary parameters $\left(\mathrm{D}_{3}\right.$ and $\left.\mathrm{L}\right)$ are key determinants of the entire system's effective stiffness and commercial products are often differentiated at this level. Since a softer coil will demonstrate improved placement in an aneurysm, the coils are typically sold as "soft," "supersoft" and "ultrasoft". 


$$
k=\frac{D_{1}{ }^{4} G}{8 D_{2}{ }^{3} n}=\text { Stiffness } \propto \frac{D_{1} G}{D_{2} n} .
$$

\section{Equation 1. Coil stiffness equation}

Complex or spherical coils with a 3D structure are the most frequently selected as the first coil to construct a frame to allow further insertion of embolization coils. The 3D framing coils can be divided into stable and unstable shapes. A 3D coil with a stable shape will keep its precontoured shape inside the aneurysm sac to allow more coils to be inserted in the future. Commercially available examples of such coils include the Guglielmi detachable coil (GDC) 3D (Stryker), Orbit (Codman Neurovascular), Micrus Presidio (Codman Neurovascular) and Target 360 (Stryker) coils. A 3D coil with an unstable shape has better flexibility and its precontoured 3D shape can be adjusted to irregular sacs, as demonstrated by products such as Cosmos (MicroVention/Terumo, Inc.; Aliso Viejo, Calif), Axium (Covidien/ev3) and Target nano 360 (Stryker) coils. The Target Nano (Stryker), Delta Plush (Codman Neurovascular) and Axium Prime (Covidien/ev3) are 2D coils with a helical shape that are primarily used for embolization. Some ultrasoft coils with small diameters are specifically designed to perform embolization as the last or finishing coil, such as the VFC (MicroVention/Terumo), Target Nano (Stryker) and Axium Prime (Covidien/ev3). Meanwhile, many kinds of modified coils have been developed to improve embolism outcomes by promoting blood coagulation or by enabling increased packing densities; these include polyglycolic acid (PGA)-core coils, polylactic-co-glycolic acid (PLGA) coated coils, coils with PGLA or nylon fibers attached or expandable hydrogel coils, which are also called "bioactive coils" ${ }^{[8 b]}$ (Figure 2) (Table 1).

To perform an embolism treatment, a coil is delivered through the lumen of a microcatheter to the target lesion via a push wire. There are many kinds of microcatheters that can be used for coil system delivery. Typically, they have inner lumen diameters between 0.015-0.027 inches. However, a larger lumen diameter of 
microcatheter does not always mean that the coil will pass through more smoothly. In fact, a mis-matched bigger catheter lumen is likely to cause the pre-shaped coil to buckle, therefore preventing the pushing force from being transmitted along its axis. This may increase friction between the coil and the catheter wall, and cause uncontrollable coiling within the aneurysm. Presently available coils use three types of detachment methods: 1) electrolytic detachment; 2) hydraulic detachment and 3) mechanical detachment. The principle of electrolytic detachment, which was first applied by Guglielmi, is to use an electric current to melt the metallic connection between the coil and the delivery wire to achieve coil detachment. The primary advantage of this detachment method is that the metal connection between coil and the push wire makes it firm. However, sometimes electrolytic detachment may require repeated attempts, so the detachment time can range from a few seconds to several minutes. Moreover, detachment of the Guglielmi coil resulted in gas generation and increased risk of clot formation ${ }^{[12]}$. Hydraulic detachment and mechanical detachment are newer methods and are superior to electrolytic detachment because there is no metal at the connection between the coil and the push wire, which may not increase the stiffness of the whole coil system. More importantly, the more consistent seconds-long detachment time and success rate are improvements over electrolytic detachment.

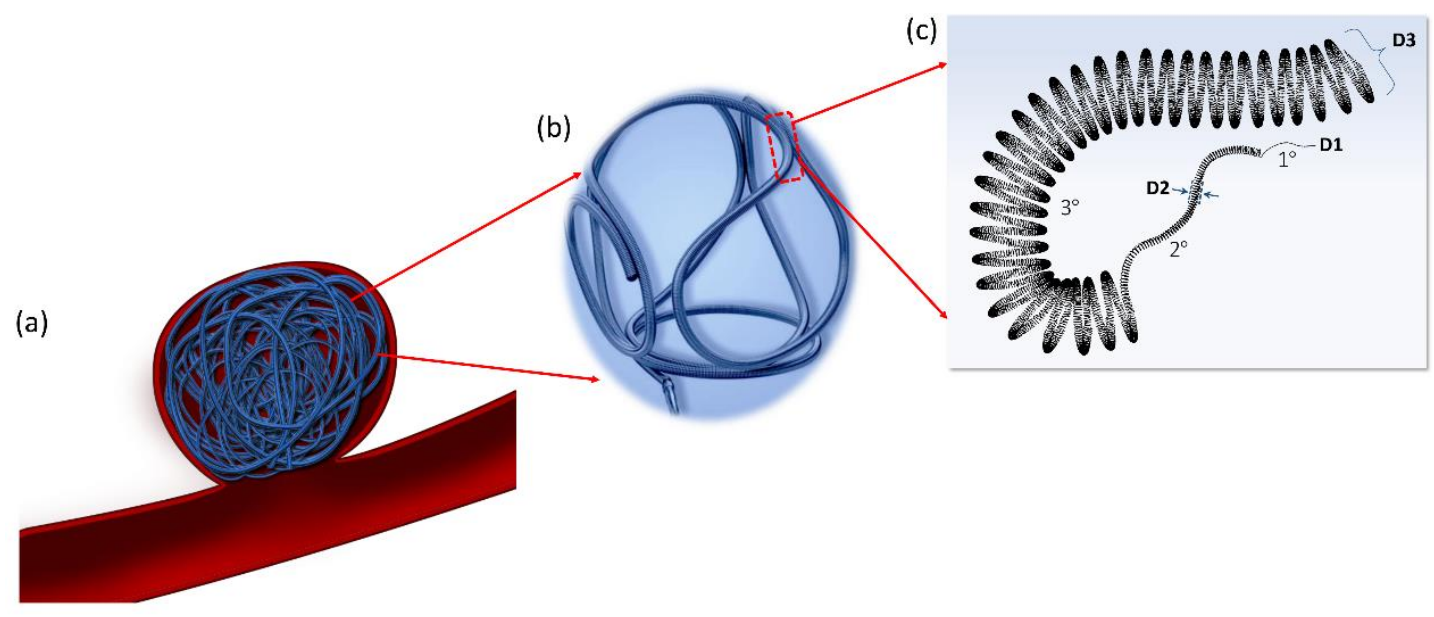


Figure 2. Structure design of platinum coils. Two-dimensional and three-dimensional platinum coils can be applied for aneurysm sac embolism (a) and a typical threedimensional platinum coil $(b)$ configuration from a primary $\left(1^{\circ}\right)$ to secondary $\left(2^{\circ}\right)$ to tertiary $\left(3^{\circ}\right)$ structure $(c)$. 
Table 1. Detailed information and parameters of metal devices used in clinic for the treatment of cerebral aneurysms

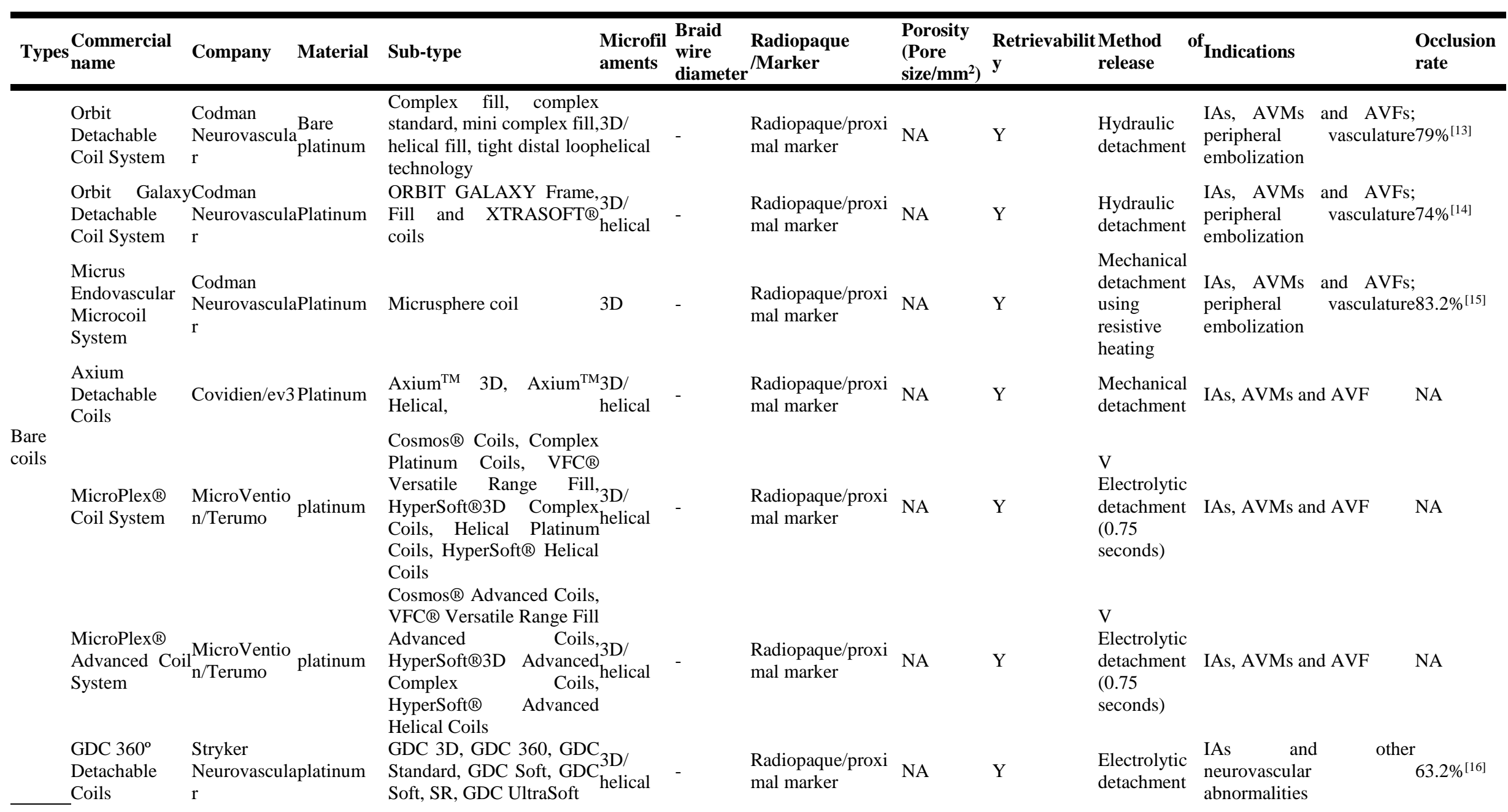




\begin{tabular}{|c|c|c|c|c|c|c|c|c|c|c|c|}
\hline \multirow{2}{*}{\multicolumn{2}{|c|}{$\begin{array}{l}\text { Target } \\
\text { Detachable } \\
\text { Coils } \\
\\
\text { Penumbra } \\
\text { Coil } 400\end{array}$}} & \multicolumn{2}{|c|}{$\begin{array}{lc}\text { Stryker } & \text { 316LVM } \\
\text { Neurovasculastainless } \\
\mathrm{r} & \text { steel }\end{array}$} & \multirow{2}{*}{$\begin{array}{l}\text { Target }{ }^{\circledR} \text { XL, Target }{ }^{\circledR} 3 \mathrm{D}, \\
\text { Target }{ }^{\circledR} 360 \text { and } \text { Target }{ }^{\circledR} / \\
\text { Nano coils } \\
\text { helical } \\
\text { Complex } \\
\text { complex } \\
\text { soft, J-soft, curve extra soft }\end{array}$} & \multirow{2}{*}{$\begin{array}{l}- \\
-\end{array}$} & \multirow{2}{*}{$\begin{array}{l}\text { Radiopaque/proxi } \\
\text { mal marker } \\
\text { Radiopaque/proxi } \\
\text { mal marker }\end{array}$} & \multirow{2}{*}{$\begin{array}{l}\text { NA } \\
\text { NA }\end{array}$} & \multirow{2}{*}{$\begin{array}{l}\mathrm{Y} \\
\mathrm{Y}\end{array}$} & \multirow{2}{*}{$\begin{array}{l}\text { Electrolytic } \\
\text { detachment } \\
\text { (InZone } \\
\text { detachment) } \\
\\
\text { mechanical } \\
\text { detachment }\end{array}$} & \multicolumn{2}{|c|}{$\begin{array}{l}\text { Obstruct blood flow in } \\
\text { vascular abnormalities of } \\
\text { the neurovascular and } 90 \% \%^{[17]} \\
\text { peripheral } \\
\text { vessels }\end{array}$} \\
\hline & & $\begin{array}{l}\text { Penumbra, } \\
\text { Inc. }\end{array}$ & $\begin{array}{l}\text { Stretch } \\
\text { resistant } \\
\text { bare } \\
\text { platinum }\end{array}$ & & & & & & & $\begin{array}{l}\text { IAs, AVMs and AVH } \\
\text { peripheral vasculature }\end{array}$ & $56 \%[18]$ \\
\hline & $\begin{array}{l}\text { Hydrogel } \\
\text { Advanced } \\
\text { Coated Coils }\end{array}$ & $\begin{array}{l}\text { MicroVentio } \\
\text { n Terumo }\end{array}$ & $\begin{array}{l}\text { Platinum } \\
\text { and } \\
\text { polymeric } \\
\text { hydrogel }\end{array}$ & $\begin{array}{l}\text { HydroCoil }{ }^{\circledR}, \text { HydroSoft } \AA, \\
\text { HydroFrame }{ }^{\circledR D} / \\
\text { HydroFill }{ }^{\circledR}\end{array}$ & - & $\begin{array}{l}\text { Radiopaque/proxi } \\
\text { mal marker }\end{array}$ & NA & $\mathrm{Y}$ & $\begin{array}{l}\text { Electrolytic } \\
\text { detachment } \\
(0.75 \\
\text { seconds })\end{array}$ & IAs, AVMs and AVF & $77.8 \%^{[19]}$ \\
\hline & Matrix coil & $\begin{array}{l}\text { Stryker } \\
\text { Neurovascula } \\
\mathrm{r}\end{array}$ & $\begin{array}{l}\text { Platinum } \\
\text { aand PLGA } \\
\text { coating }\end{array}$ & $\begin{array}{l}\text { Matrix } 1 \text { coil; } \\
\text { Matrix } 2 \text { coil }\end{array}$ & - & $\begin{array}{l}\text { Radiopaque/proxi } \\
\text { mal marker }\end{array}$ & NA & $\mathrm{Y}$ & $\begin{array}{l}\text { Electrolytic } \\
\text { detachment }\end{array}$ & $\begin{array}{l}\text { IAs and } \\
\text { neurovascular } \\
\text { abnormalities }\end{array}$ & $86.7 \%^{[20]}$ \\
\hline & Nexus coil & Covidien/ev3 & $\begin{array}{l}\text { PGLA } \\
\text { microfilam } \\
\text { ent and } \\
\text { Platinum }\end{array}$ & 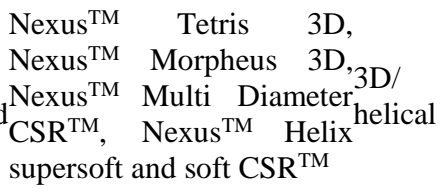 & - & $\begin{array}{l}\text { Radiopaque/proxi } \\
\text { mal marker }\end{array}$ & NA & $\mathrm{Y}$ & $\begin{array}{l}\text { Mechanical } \\
\text { detachment }\end{array}$ & IAs, AVMs and AVF & $48 \%^{[21]}$ \\
\hline $\begin{array}{l}\text { Bioacti } \\
\text { ve coils }\end{array}$ & $\begin{array}{l}\text { Axium } \\
\text { MicroFX }\end{array}$ & Covidien/ev3 & $\begin{array}{l}\text { PGLA, } \\
\text { nylon fiber } \\
\text { and } \\
\text { Platinum }\end{array}$ & $\begin{array}{l}\text { Axium }^{\mathrm{TM}} \quad \text { PGLA } 3 \mathrm{D}, \\
\text { Axium }{ }^{\mathrm{TM}} \text { Helix, Axium } \\
\text { nylon Helix coil }\end{array}$ & - & $\begin{array}{l}\text { Radiopaque/proxi } \\
\text { mal marker }\end{array}$ & NA & $\mathrm{Y}$ & $\begin{array}{l}\text { Mechanical } \\
\text { detachment }\end{array}$ & IAs, AVMs and AVF & $90.6 \%{ }^{[22]}$ \\
\hline & $\begin{array}{l}\text { Micrus } \\
\text { Endovascular } \\
\text { Microcoil } \\
\text { System }\end{array}$ & $\begin{array}{l}\text { Codman } \\
\text { Neurovascula } \\
\mathrm{r}\end{array}$ & $\begin{array}{l}\text { PGA } \\
\text { running } \\
\text { through the } \\
\text { alumen of } \\
\text { the primary } \\
\text { platinum } \\
\text { wind }\end{array}$ & ferecyte & & & & & & & $59 \%^{[23]}$ \\
\hline & $\begin{array}{l}\text { Micrus } \\
\text { Endovascular } \\
\text { Microcoil } \\
\text { System }\end{array}$ & $\begin{array}{l}\text { Codman } \\
\text { Neurovascula } \\
\text { r }\end{array}$ & $\begin{array}{l}\text { Stretch- } \\
\text { resistant } \\
\text { PGA } \\
\text { a element } \\
\text { and } \\
\text { Platinum }\end{array}$ & 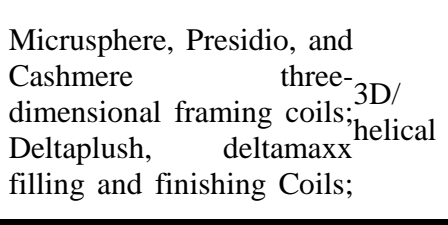 & - & $\begin{array}{l}\text { Radiopaque/proxi } \\
\text { mal marker }\end{array}$ & NA & $\mathrm{Y}$ & $\begin{array}{l}\text { Mechanical } \\
\text { detachment } \\
\text { using } \\
\text { resistive } \\
\text { heating }\end{array}$ & $\begin{array}{l}\text { IAs, AVMs } \\
\text { and AVFs; embolization } \\
\text { of peripheral } \\
\text { vasculature }\end{array}$ & $83.2 \%^{[15]}$ \\
\hline
\end{tabular}




\section{ADVANCED

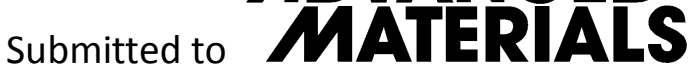

Ultipaq and Helipaq two-

dimensional filling coi

AVF, arteriovenous fistula; AVM, arteriovenous malformation; GDC, Guglielmi Detachable Coil; PGA, polyglycolic acid; PLGA, polylactic-co-glycolic acid. 


\section{ADVANCED \\ Submitted to}

\subsection{Typical coils}

\subsubsection{Axium $^{\mathrm{TM}}$ coils}

The Axium $^{\mathrm{TM}}$ detachable coil system consists of a tertiary structure coil and a delivery system. The coil is constructed of a platinum/tungsten alloy primary line, a polypropylene core wire and a 316L stainless detachable zone. The coil system sizes range from the largest $(25 \mathrm{~mm})$ to the smallest $(1.5 \mathrm{~mm})$ available $3 \mathrm{D}$ helices. The coil design aims to balance the softness of a size "10" serial coil with the stability and volume of an "18" serial coil. All Axium ${ }^{\mathrm{TM}}$ coils are mechanically detached by a simple push movement that separates the link from coils' body without any cables, boxes or batteries. This detachment method is fast and facilitates precise coil placement, both of which are especially important when treating a ruptured aneurysm.

Axium $^{\mathrm{TM}}$ coils include bare platinum coils, PGLA microfilament coils, and nylon microfilament coils in stiffnesses from soft to super soft. In most coil sizes, various 2D helix shapes and 3D tertiary shapes are available for clinical selection. The 3D Axium ${ }^{\mathrm{TM}}$ has large loops which can change packing direction when they touch the aneurysm wall; this design makes the coil adapt well to irregular sacs and provides good mechanical stability for subsequent insertion of $2 \mathrm{D}$ coils. The Axium ${ }^{\mathrm{TM}}$ Prime (Super Soft) coil (44\% thinner primary wire, $38 \%$ thinner stretch-resistant strands) is four times softer than the routine Axium bare coils, enabling the coils to better conform to the aneurysm shape and fill in open spaces. Axium ${ }^{\mathrm{TM}}$ MicroFX $^{\mathrm{TM}}$ coils have additional overlapped nylon or PGLA microfilaments between coil loops, which are both procoagulant materials that prompt thrombosis inside the aneurysm sac to further reduce the risk of aneurysm bleeding or recurrence ${ }^{[22,24]}$. PLGA is a bio-absorbable material and nylon is a more durable but non-absorbable material, so the overlapped design creates a more structurally sound lattice effect. 


\section{Submitted to

\subsubsection{Target $^{\circledR}$ coils $^{2}$}

The Target ${ }^{\circledR}$ detachable coil is a new generation bare coil from the Stryker Company; it is an update from the first generation GDC coil. The Target ${ }^{\circledR}$ coil has a laser-ablated detachment zone that uses $82 \%$ less metal and can be detached more quickly than GDC (around 30 seconds compared with minutes). Less metal between the coil and push wire makes the connection zone shorter and softer, which minimizes microcatheter kickback and enhances stability during coiling.

The Target ${ }^{\circledR}$ detachable coil family includes Target ${ }^{\circledR}$ XL, Target ${ }^{\circledR}$ 3D, Target ${ }^{\circledR} 360$ and Target ${ }^{\circledR}$ Nano coils. The Target ${ }^{\circledR}$ XL and 3D are used for regular embolization; the 360 is designed especially for frame building and Nano coils are optimized to be the last coil during embolization ${ }^{[25]}$. The first 1.5 loops of the $\operatorname{Target}^{\circledR} 360^{\circ}$ coil are $25 \%$ smaller than the specified secondary coil diameter, which allows the first few loops to roll freely within the aneurysm sac to adhere to the outer wall and leave an open center, making it suitable for further filling and neck coverage using concentric coils ${ }^{[26]}$. The Nano ${ }^{\mathrm{TM}}$ detachable coil is softer than most coils with a diameter $<2 \mathrm{~mm}$ and 2 times softer than normal Target ultrasoft coils. It is constructed by using a smaller primary wire and the most flexible delivery wire. The increased conformability of $\mathrm{Nano}^{\mathrm{TM}}$ coils is designed to treat challenging, small aneurysms or residual spaces after coilingh ${ }^{[27]}$. The $\mathrm{Nano}^{\mathrm{TM}}$ coils come in two shapes, Target ${ }^{\circledR} 360$ Nano $^{\mathrm{TM}}$ coils and Target $^{\circledR}$ Helical Nano ${ }^{\mathrm{TM}}$ coils, with minimal sizes of only $1 \mathrm{~mm} \times 2 \mathrm{~cm}$ and $2 \mathrm{~mm} \times 1 \mathrm{~cm}$, respectively. 


\section{Submitted to

\subsubsection{Hydrogel Coils}

Hydrogel coils were developed to improve packing density by using an expansible hydrogel that is more effective at filling the aneurysm lumen compared to bare platinum coils. Examples of hydrogel coils include the HydroCoil ${ }^{\circledR}$ Embolic system, the HydroSoft $^{\circledR}$ and HydroFrame ${ }^{\circledR}$ Advanced Embolic coils and the HydroFill ${ }^{\circledR}$ Advanced Embolic coil.

The HydroCoil ${ }^{\circledR}$ Embolic System is the first generation of hydrogel coils. The device has a platinum coil base with a synthetic, polymeric hydrogel attached to the surface. The hydrogel swells to a nine-fold increase in volume in a physiological environment ${ }^{[28]}$. The initial diameter of these devices is approximately 0.010 inches, which is compatible with the 0.017 inch inner diameter of microcatheters. The hydrogel coating will significantly expand after only 5 minutes, thus the HydroCoil needs to be deployed or retracted back into the microcatheter within this period of time. In blood, the hydrogel material reaches its maximum size, approximately 0.035 inches in diameter, in 20 minutes. 


\section{Submitted to

HydroSoft ${ }^{\circledR}$ and HydroFrame ${ }^{\circledR}$ Advanced Embolic Coils belong to the new generation of the HydroCoil ${ }^{\circledR}$ Embolic System. Both of these coils have a hydrogel core inside an outer platinum coil. Due to a 2D helical shape and ultra-soft stiffness, the HydroSoft ${ }^{\circledR}$ coil seeks out small spaces and delivers hydrogel at the aneurysm neck to improve aneurysm sac occlusion and reduce aneurysm recurrence rates as compared to bare platinum coils ${ }^{[29]}$. HydroFrame ${ }^{\circledR}$ has variable diameter loops to facilitate the formation of a frame in irregularly shaped aneurysms ${ }^{[30]}$. Hydrogel coils at the aneurysm neck are more likely to increase the neck coverage than bare coils. In addition, the expanded hydrogel can provide extra scaffolding to facilitate neointima formation across the neck to prompt histological healing. As a result of the new design, the second-generation coils need no prepping or steaming before usage and have an extended 30-minute working time. Both kinds of new coil systems are compatible with $0.0165 "$ to $0.021 "$ inner diameter microcatheters.

The HydroFill@ Advanced Embolic coil is designed for volumetric filling of aneurysm sac and can reduce intra-aneurysm flow using fewer coils than bare coils ${ }^{[31]}$. In experimental aneurysms created to test the occlusion effect of HydroFill, the hydrogel material swelled through the platinum coil and expanded the diameter by $20 \%$, increasing volumetric occlusion compared with a bare platinum coil ${ }^{[32]}$. Similar to bare platinum coils, HydroSoft ${ }^{\circledR}$ and HydroFrame ${ }^{\circledR}$, a HydroFill ${ }^{\circledR}$ coil does not need to be steamed prior to working and has a reasonable 10-30 minute working time for coil insertion and adjustment.

\subsection{Clinical applications}

Metal coils are always the first choice in the clinic for endovascular embolization of aneurysm sacs because they reduce the risk of subarachnoid hemorrhaging caused by a ruptured aneurysm, a serious complication that results in a nearly $50 \%$ mortality rate clinically. Comparing and analyzing the performance of different types of coils is 


\section{Submitted to

necessary to rationalize the choice of devices for better treatment outcomes and to reduce complications. Meanwhile, other devices such as balloons and stents are also widely used in conjunction with coils to facilitate and increase the coil packing rate, reduce coil herniation and maintain parent artery patency. A thorough understanding of the feasibility, efficacy and safety of these assisting techniques may guide the practitioner in their treatment approach during clinical application.

\subsubsection{Endovascular coiling for cerebral aneurysm}

The development of coils with very controlled detachment systems is crucial for their widespread use in endovascular treatments ${ }^{[7,33]}$. Despite the fact that coils have also been used successfully for cerebrovascular diseases such as direct arteriovenous fistulas, dural arteriovenous fistulas and arteriovenous malformations, coils are most widely used for aneurysm embolization in the clinic. The International Subarachnoid Aneurysm Trial (ISAT) revealed that endovascular coiling treatment has a more favorable early survival advantage as well as lower morbidity and mortality rates than surgical clipping, which tries to cut off blood flow to the aneurysm by inserting a metal clip at the aneurysm neck ${ }^{[34]}$. Large studies from single or multiple centers showed acceptable mortality $(\approx 2 \%)$ and morbidity rates (between $4 \%$ and $9 \%$ ) after coiling treatments, most of which were related to thromboembolic complications and intraoperative rupture ${ }^{[35]}$. Due to the development of noninvasive imaging techniques, increasing numbers of intracranial aneurysms diagnosed before rupture are able to receive coiling treatments. In the first prospective multicenter study, Analysis of Treatment by Endovascular approach of Nonruptured Aneurysms (ATENA), a total of 739 coiled unruptured aneurysms yielded a technique success rate of $95.7 \%$, technical adverse event rate of $15.4 \%, 1$-month morbidity rate of $1.7 \%$ and 1-month mortality rate of $1.4 \%^{[36]}$. The results of the prospective ISUIA study also indicate a better outcome associated with coiled aneurysms ${ }^{[37]}$. Thus, coiling for aneurysms, whether ruptured or unruptured, is a feasible and effective treatment option. 


\section{Submitted to

With the development of more flexible, shaped and bio-material coated coils, endovascular coiling treatment outcomes are consistently improving. The final treatment outcome may depend on many factors including coil size, stiffness, configuration, surface modification techniques and most importantly, the doctor's experience with the principles of coil selection. Packing density, defined as the ratio of the inserted coil volume to the total aneurysm volume, can also affect aneurysm recurrence rate observed during angiographic follow up. To achieve a higher packing density, the inserted coil volume, which is dependent on both coil thickness and length, must be increased. Theoretically, thicker coils should have a higher packing density than thinner ones of the same length ${ }^{[38]}$.

\subsubsection{Treatment outcomes using modified coils}

Many modified coils have been developed to increase the coil packing rate, clot formation or inflammatory response within the aneurysm sac to promote mechanical or histological healing of an aneurysm. Typical surface-modified coils include the HydroCoils, Axium MicroFX, Micrus Cerecyte and Matrix coils. Modification techniques include coating with a hydrogel or PGLA, or microfiber attachment. Applying these techniques on bare coils can reduce the risk of aneurysm recurrence, rebleeding, and the need for retreatment.

The HydroCoil embolic system obviously improves the packing rate in the aneurysm lumen, $72 \%$ as compared to $32 \%$ with standard platinum coils ${ }^{[39]}$. In the HydroCoil for Endovascular Aneurysm Occlusion (HEAL) Study, the recurrence rate after coiling was $0 \%$ when HydroCoil represented $\geq 75 \%$ of the total coil length compared with a recurrence rate of $23 \%$ when $<75 \%$ of the length was HydroCoil $(\mathrm{P}=.035)$. Similarly, when the final coil inserted was a HydroCoil, the recurrence rate was $11 \%$, considerably lower than the $29 \%$ recurrence rate when the final coil was a bare platinum coil (P $=0.047)^{[40]}$. These data suggest that HydroCoil can increase the coil packing rate to both 


\section{Submitted to

the aneurysm sac and the aneurysm neck to reduce recurrence. However, some concerns remain when using HydroCoil at the aneurysm neck as the swelled hydrogel may herniate into the parent artery and result in stenosis or occlusion. Even so, the further randomized HydroCoil Endovascular Aneurysm Occlusion and Packing Study (HELPS) trial revealed that using hydrogel coils gave an absolute $7.0 \%$ reduction in the proportion of major aneurysm recurrence at 18 months after treatment ( $28 \%$ vs. $36 \%$ for the control patients), which indicated hydrogel coils were more effective than bare coils. Possible reasons for the reduction may be that hydrogel coils reduce the number of coils necessary, and thus, the procedure time. In patients with recently ruptured aneurysms, the hydrogel group had $8.6 \%$ fewer major angiographic recurrences than the control group, suggesting improved adverse primary outcomes ${ }^{[41]}$. The German Randomized Endovascular Aneurysm Trial (GREAT) was conducted to compare HydroSoft/HydroFrame coils with standard platinum coils and the results also indicated higher packing densities with hydrogel coils while complication and angiographic occlusion rates were the same for both two groups ${ }^{[30,42]}$. In the Axium MicroFX for Endovascular Repair of IntraCranial Aneurysm (AMERICA) study, 100 aneurysms were treated with Axium MicroFX Coils. The total technical success was 99\%, and $90.6 \%$ of the aneurysms with follow-up data had Raymond grade I (complete) or II (residual neck only) occlusion ${ }^{[22,43]}$.

Despite indications that hydrogel coils and nylon or PGLA microfilament coils should yield more favorable treatment outcomes than bare platinum coils, clinical trials have so far revealed results to the contrary. Kang et al. found that even though the mean coil volume deployed and packing density were notably higher when PGLA coils (Matrix coil, Boston Scientific) were used, the incidence of recanalization was the same as for bare coils ${ }^{[4]}$. Similar results were also observed for Cerecyte (Micrus Endovascular, San Jose, CA, USA) coils during a 6-month angiographic follow-up ${ }^{[23]}$. Moreover, meta-analysis on the current use of bioactive coils does not indicate any 


\section{Submitted to \\ ADVNAMEP
MATERRALS}

overall benefit over the standard platinum coils ${ }^{[45]}$. We believe that reasons for these disappointing results may include: 1) only a few randomized clinical trials have been conducted on this topic, and bias arises from the fact that aneurysms treated using bioactive coils are mostly complex aneurysms, such as wide-necked, large, giant or dissecting aneurysms, which are more challenging to treat than typical cases; 2) no principle of selection for bioactive or bare coils was strictly defined and followed by the different studies; and 3) as with bare coils, the experience level of the operators can greatly influence the final occlusion rate of the aneurysms.

\subsubsection{Balloon remodeling technical for aneurysm coiling}

For complicated cerebral aneurysms, such as wide-necked, large or giant aneurysms, simple coil embolization often runs a risk of low coil packing rate and incomplete neck occlusion, which is likely to result in residual neck/sac or aneurysm recanalization. An increased packing density is the key to increasing the healing rate of complicated cerebral aneurysms. Balloon deployment in the parent artery increases metal packing density to avoid recanalization caused by blood flow and can also help seal or remodel the aneurysm neck shape to prevent coil protrusion or herniation back into the parent artery.

The balloon remodeling technique entails the temporary inflation of a balloon catheter during the coiling procedure. The balloon is placed in front of the aneurysm neck to prevent protrusion and herniation back into the parent artery and is removed at the end of the procedure so no device is left in the vessel ${ }^{[46]}$. The most popular balloon catheters for remodeling are currently the HyperGlide ${ }^{\mathrm{TM}} / \mathrm{HyperForm}^{\mathrm{TM}}$, which are compatible with a 0.010-inch microguidewire, and the Transform ${ }^{\mathrm{TM}}$ and the Septer ${ }^{\mathrm{TM}}$, which are both compatible with a 0.014-inch microguidewire. The Scepter balloon catheter allows the placement of a stent (LVIS JR stent) by inserting the stent through the catheter lumen after withdrawing the guide wire ${ }^{[47]}$. Another advantage of the 


\section{Submitted to

balloon remodeling technique is that the balloon can be used as a rescue tool to temporarily occlude the parent artery if the aneurysm ruptures during coiling.

In the Clinical and Anatomic Results in the Treatment of Ruptured Intracranial Aneurysms (CLARITY) study, two options for treating ruptured aneurysms, conventional coil embolization or balloon remodeling coiling, were found to have similar levels of safety as determined by perioperative complications and clinical outcomes $^{[48]}$. The rates of treatment-related complications, thromboembolic events, intraoperative rupture, and early rebleeding were not significantly different between the two groups. Furthermore, the cumulative morbidity and mortality rates were similar (3.8\% in the remodeling group vs. $5.1 \%$ in the coil embolization group). For unruptured aneurysms, the ATENA study found that the overall complication rate was $11.7 \%$ for balloon remodeling coiling and $10.8 \%$ for standard coiling. Interestingly, thromboembolic events occurred slightly more often in the standard coiling group than in the balloon remodeling coiling group (6.2\% vs. $5.4 \%$, respectively $)^{[49]}$. This was also reported in the meta-analysis by Shapiro et $\mathrm{al}^{[50]}$. We estimate that the balloon remodeling technique may make coiling in aneurysm sacs smoother and significantly simplify the interventional manipulation, as ischemic complications are always believed to be proportional to the total procedure time.

\section{Stent devices}

\subsection{Overview}

The tortuous course of the cerebrovasculature, especially at the siphon segment of the internal carotid artery, can form relatively sharp spatial angles. On one hand, these anatomic features require higher flexibility in the stent delivery system to arrive at the target lesion site, but on the other hand, they also need enough radial force provided by 


\section{Submitted to \\ ADVANCEDS
MATERIALS}

the stent to adapt to the complex arterial wall shape after release. In addition to their typical use in the treatment of stenosis, stent assisted coiling (SAC) is an effective combination technique to stabilize coils inside the aneurysmal sac. So far, most clinically-available intracranial stents are bare metal stents that are made of materials including nickel-titanium alloys (nitinol), cobalt-based alloys and medical-grade stainless-steel alloys. A nitinol alloy is used to manufacture self-expandable stents while cobalt-based alloys and stainless-steel alloys are used for balloon expandable stents. Cobalt-based alloys have superior mechanical performance, such as a larger radial force, than stainless steel.

Stent cell structures can be generally divided into three types of designs: open cell stents, closed cell stents and half-open cell stents. Each cell in a closed cell stent is fully enclosed by struts while open cell stents have some open-ended cells. Usually, open cell designs are differentiated from closed cell designs based on the number and arrangement of bridge connectors. A braided stent, such as the LVIS stent (Microvention), is a typical closed cell stent design. Its advantages include a high compression rate to reduce the stent profile and provide uniform radial force or dilation against the vessel wall, however, it also comes with increased risk of stent migration and reduced flexibility, high stent shortening rate, and difficult positioning during deployment ${ }^{[51]}$. Closed cell stents can also be made by laser cutting, such as Enterprise stent (Cordis), although such designs do not have as high a compression rate. In order to maintain sufficient flexibility, the thickness of stent struts must be reduced, which often indicates a sacrifice of stent radial force. Because of its design, a closed-cell stent has limited flexibility to conform to curved or irregular anatomies, which may cause the stent to flatten or kink, resulting in incomplete stent apposition and running the risk of higher thromboembolic complication rates ${ }^{[52]}$. Most open or half open cell stents are made by laser cutting. Open cell stents provide better conformability to curved vessel walls because they are more flexible, which is beneficial for cerebrovascular 


\section{Submitted to

applications However, its struts can kink in curved vessels during deployment to cause acute in-stent thrombosis or long term in-stent re-stetnosis. The Neuroform stent (Boston Scientific) and the Winspan stent (Boston Scientific) are common open cell stents

The delivery system is also very important, especially when the stent is used in cerebrovascular systems, as the flexibility of the whole stent system depends largely on the delivery system. A self-expandable nitinol alloy stent only needs a microcatheter or delivery sheath, while cobalt-based alloy or stainless steel stents are compressed around a balloon catheter and expanded during balloon dilation. The catheter delivery system is more flexible than a balloon catheter. Thus, most intracranial stents use this method to increase the chances of successfully arriving at the target: a catheter is first navigated to the lesion and then the stent is delivered within the catheter lumen. (Figure 3) (Table 2) 


\section{Submitted to ADVANCEDS
MATERIALS}

1

2

3

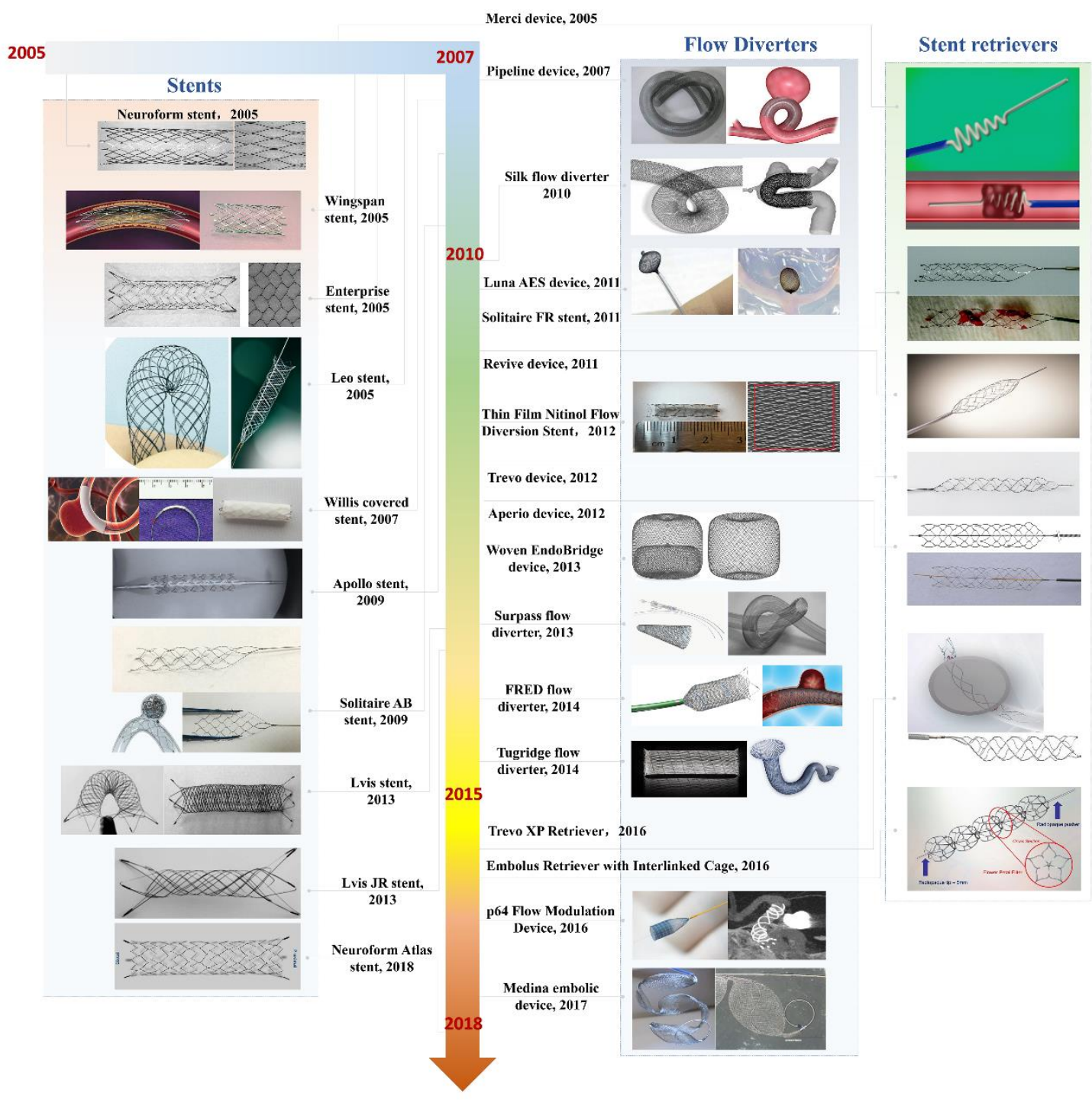

Figure 3. Typical stents used in clinical treatment of cerebral aneurysms and intracranial atherosclerotic stenosis ${ }^{[53]}$. 
Table 2. Detailed characteristics and parameters of stents used in cerebrovascular

\begin{tabular}{|c|c|c|c|c|c|c|c|c|c|c|c|c|c|}
\hline $\begin{array}{l}\text { Stent } \\
\text { Name }\end{array}$ & $\begin{array}{l}\text { Compa } \\
\text { ny }\end{array}$ & $\begin{array}{l}\text { Mater } \\
\text { ial }\end{array}$ & Sub-type & $\begin{array}{l}\text { Microfil } \\
\text { aments }\end{array}$ & $\begin{array}{l}\text { Diam } \\
\text { eter/ } \\
\text { mm }\end{array}$ & $\begin{array}{l}\text { Lengt } \\
\text { h/mm }\end{array}$ & $\begin{array}{l}\text { Radiopaque } \\
\text { /Marker }\end{array}$ & $\begin{array}{l}\text { Retrievab } \\
\text { le }\end{array}$ & $\begin{array}{l}\text { Method } \\
\text { of } \\
\text { release }\end{array}$ & $\begin{array}{l}\text { Compatible } \\
\text { microcathete } \\
\text { r/deliver } \\
\text { system (inch) }\end{array}$ & $\begin{array}{l}\text { Target } \\
\text { vessel } \\
\text { diameter/ } \\
\text { mm }\end{array}$ & $\begin{array}{l}\text { Indicatio } \\
\text { ns }\end{array}$ & Technique success rate \\
\hline $\begin{array}{l}\text { Neur } \\
\text { ofor } \\
\mathbf{m}^{[54]}\end{array}$ & $\begin{array}{l}\text { Stryker } \\
\text { Neurova } \\
\text { scular }\end{array}$ & $\begin{array}{l}\text { Nitino } \\
1 \text { alloy }\end{array}$ & $\begin{array}{l}\text { Neurofor } \\
\mathrm{m} \quad 1,2,3 \text {, } \\
\text { EZ,Atlas }\end{array}$ & $\begin{array}{l}\text { Opened } \\
\text { cell }\end{array}$ & $\begin{array}{l}2.5- \\
4.5\end{array}$ & $15-30$ & $\begin{array}{lc}4 & \text { radiopaque } \\
\text { markers } & \text { on } \\
\text { proximal } & \& \\
\text { distal ends } & \end{array}$ & $\mathrm{N}$ & $\begin{array}{l}\text { Self- } \\
\text { expanda } \\
\text { ble }\end{array}$ & 0.027 & $2.0-4.5$ & $\begin{array}{l}\text { Stent } \\
\text { assisted } \\
\text { coiling for } \\
\text { wide- } \\
\text { necked } \\
\text { aneurysm }\end{array}$ & $\begin{array}{l}\text { Deployment success } \\
85.7 \% ; \quad \geq 90 \% \quad \text { immediate } 79.0- \\
\text { occlusion: } 73-81.3 \%\end{array}$ \\
\hline $\begin{array}{l}\text { Wing } \\
\text { span } \\
\text { 55] }\end{array}$ & $\begin{array}{l}\text { Stryker } \\
\text { Neurova } \\
\text { scular }\end{array}$ & $\begin{array}{l}\text { Nitino } \\
1 \text { alloy }\end{array}$ & NA & $\begin{array}{l}\text { Opened } \\
\text { cell }\end{array}$ & $\begin{array}{l}2.5- \\
4.5\end{array}$ & $9-20$ & $\begin{array}{lr}4 & \text { radiopaque } \\
\text { markers } & \text { on } \\
\text { proximal } & \& \\
\text { distal ends } & \end{array}$ & $\mathrm{N}$ & $\begin{array}{l}\text { Self- } \\
\text { expanda } \\
\text { ble }\end{array}$ & $0.031-0.042$ & $2.0-4.5$ & $\begin{array}{l}\text { Cerebral } \\
\text { arterioscle } \\
\text { rotic } \\
\text { vascular } \\
\text { disease }\end{array}$ & $\begin{array}{l}\text { Deployment success rate:94.6- } \\
99.0 \% \text {; 30-days and 1-year } \\
\text { primary end point events (any } \\
\text { stroke or death and ipsilateral } \\
\text { ischemic stroke afterward):5.0- } \\
14.7 \% \text { and } 7.3-20.0 \%\end{array}$ \\
\hline $\begin{array}{l}\text { Enter } \\
\text { prise } \\
54 a, 56]\end{array}$ & $\begin{array}{l}\text { Codman } \\
\text { Neurova } \\
\text { scular }\end{array}$ & $\begin{array}{l}\text { Nitino } \\
1 \text { alloy }\end{array}$ & $\begin{array}{l}\text { With } \\
\text { distal tip } \\
\text { No distal } \\
\text { tip }\end{array}$ & $\begin{array}{l}\text { Closed } \\
\text { cell }\end{array}$ & 4.5 & $14-37$ & $\begin{array}{l}4 \quad \text { radiopaque } \\
\text { markers on } \\
\text { proximal \& } \\
\text { distal } \\
\text { ends/Radiopaqu } \\
\text { e delivery wire } \\
\text { marker }\end{array}$ & $\begin{array}{l}\text { Resheatha } \\
\text { ble from } \\
\text { its } \\
63 \% \sim 85 \% \\
\text { deployme } \\
\text { nt }\end{array}$ & $\begin{array}{l}\text { Self- } \\
\text { expanda } \\
\text { ble }\end{array}$ & 0.021 & $2.0-4.0$ & $\begin{array}{l}\text { Stent } \\
\text { assisted } \\
\text { coiling for } \\
\text { wide- } \\
\text { necked } \\
\text { aneurysm }\end{array}$ & 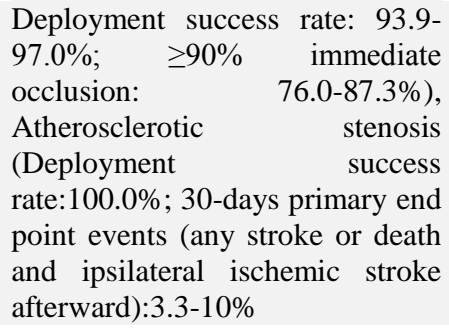 \\
\hline $\mathbf{L e o}^{[57}$ & Balt & $\begin{array}{l}\text { Nitino } \\
1 \text { alloy }\end{array}$ & $\begin{array}{l}\text { Leo plus, } \\
\text { Leo plus } \\
\text { baby }\end{array}$ & Braided & $\begin{array}{l}3.5- \\
5.5\end{array}$ & $12-75$ & $\begin{array}{l}\text { Two } \\
\text { longitudinal } \\
\text { radio-opaque } \\
\text { platinum wires }\end{array}$ & $\begin{array}{l}\text { Resheatha } \\
\text { ble up to } \\
\text { its } 90 \% \\
\text { deployme } \\
\text { nt }\end{array}$ & $\begin{array}{l}\text { Self- } \\
\text { expanda } \\
\text { ble }\end{array}$ & $0.03-0.04$ & $\begin{array}{l}1.5-3.1 \\
3.1-6.5\end{array}$ & $\begin{array}{l}\text { Stent } \\
\text { assisted } \\
\text { coiling for } \\
\text { wide- } \\
\text { necked } \\
\text { aneurysm }\end{array}$ & $\begin{array}{l}\text { Deployment success } \\
100 \% ; \geq 90 \% \quad \text { immediate } \\
\text { occlusion:75.0-100\% }\end{array}$ \\
\hline $\begin{array}{l}\text { Solita } \\
\text { ire } \\
\text { AB } \\
\text { [58] }\end{array}$ & $\begin{array}{l}\text { Covidie } \\
\text { n/ev3 }\end{array}$ & $\begin{array}{l}\text { Nitino } \\
1 \text { alloy }\end{array}$ & - & $\begin{array}{l}\text { Closed } \\
\text { cell }\end{array}$ & $4-6$ & $15-30$ & $\begin{array}{l}3 \text { or } 4 \\
\text { radiopaque } \\
\text { markers on } \\
\text { distal end and } 1 \\
\text { on proximal end }\end{array}$ & $\begin{array}{l}100 \% \\
\text { retrievable }\end{array}$ & $\begin{array}{l}\text { Self- } \\
\text { expanda } \\
\text { ble }\end{array}$ & $0.021-0.027$ & $2.2-6.0$ & $\begin{array}{l}\text { Stent } \\
\text { assisted } \\
\text { coiling for } \\
\text { wide- } \\
\text { necked } \\
\text { aneurysm }\end{array}$ & $\begin{array}{l}\text { Deployment success rate: } 95.9- \\
100 \% \text {; complete immediate } \\
\text { occlusion: } 48.7-59 \%)\end{array}$ \\
\hline
\end{tabular}




\begin{tabular}{|c|c|c|c|c|c|c|c|c|c|c|c|c|c|}
\hline LVIS & $\begin{array}{l}\text { Microve } \\
\text { ntion }\end{array}$ & $\begin{array}{l}\text { Nitino } \\
1 \text { alloy }\end{array}$ & $\begin{array}{l}\text { LVIS and } \\
\text { LVIS JR }\end{array}$ & Braided & $\begin{array}{l}3.5- \\
5.5\end{array}$ & $17-33$ & $\begin{array}{l}\text { distal/proximal } \\
\text { markers/ } 2 \\
\text { radiopaque } \\
\text { strands }\end{array}$ & $\begin{array}{l}\text { bup to its } \\
80 \% \\
\text { deployme } \\
\text { nt }\end{array}$ & $\begin{array}{l}\text { Self- } \\
\text { expanda } \\
\text { ble }\end{array}$ & $0.017-0.021$ & $2.0-5.0$ & $\begin{array}{l}\text { assisted } \\
\text { coiling for } \\
\text { wide- } \\
\text { necked } \\
\text { aneurysm }\end{array}$ & $\begin{array}{l}\text { Deployment success rate:96.8- } \\
\text { 100\%; complete immediate } \\
\text { occlusion:50.0-73.0\% }\end{array}$ \\
\hline $\begin{array}{l}\text { Apoll } \\
\text { o }^{[60]}\end{array}$ & $\begin{array}{l}\text { MicroPo } \\
\text { rt }\end{array}$ & $\begin{array}{l}\text { Stainl } \\
\text { ess } \\
\text { Steel }\end{array}$ & - & $\begin{array}{l}\text { Open- } \\
\text { cell }\end{array}$ & $\begin{array}{l}2.5- \\
4.0\end{array}$ & $8-23$ & $\begin{array}{l}\text { Radiolucent } / 2 \\
\text { radiopaque } \\
\text { markers on } \\
\text { balloon catheter }\end{array}$ & NA & $\begin{array}{l}\text { Balloon } \\
\text { expanda } \\
\text { ble }\end{array}$ & $0.037-0.040$ & $2.5-4.0$ & $\begin{array}{l}\text { Cerebral } \\
\text { arterioscle } \\
\text { rotic } \\
\text { vascular } \\
\text { disease }\end{array}$ & $\begin{array}{l}\text { Deployment success rate: } 91.7 \% \text {; } \\
\text { 30-days and 1-year primary end } \\
\text { point events (any stroke or death } \\
\text { and ipsilateral ischemic stroke } \\
\text { afterward): } 97.8 \% \text { and } 11.0 \%\end{array}$ \\
\hline $\begin{array}{l}\text { Willis } \\
{[10 c, 61]}\end{array}$ & $\begin{array}{l}\text { MicroPo } \\
\text { rt }\end{array}$ & $\begin{array}{l}\text { cobalt } \\
- \\
\text { chrom } \\
\text { ium } \\
\text { alloy }\end{array}$ & - & $\begin{array}{l}\text { Open- } \\
\text { cell }\end{array}$ & $\begin{array}{l}3.5- \\
5.0\end{array}$ & $7-16$ & $\begin{array}{l}\text { radiopaque stent } \\
\text { body/2 } \\
\text { radiopaque } \\
\text { markers on } \\
\text { balloon catheter }\end{array}$ & NA & $\begin{array}{l}\text { Balloon } \\
\text { expanda } \\
\text { ble }\end{array}$ & $0.045-0.050$ & $3.5-4.5$ & $\begin{array}{l}\text { Complicat } \\
\text { ed } \\
\text { intracrania } \\
1 \\
\text { aneurysms }\end{array}$ & $\begin{array}{l}\text { Technical success for treating } \\
\text { distal ICA and VA aneurysms can } \\
\text { reach } 97.6 \% \text {; aneurysm occlusion } \\
\text { rate } 78.1 \%-87 \%\end{array}$ \\
\hline
\end{tabular}




\section{Submitted to

\subsection{Typical stents}

\subsubsection{Neuroform ${ }^{T M}$ stent}

The Neuroform ${ }^{\mathrm{TM}}$ stent (Boston Scientific/Stryker) is a nitinol self-expanding intracranial device designed to prevent coil protrusion during stent-assisted coiling of intracranial wide-necked aneurysms. The open-cell design provides good flexibility and conformability. Importantly, this architecture can be expanded segmentally to promote stent anchoring and stability during coiling. The first three generations of Neuroform ${ }^{\mathrm{TM}}$ stents were pre-loaded on an enhanced stent delivery wire and sheath system, but were not flexible enough to be accessibly navigated in the tortuous brain vasculature. To improve flexibility, the Neuroform ${ }^{\mathrm{TM}}$ stent system has further undergone multiple iterations including the Neuroform ${ }^{\mathrm{TM}}$ 2, Neuroform ${ }^{\mathrm{TM}} 2$ Treo, Neuroform ${ }^{\mathrm{TM}} 3$, Neuroform ${ }^{\mathrm{TM}} \mathrm{EZ}^{\circledR}$ and Neuroform ${ }^{\mathrm{TM}}$ Atlas stents.

The Neuroform EZ ${ }^{\circledR}$ Stent System has a $19 \mathrm{~mm}$ distal radiopaque tip with similar tip softness as the micro guidewire used in clinic, and it has a 45 degree pre-shape to aid in navigation. The Neuroform EZ ${ }^{\circledR}$ Stent is pre-loaded on a 0.027 inch microcatheter delivery system. The stent delivery wire is a $185 \mathrm{~cm}$ stainless steel, with its diameter tapers from 0.018 inch to approximately 0.010 inch at the distal tip to increase flexibility and pushability. The Neuroform ${ }^{\mathrm{TM}}$ EZ® Stent System has a simplified delivery system that can be handled by single operator and does not require delivery system exchange like the Neuroform ${ }^{\mathrm{TM}} 3$ stent system does. The deployment failure rate of the Neuroform ${ }^{\mathrm{TM}}$ stent is only $2.3 \%^{[62]}$, which indicates that it is safe and effective for SAC applications. However, a delayed self-expansion phenomenon has been reported ${ }^{[63]}$ during a stent-assisted coiling procedure for a ruptured intracranial aneurysm, possibly due to the stent unfolding inside the sheath before deployment. Alternatively, failure to mechanically expand can also occur the moment the stent comes out from the sheath. Although this phenomenon is rare and not predictable, 


\section{Submitted to

interventionists should keep it in mind, especially for small parent arteries or any other factors that increase the risk of unstable stent deployment. The Neuroform ${ }^{\mathrm{TM}}$ Atlas stent is a new generation of stent with a mixed architecture of open and closed cells. The closed cells at its proximal ends can facilitate re-cross of the microcatheter with its lumen Open cells designs in other segments promise more reliable stent opening at sharp bends of the parent artery resulting in good wall apposition. Meanwhile, alternating 8 cell and 12 structure elements can improve stent flexibility. The Neuroform ${ }^{\mathrm{TM}}$ Atlas stent is delivered and deployed by 0.017-inch inner lumen microcatheter and should be capable of assisting aneurysm embolism in distal, smaller or even more tortuous vessel lumens ${ }^{[64]}$. However, because the stent strut thickness is greatly reduced, users should monitor it for weakness of radial force and potential lower metal coverage rate (defined as the ratio of the surface area covered by metal to the total surface area) in the aneurysm neck, which results in a higher risk of aneurysm recanalization.

\subsubsection{Wingspan ${ }^{T M}$ stent}

The Wingspan ${ }^{\mathrm{TM}}$ stent system (Stryker Neurovascular, Kalamazoo, Michigan) and Gateway ${ }^{\mathrm{TM}}$ percutaneous transluminal angioplasty (PTA) balloon catheter (Stryker Neurovascular, Kalamazoo, Michigan) were approved by the FDA in 2005 for patients with severe intracranial atherosclerotic stenosis $(\geqslant 50 \%)$ for whom antiplatelet therapy was not effective. To use the stent system, the Gateway ${ }^{\mathrm{TM}}$ PTA balloon catheter is first inflated to dilate the stenotic artery, and is then followed by placement of Wingspan ${ }^{\mathrm{TM}}$ stent within the target vessel to maintain its patency after dilation ${ }^{[65]}$. The distal tip of Wingspan ${ }^{\mathrm{TM}}$ inner shaft is spindle-shaped, which is helpful for it to cross the target lesion and draw it back within the deployed stent. The delivery line is covered with hydrophilic material, while its taper changes from $2.4 \mathrm{~F}(0.8 \mathrm{~mm})$ distally to $3.2 \mathrm{~F}$ $(1.07 \mathrm{~mm})$ proximally to increase flexibility and safety. However, negative results about its clinical application were reported by the Stenting vs. Aggressive Medical 


\section{Submitted to \\ ADVANCED}

Management for Preventing Recurrent Stroke in Intracranial Stenosis (SAMMPRIS) trial $^{[66]}$. Thus, additional caution should be paid to its safety and the following criteria should be met before its intracranial insertion, according to the FDA Humanitarian Device Exemption documentation ${ }^{[67]}$ for the Wingspan stent system: 1) patients should have had two or more strokes even under aggressive medical management; 2) the most recent stroke occurred more than seven days prior to planned treatment with Wingspan; 3) patients should have $70-99 \%$ stenosis due to atherosclerosis of the intracranial artery related to the recurrent strokes; and 4) patients have made good recovery from previous strokes and have a modified Rankin score of 3 or less prior to Wingspan treatment. Moreover, the Wingspan stent should not be used for patients for whom the treatment of stroke has an onset of symptoms within seven days or less of treatment, or for the treatment of transient ischemic attacks (TIAs) ${ }^{[66]}$.

\subsubsection{Enterprise ${ }^{T M}$ stent}

The Enterprise ${ }^{\mathrm{TM}}$ stent (Codman \& Shurtleff) is a closed-cell, self-expanding stent with flared ends. This design enhances stent apposition to the vessel wall, so it is appropriate for the treatment of wide-necked intracranial aneurysms and stent-assisted coiling procedures. The Enterprise ${ }^{\mathrm{TM}}$ stent received FDA approval for clinical usage in 2007. So far, the Enterprise stent has been further developed into the Enterprise ${ }^{\circledR} 2$ vascular reconstruction device. The Enterprise ${ }^{\circledR} 2$ is more radiopaque, making it more easily observed under fluoroscopes. The Enterprise stent system can be introduced by a standard microcatheter and recaptured or redeployed if $\leq 70 \%$ is deployed. The flared end of the Enterprise stent promotes wall apposition and conformability, as well as facilitates re-access though stent. The closed-cell design improves its ability to maintain the coil in the aneurysm and prevent it from protruding into the parent artery. Many studies indicate that the Enterprise stent can safely treat wide-necked aneurysms ${ }^{[53 k, 62 \text {, }}$ ${ }^{68]}$, but some reports mentioning post-procedure migration of an intracranial Enterprise stent should also be taken into account ${ }^{[69]}$. The delayed migration may be caused by the 


\section{Submitted to

lubricated polymer, the closed-cell design, differences in outward radial force between the flared end and the stent body, or particular anatomic scenarios of posterior circulation.

\subsubsection{Leo stent}

The Leo stent (Balt, Montmorency, France) was the first braided, retrievable, and self-expanding stent developed for the treatment of intracranial wide-neck aneurysms. The Leo stent body is composed of twisted nitinol wires for high radial force and continuous surface coverage, and two platinum markers for visualization of both the stent diameter and its length. To date, the Leo stent has two product lines: Leo plus stent and Leo plus baby stent. The Leo plus stent consists of 16 braided wires to form dense mesh cells to provide good coil support. The Leo plus stent is pre-loaded onto its own delivery wire. Also, it is resheathable up to $90 \%$ of its deployment length, and thus, can be easily repositioned. Two helical markers running down the entire body of Leo plus stent make the full stent visible under fluoroscopy. The end of the stent is a rounded short flare similar to the Enterprise stent, which ensures smooth wall apposition and easy navigation. The Leo plus baby stent is also a self-expanding and braided stent with radiopaque markers on its two ends, but it has three additional radiopaque tantalum threads in the body. The Leo plus baby stent is compatible with a low profile microcatheter $(0.017$ inch) that allows the stent to gain access to vessels down to a diameter of $2 \mathrm{~mm}$. However, in wider arterial lumens, the braided structure design decreases radial force compared to the Neurform Atlas stent and it is not suitable for deployment in tortuous arteries.

\subsubsection{Solitaire AB stent}

The Solitaire stent (EV3) is the only nitinol and self-expanding stent designed with an open slit along the axis and closed cells that is fully retrievable for stent-assisted coiling of wide-neck aneurysms and for retrieving clots from occluded blood vessels in 


\section{Submitted to

the brain. This stent is delivered through a standard 0.021 or 0.027 inch microcatheter using a 0.016 inch pushwire. The Solitaire stent allows for multiple retrievals and adjustment after full deployment, just like detachable coil manipulation. It can be electrolytically detached after deployment. When not detached, Solitaire stent can be safely held or placed without risk of migration during coil placement or balloon use. There are 3 or 4 radiopaque markers on the distal end of the stent and one marker on the proximal end for increased visibility. The overlapping curled design increases stent softness and allows the stent to expand in larger vessels and compress in smaller vessels during deployment. There is a non-working length between the working length and the proximal marker to facilitate stent retrieval, but this design makes the microcatheter recross the stent lumen or double stent overlapping deployment becomes difficult. A 0.021-inch microcatheter is suitable for a stent with $4 \mathrm{~mm}$ diameter and 0.027 -inch for a stent with a $6 \mathrm{~mm}$ diameter. The overlapping, highly flexible and retrievable structure are reasons why the Solitaire stent has been applied to a diverse range of stent techniques. Besides the normal single-stent assisted coiling technique, Y-stenting and Kiss-stenting coiling techniques are also frequently employed using the Solitaire stent. One general limitation of the Solitaire stent is its low metal coverage rate, which makes it difficult to prevent coil protrusion and aneurysm neck healing ${ }^{[58 c, 70]}$.

\subsubsection{LVIS stent}

The LVIS stent (Microvention) is a self-expandable, 16-wire, low-profile nitinol braid stent that can be visualized under fluoroscopy. It is intended for use in SAC procedures for the treatment of wide-necked and dissecting aneurysms ${ }^{[71]}$. It has a smaller than average cell size $(0.9 \mathrm{~mm})$ and approximately $23 \%$ metal coverage, which is much higher than normal coil-assist stents, which average between 6-8\% metal coverage. The increased metal coverage provides better protection against coil protrusion and flow diversion of the parent artery to accelerate thrombosis in the aneurysm sac. Furthermore, the LVIS stent consists of 4 radiopaque markers on each 


\section{Submitted to \\ ADVANCED}

end in addition to dual helical strands, so it is easily-visualized throughout the procedure course under X-ray. The LVIS stent is compatible with 0.021 inch Headway® microcatheters. To improve wall apposition, conformability, and to facilitate stent access, the end of LVIS stent is flared, a design similar to the Enterprise and Leo stents. Meanwhile, the similarly-designed LVIS Junior has a 50\% larger cell $(1.5 \mathrm{~mm})$ than the standard LVIS stent, which enables it to be delivered through even lower-profile microcatheters $(0.017 \mathrm{inch})$ for parent vessels $2.0-3.5 \mathrm{~mm}$ in size. The LVIS Junior is a self-expanding Nitinol 12-wire braided device with three radiopaque tantalum threads within the body and radiopaque markers on each end of stent. The Headway®17 advanced microcatheter and scepter occlusion balloon catheter are both compliant with the LVIS Junior stent. As the LVIS and LVIS JR stent both have a much higher metal coverage rate than normal coil-assist stents, it is important to pay additional attention during its deployment at tortuous or bifurcated arteries, as there is a risk of in-stent thrombosis due to stent kinking or occlusion of the bifurcated arteries if it is pushed too much.

\subsubsection{Apollo $^{T M}$ stent}

The Apollo stent (MicroPort) is a balloon expandable stent designed for the treatment of intracranial artery stenosis. The support units of this open-cell stent are shaped like sine waves and segments are connected with asymmetrical strengthening rings to enhance radial strength and flexibility for navigating tortuous intracranial arteries. The stent is laser-cut from medical-grade 316L stainless steel with diameters between 2.0$4.0 \mathrm{~mm}$ and lengths of 8 to $23 \mathrm{~mm}$. The Apollo stent has a metal coverage rate between 10.6-15.2\% and strut thickness of 0.004 inch. This stent system has a 0.040 inch maximum crossing profile and is delivered by a 0.014 inch microwire. The relatively low pressure $(6 \mathrm{~atm})$ it needs to release decreases the likelihood of vessel tearing or rupture. The greatest advantages of the Apollo stent are accurate positioning during expansion and good visibility under fluoroscopy. However, despite many stent design 


\section{Submitted to

improvements to improve its flexibility, this stent system is still not flexible enough for use in tortuous brain vasculature and the balloon dilation is likely to cause arterial wall damage or occasionally artery rupture.

\subsubsection{Willis $^{T M}$ stent graft}

The Willis covered stent or stent graft is a newer stent designed for intracranial vasculature applications, including the treatment of cerebral aneurysms or arteriovenous fistulas ${ }^{[10 c, 61,72]}$. It consists of 3 parts: a bare stent, an expandable polytetrafluoroethylene (ePTFE) membrane, and a low-pressure flexible balloon catheter. It is produced in diameters from 3 to $5 \mathrm{~mm}$ and in lengths from 7 to $19 \mathrm{~mm}$. This stent system is very flexible because multiple stent bodies are connected at 2 asymmetric points between the crest walls. The thin, tubular ePTFE membrane of the stent is only 30-50 $\mu \mathrm{m}$ thick, and the balloon has 5 valves (instead of 3) to prevent it from climbing the inner wall of the stent when withdrawing. To facilitate precise placement, the whole body of the stent is made of a radiopaque cobalt alloy. Similar to the Apollo stent, the balloon-expandable stent release method makes this stent system slightly stiffer and thus it can only be used in vessels with few curves and in arterial segments without important branches or perforators give out.

\subsection{Clinical applications}

Stent insertion can be applied directly or indirectly to the treatment of different cerebrovascular diseases, including hemorrhagic stroke (cerebral aneurysm) and brain ischemia (intracranial atherosclerotic stenosis). For cerebral aneurysms, bare stents are often used as an assisting tool to increase the coil packing density. The Neuroform and Enterprise stents are typical open-cell and closed-cell stents, respectively, with low metal coverage, around $10 \%$, to facilitate coiling; in contrast, the Leo and LVIS stents are designed not only to facilitate coiling but also to improve coverage at the aneurysm neck with around $23 \%$ metal coverage ${ }^{[73]}$. Covered stents can directly be used to 


\section{Submitted to

occlude the aneurysm sac while reconstructing the diseased parent artery ${ }^{[10 c, 61]}$. For treatment of atherosclerotic stenoses, stents can be used to remodel the target vessel to maintain patency following balloon catheter inflation. Stents used for such procedures include the Wingspan and Apollo stents. Stents designed to dilate atherosclerotic stenotic arteries often require high radial force compared to stents designed for coiling assistance, which is often deployed within normal arterial lumens ${ }^{[74]}$.

\subsubsection{Stent used for aneurysm coiling assistance}

Stent assisted coiling (SAC) is an effective technique used in the treatment of widenecked complex aneurysms to stabilize coils inside the aneurysmal sac, which prevents herniation back into the parent artery. SAC has been applied to treat a wide range of aneurysms and it is considered a feasible technique to decrease the risk of aneurysm recurrence. There are two major kinds of SAC techniques: jailed coiling and trans-cell coiling. To apply the jailed coiling technique, a microcatheter is first inserted into the aneurysm sac and then the stent is semi- or fully released to jail the microcatheter while stent struts can seal the aneurysm neck. A great advantage of the jailed coiling technique is that the stent can be adjusted or re-sheathed after being partially released. Consequently, although any kind of stent can theoretically be used for this technique, most operators prefer to use re-sheathable closed-cell stents as they may also allow for loose jailing of the microcatheter head to enable better coiling. Frequently used jailing stents include laser-cut stents (the Enterprise ${ }^{\mathrm{TM}}$ and the Solitaire ${ }^{\mathrm{TM}}$ stent) and braided stents (the LVIS ${ }^{\mathrm{TM}}$ and the LEO ${ }^{\mathrm{TM}}$ ).

Trans-cell coiling is the earliest stent assisted technique used to increase packing in the aneurysm sac. After the stent is deployed, the microcatheter advances into the stent lumen and its head goes into the aneurysm sac to perform coiling. This technique is more complicated to implement than the jailed technique, and often requires that stent struts appose well to the vessel wall; otherwise, it is difficult for the microguidewire or 


\section{Submitted to

microcatheter to enter the aneurysm sac. In this situation, open-cell stents often perform better than closed-cell stents, especially when the parent artery is tortuous. Open-cell stents can cover the aneurysm neck better than closed-cell stents as they may gather their struts at the neck of the aneurysm and conform to the vessel curvature, which induces less vessel straightening. Open-cell stents typically used for the trans-cell coiling technique are the Neuroform ${ }^{\mathrm{TM}}$ and Neuroform EZ ${ }^{\mathrm{TM}}$ stents. A new kind of open-cell stent, the Neuroform ${ }^{\mathrm{TM}}$ Atlas, has also been applied for assisted embolism in vessel lumens sized between 2-4.5 mm.

Despite complete occlusions occurring less frequently in stented aneurysms immediately following the procedure, the complete occlusion rate increases to $73.4 \%$ at the follow-up angiogram, compared to $54.0 \%$ for the no-stent group ${ }^{[75]}$. Angiographic recurrence occurs in $14.9 \%$ of aneurysms after stent assisted coiling compared with $33.5 \%$ for coiling-only aneurysms ${ }^{[76]}$. Stent insertion is also likely to cause in-stent stenosis approximately $3.5 \%$ of the time, but most are asymptomatic ${ }^{[77]}$. However, permanent neurological procedure-related complications occurred more often in procedures with stents than without stents $(7.4 \% \text { vs. } 3.8 \%)^{[76]}$. Compared with the balloon remodeling technique, other important factors have to be taken into consideration when using a stent, especially the necessity of antiplatelet therapy, which brings inherent risks of intracranial bleeding as well as delayed in-stent stenosis and parent vessel occlusion. (Figure 4) 


\section{ADVANCED
submited to MATERIALS}
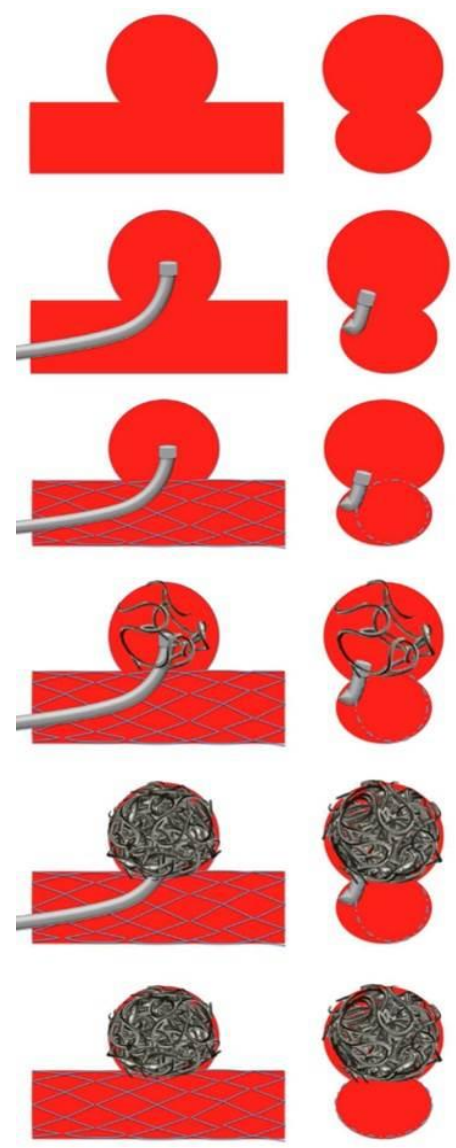

Jailed
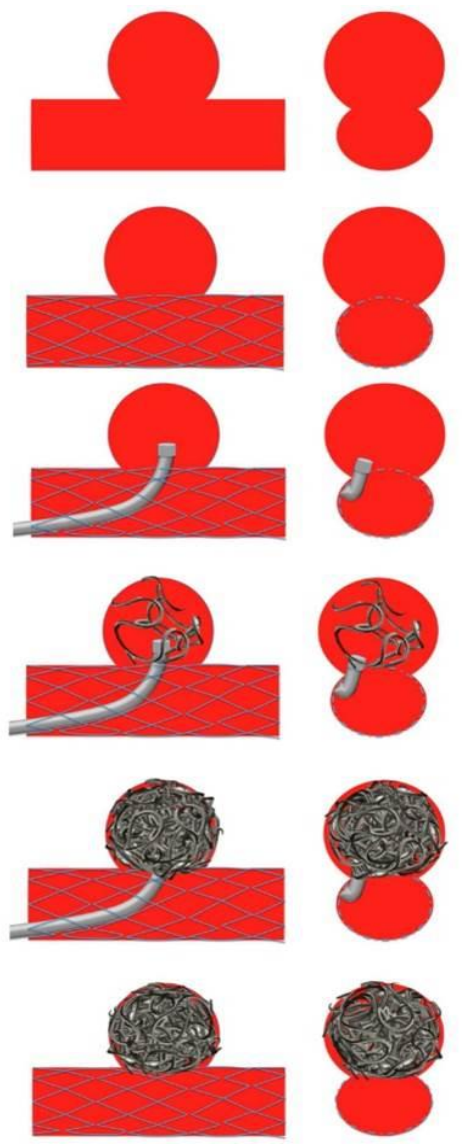

Trans-cell

Figure 4. Two different kinds of stent-assisted coiling techniques for aneurysm treatment: jailed coiling and trans-cell coiling ${ }^{[10 b]}$

\subsubsection{Covered stent for aneurysm}

A more ideal approach to aneurysm treatment is to shift the treatment target from the aneurysm sac to the diseased parent artery for histological healing of aneurysm. Immediate occlusion promotes thrombus formation, which may in turn further reduce the hemorrhage rate caused by maneuvering within the aneurysm sac. Overlapping deployment of two or three bare stents and flow diverter devices can encourage flow diversion, but these devices cannot fully realize immediate occlusion of an aneurysm. Covered stents, however, can both completely occlude the aneurysm sac and keep the parent artery patent; furthermore, covered stents can greatly reduce the hemorrhage rate after treatment ${ }^{[72]}$. Thus, covered stents may be especially suitable for the treatment of 


\section{Submitted to

complex aneurysms such as pseudo-aneurysms, wide aneurysms and large or giant aneurysms. Until recently, the only covered stents available were coronary stents like Jostent (Abbott Vascular, Redwood City, Calif) and Symbiot (Boston Scientific). In 2002, Islak et al. reported the use of a coronary covered stent to treat giant and fusiform aneurysms ${ }^{[78]}$. In 2004 , Saatci et al. reported using a coronary stent to treat twenty-five intracranial aneurysms, of which only eight patients had experienced transient endoleaks, which were all handled by post balloon dilation ${ }^{[79]}$. No recurrence was found during angiographic follow up. However, the coronary stent system has not been widely adopted since they are very stiff, lacking in longitudinal flexibility, and challenging to navigate. Moreover, they cannot easily adapt to the extreme curves of the intracranial vasculature and can cause damage to the vessel during stent deployment. The Willis ${ }^{\mathrm{TM}}$ covered stent improves on coronary stents in different aspects for intracranial applications, including stent structure, membrane thickness and the delivery system. These improvements work together to expand the flexibility of the system and to ease its passage through the tortuous intracranial vasculature. This new kind of intracranial covered stent graft has been used for the treatment of recurrent aneurysm ${ }^{[80]}$, large or giant aneurysm ${ }^{[61]}$ and carotid-cavernous sinus fistula $(\mathrm{CCF})^{[81]}$. The 3-5 year angiographic follow-up revealed that $87.2 \%$ were completely occluded ${ }^{[10 c]}$.

\subsubsection{Stenting for atherosclerotic stenosis}

Arteriosclerotic vascular disease is a specific form of arteriosclerosis where the artery wall thickens along with the invasion and accumulation of foam cells and the proliferation of intimal smooth-muscle cells. These physiological processes can cause lumen stenosis or even occlusion. In the US, according to Banerjee's statistics, acute ischemic infarctions from intracranial atherosclerotic disease account for about 9 17\% of strokes each year ${ }^{[82]}$. Balloon dilation and/or stent insertion can restructure the diseased lumen to allow sufficient blood flow for the brain tissue and prevent distal embolisms caused by plaque fall off. Sundt, et al. first reported the utility of 


\section{Submitted to \\ ADVANCED}

percutaneous transluminal angioplasty (PTA) in intracranial vessels in 1980. By using coronary angioplasty catheters after surgical exposure of the vertebral artery at its V3 segment, they successfully dilated high-grade basilar artery atherosclerotic stenotic lesions in two patients who had severe symptoms that were progressing despite anticoagulant therapy ${ }^{[83]}$. Since their report, PTA and stent insertion (PTAS) has been applied more frequently for atherosclerotic stenosis treatment in selected patients with extracranial and intracranial arteries ${ }^{[84]}$. Since the use of a stent led to better angiographic results, less chance of arterial wall dissection, distal embolism, and lower restenosis rate, stent insertion is gradually considered as superior to PTA alone for cerebral artery stenotic diseases. Stents used in intracranial arteries are often selfexpanding, either closed-cell or open-cell, and they are made of various metallic materials, but mainly nitinol. Most observational and retrospective single center reports show positive results until the SAMMPRIS trial results were first published ${ }^{[55 b, 56 b]}$. The SAMMPRIS study, a randomized controlled trial (RCT), compared treatment outcomes with or without stenting for patients with severe (70\%-99\%) symptomatic stenosis of a major intracranial artery ${ }^{[66]}$. Unfortunately, this study was aborted at an early stage after only 451 of the planned 764 patients, because at 30 days, a significantly higher rate of stroke and death (14.7\%) was observed in the stented patients compared to the patients who received aggressive medical therapy alone (5.8\%). This failed study drove the FDA to reduce the recommendations for Wingspan stent usage to patients who had had two or more recurrent strokes despite intensive dual antiplatelet medication and risk factor corrections. Meanwhile, the Vitesse Intracranial Stent Study for Ischemic Stroke Therapy (VISSIT) trial, another multicenter and prospective RCT, was initiated with the goal of evaluating the placement of a Pharos Vitesse balloon-expandable stent to treat intracranial stenosis in patients with cerebral or retinal ischemia symptoms. This study was also stopped early, after 112 of the intended 250 patients had enrolled. Again, the early analysis showed a higher risk of stroke or death in the stented patients within 


\section{Submitted to

the first 30 days $(24.1 \%)$ compared to those who only received medical therapy $(9.4 \%)^{[85]}$. So far, there is still no significant evidence to show that intracranial stenting is more effective than aggressive medication when it comes to preventing strokes in patients with intracranial stenosis. However, some important criticisms of the SAMMPRIS trial cannot be ignored, including the lack of operator experience, treatment in an acute setting following stroke, no strict selection of patients who failed intensive medical therapy, stroke caused by perforator occlusion instead of low perfusion, and stenting in high-risk perforator rich areas. Further research with improved design is required to objectively evaluate intracranial stenting for arteriosclerotic vascular disease. In addition, procedure related complications can be decreased by conducting the necessary systematic training. The China Angioplasty and Stenting for Symptomatic Intracranial Severe Stenosis (CASSISS) trial is a new ongoing prospective multicenter RCT that overcomes the shortcomings of previous RCTs and aims to redefine the role of stenting in selected patients with symptomatic intracranial arterial stenosis ${ }^{[86]}$. Intracranial PTAS may further be proven to be safe and effective if refinements in patient and device selection or technique innovation occur in future studies.

\section{Flow diverter devices}

\subsection{Overview}

Flow diverter devices (FDDs) are breakthrough inventions for intracranial aneurysm treatment. The concept developed from the use of overlapping traditional stents to obstruct cerebral aneurysms without placing any coils ${ }^{[87]}$. Since their first application in 2007, FDDs have evolved as endoluminal approaches in the management of intracranial aneurysms ${ }^{[53 t]}$. This relatively new method is now rapidly becoming the first-line treatment modality for numerous complex cerebral aneurysms since large multicenter clinical trials have yielded satisfactory results ${ }^{[88]}$. With active development 


\section{Submitted to

of such devices, multiple kinds of flow diverters have been ratified for clinical use. To support future device development, it is necessary to review the mechanisms that are responsible for aneurysm closure, the stent design, the delivery of stents, and the stent material $^{[89]}$.

Flow diversion involves placement of a semipermeable stent to reshape the parent artery and direct blood flow away from the aneurysm neck while maintaining natural flow through the parent vessel. The efficacy of flow diverters greatly depends on their hemodynamic diversion causing flow stasis within the aneurysm sac leading to gradual thrombosis, which eventually results in occlusion of aneurysm ${ }^{[90]}$. Computational hemodynamics studies show that FDDs do attenuate the peak and mean kinetic energy of blood entering the aneurysm. An overall metal coverage rate of 30-50\% in FDDs can reduce the maximum flow velocity at the aneurysm neck by about $80 \%{ }^{[91]}$. In some cases, however, an FDD may generate varying mesh density over the aneurysm orifice during deployment and create inconsistent patterns of intra-aneurysmal flow ${ }^{[92]}$. FDDs further promote thrombus formation because once activated platelets pass through the mesh, they have a long residence time in the aneurysm ${ }^{[93]}$. The stent material itself can also trigger thrombus formation; small fibrin- and platelet-rich thrombi can be detected at the FDD surface before any observable thrombus forms in the aneurysm ${ }^{[94]}$. In parallel, endothelial cells can creep along the FDD surface to occlude the aneurysm neck over 6-12 months ${ }^{[95]}$. However, a recent study showed that until the aneurysm is completely sealed, there is a risk of the thrombus escaping out of the aneurysm with blood flow ${ }^{[96]}$. Most FFDs are comprised of microfilaments between 30 to $35 \mu \mathrm{m}$, and their pore size typically varies between 110 to $250 \mu \mathrm{m}$. These characteristics allow small perforators, with a diameter of $100 \mu \mathrm{m}$, to still provide sufficient (>55\%) blood flow $^{[97]}$. (Table 3) (Figure 3) 
Table 3. Detailed information and parameters of flow diverter devices used clinically for the treatment of cerebral aneurysms

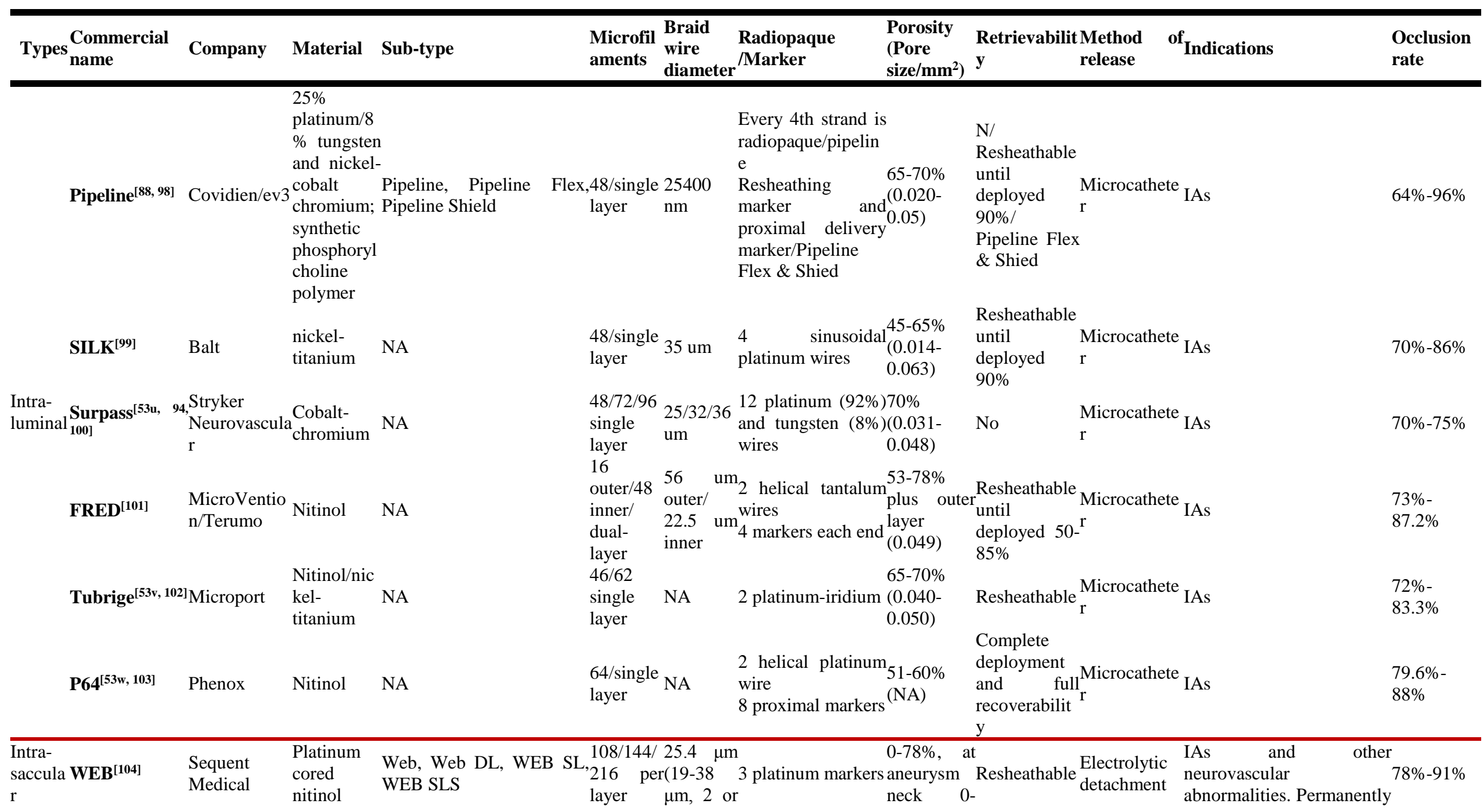




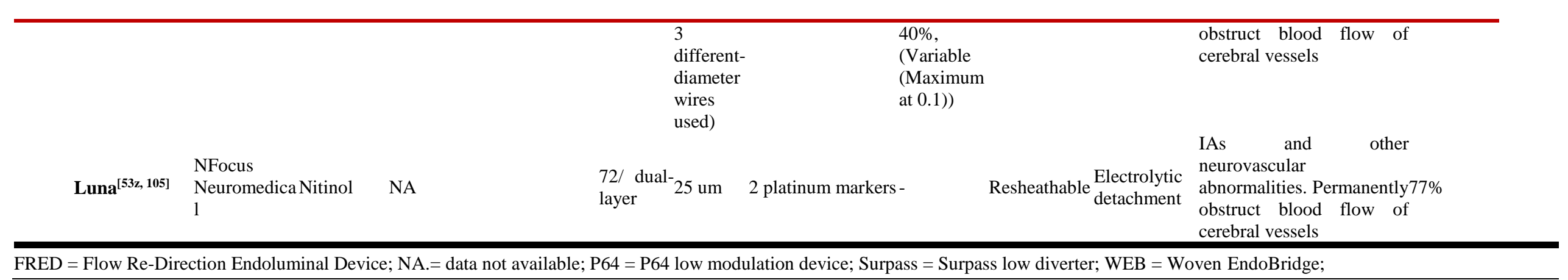




\section{Submitted to

\subsection{Typical Intra-luminal flow diverters}

\subsubsection{Pipeline embolization device}

\subsubsection{PED:}

The pipeline embolization device (PED; ev3/Covidien, Irvine, CA, USA) is a flexible self-expanding, braided cylindrical device that consists of 48 individual strands made of $25 \%$ platinum, $8 \%$ tungsten and $75 \%$ nickel-cobalt-chromium alloy. It comes in diameters between 2.5 to $5.0 \mathrm{~mm}$, and in lengths between 10 to $35 \mathrm{~mm}$. The devices have a pore size of $0.020-0.052 \mathrm{~mm}^{2}$ with porosity of $65-70 \%$ at its nominal diameter ${ }^{[53 t]}$. The device is loaded in a delivery sheath and delivered through a 0.027 inch microcatheter, where it is compressed and elongated to 2.5 times its nominal length. The delivery wire extends $15 \mathrm{~mm}$ distal to the PED and sometimes requires a clockwise turn to release the PED distal end. Forward pressure from the delivery wire allows the PED to expand and appose the vessel wall. Multiple PEDs can be telescoped over each other by delivery wire recapture after the previous PED is fully deployed. When a PED is deployed in a vessel less than $2 \mathrm{~mm}$ in size, the stent pores may become larger ${ }^{[98 \mathrm{~g}]}$.

\section{(Figure 5)}
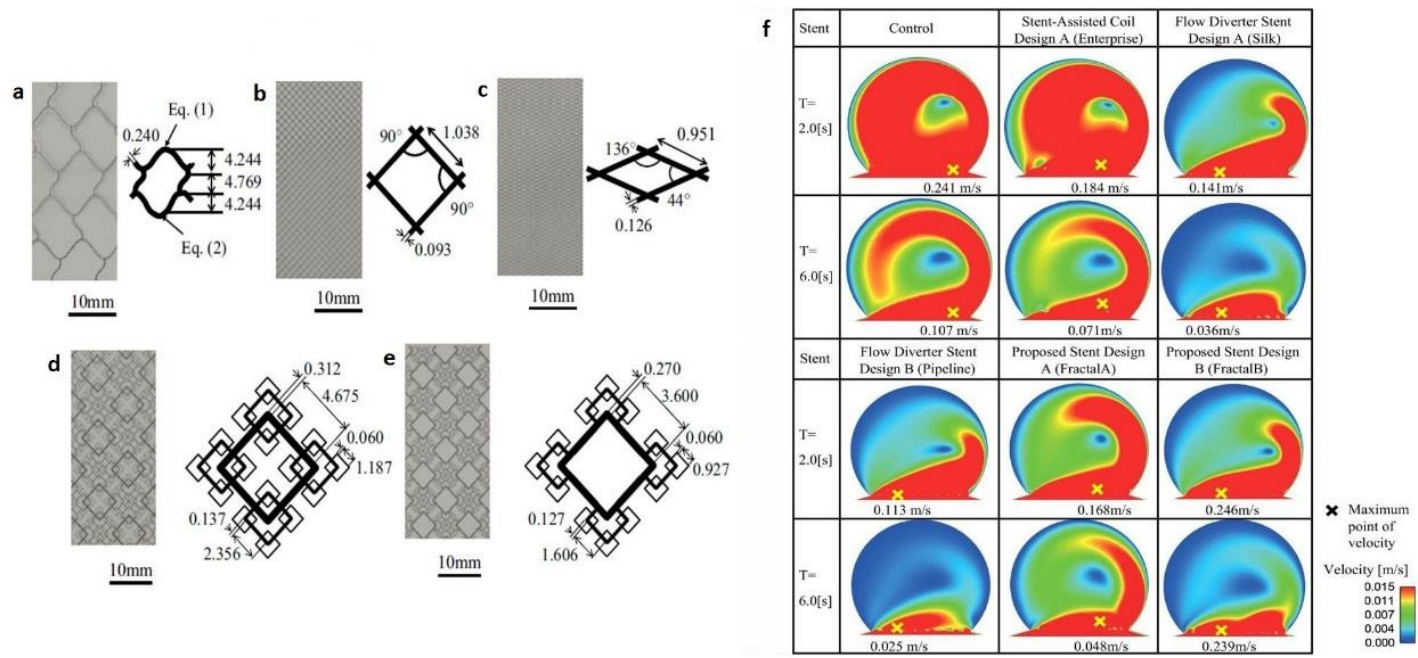

Figure 5. Photos and schematics of fabricated stent sheets. (a) mesh of the Enterprise stent, (b) mesh of the Silk stent, (c) mesh of the Pipeline FDD, $(d, e)$ mesh of new stent design $A$ and $B$. (f) Flow velocity inside an aneurysm by $C F D$ simulation at $T=2.0$ and 6.0 s for control and different kinds of stents, adapted from Kojima et al ${ }^{[106]}$. 


\section{Submitted to

\subsubsection{PED Flex:}

Delivery and deployment of the PED Flex is the same as for the first-generation PED. However, several major modifications have been implemented in the Pipeline Flex: 1) two polytetrafluoroethylene (PTFE) flaps that can rotate $180^{\circ}$ were added to the proximal side of the device to facilitate opening and resheathing the device when less than $90 \%$ has been deployed; 2) the laser-cut delivery wire is a noticeably stiffer hypotube than its predecessor with improved pushability and device responsiveness; 3 ) the distal end of the device is no longer constrained on a capture coil and thus it doesn ${ }^{t}$ require any torque to release the device after an initial partial release; 4) the distal tip coil is now 0.012 inches in diameter, compared to 0.014 inches in the first generation, and has a tip angle of $55^{\circ}[98 \mathrm{~b}]$.

The stiffer delivery wire of the PED Flex is also designed to facilitate retracting the microcatheter through the PED after deployment. However, failure to recapture the delivery wire after deployment of the device has been reported, which then requires removal of the delivery wire directly from the lumen of the device ${ }^{[98 c]}$.

Robust intracranial support is required for deployment of the PED Flex. The traditionally-used Marksman microcatheter often fails to provide sufficient support for delivery, deployment or resheathing of the device, particularly in cases of tortuosity. However, the VIA27 microcatheter is reported to provide excellent support for successful PED Flex delivery during procedure ${ }^{[98 i]}$. Since the Pipeline Flex can be more precisely deployed than the first generation device, fewer devices are needed per case on average ${ }^{[98 b]}$.

\subsubsection{Pipeline Shield}

The third generation Pipeline Flex Embolization Device with Shield Technology (Pipeline Shield), is a surface modified device where a synthetic phosphorylcholine 
polymer (thickness $<3 \mathrm{~nm}$ ) is covalently bonded to its strands to potentially reduce thrombogenicity and the required dose of antithrombotic medication. It has a similar thrombogenicity to devices like Solitaire AB (Covidien-Medtronic, Irvine, California, USA) and LEO plus (Balt Extrusion, Montmorency, France) stents. The Pipeline Shield was approved for clinical application in $2015^{[98 \mathrm{~d}]}$. To date, experimental research has demonstrated that the Pipeline Shield reduces platelet specific thrombogenicity compared with the FRED flow diverter, another device used in similar cases ${ }^{[88 h]}$. They also reported a high technical success rate of device insertion (98\%). The average number of Pipeline Shield devices used was $1.1 \pm 0.27$ devices per case, comparable to the Pipeline Flex ${ }^{[107]}$. The delivery system has not been updated from the previous generation device.

\subsubsection{Silk flow diverter}

The Silk flow diverter device (Silk, Balt Extrusion, Montmorency, France) is a braided device comprised of 48 nickel-titanium and 4 platinum microfilaments around $35 \mu \mathrm{m}$ each. It is a closed-cell mesh cylinder with flared ends that provides $35-55 \%$ metal coverage at its nominal diameter, with a pore size between 110 to $250 \mu \mathrm{m}^{[108]}$.

The Silk delivery wire has a $9 \mathrm{~mm}$ distal radiopaque tip. The device is deployed via a Vasco 21 (Balt Extrusion, Montmorency, France) microcatheter (0.0236 inch inner diameter) by carefully applying pressure on the delivery wire. Like the PED Flex, an advantage of the Silk device is that it can be resheathed and repositioned up until $90 \%$ deployment ${ }^{[99 c]}$. The successful deployment rate ranges between $75 \%$ and $96 \%$ (mean $88.6 \%)^{[99 b]}$. Silk flow diverters come in 2-5 mm diameters and $15-40 \mathrm{~mm}$ lengths.

\subsubsection{Surpass flow diverter}

The Surpass flow diverter device (Stryker Neurovascular, Fremont, CA, USA) is a single-layer, self-expanding, tube-shaped, braided mesh stent. It has a porosity of $70 \%$ (metal coverage rate 30\%) and high pore density of $21-32$ pores $/ \mathrm{mm}^{2}$, with rhomboid shaped pores. The device is available $2.5-5 \mathrm{~mm}$ in diameters and $10-35 \mathrm{~mm}$ in lengths ${ }^{[109]}$. Depending on the device size, the Surpass flow diverter contains different 


\section{Submitted to \\ ADVANCEDS}

numbers of strands: the $2.5 \mathrm{~mm}$ device has 48 strands, the 3 and $4 \mathrm{~mm}$ devices have 72 strands, and the $5 \mathrm{~mm}$ device has 96 strands. Twelve marker wires of platinum and tungsten wires are used for radiopacity and the rest are made of cobalt-chromium material. By increasing the strand number in larger devices, the pore configuration, porosity and pore density are all maintained, which should reduce the requirement of additional device implantation ${ }^{[100]}$. The Surpass devices foreshorten upon deployment depending on their diameter; $3 \mathrm{~mm}, 4 \mathrm{~mm}$, and $5 \mathrm{~mm}$ diameter devices shorten by $38 \%$ $42 \%$ and $26 \%$, respectively. The delivery of these devices requires a minimum microcatheter inner diameter of 0.040 inches, which is larger than the Pipeline device requirement of 0.027 inches. Because of its size, the Surpass device is not constrained at its delivery push wire, instead its pusher accommodates a standard 0.014-inch microwire. Furthermore, although deployment of the larger device is more difficult, the delivery system is more stable and allows for precise device placement.

\subsubsection{Flow Redirection Endoluminal Device System}

The flow redirection endoluminal device system (FRED; MicroVention, Tustin, CA, USA) is a newer type of paired-stent flow diversion device with a closed-cell design. FRED has a unique stent-in-a-stent design; the outer stent, made of 16 woven nitinol wires, has a high radial force that encourages stent opening while the inner stent is composed of 48 braided nitinol strands that make a low-porosity mesh and create a flow diverting effect. This design means that FRED behaves much more like laser cut stents, with markedly less foreshortening ${ }^{[101 d]}$. Redirection and attenuation of blood flow are also improved with its $16+48$ wires. Taken together, the dual-layer design may provide potential advantages in scaffolding functions, stability, deliverability and occlusion of aneurysms. Currently, the FRED is available in 3.5, 4.0, 4.5, 5.0, and 5.5 mm diameters with a working length ranging from 7 to $56 \mathrm{~mm}$.

The dual-layer design is localized only to the main tubular body and covers about $80 \%$ of its total length. The ends of the outer layer are flared approximately $3 \mathrm{~mm}$ on each side marked by 4 radiopaque and serve as landing zones during deployment while preserving side branches. An interwoven double helix of tantalum marker strands is used to delineate the working length. 


\section{Submitted to \\ ADVANCEDS}

The FRED is contracted onto a 0.027 -inch delivery push microwire with a radiopaque distal tip and can be resheathed after up to $80 \%$ deployment ${ }^{[101 \mathrm{c}]}$. A recent study suggested that its higher radial force may let deployment much more easier in certain cases $^{[101 b]}$. However, reports have also been made of the hydrophilic coating scraping off for FRED or its delivery catheter ${ }^{[101 a]}$.

\subsubsection{Tubridge}

The Tubridge flow diverter, developed by MicroPort Medical Company (Shanghai, China), is a self-expandable, low-porosity, flow-diverting mesh device with flared ends. Preliminary evidence supports its clinical safety and efficacy for the treatment of complex aneurysms. The size of Tubridge devices ranges from 2.5 to $6.5 \mathrm{~mm}$ in diameter and 12 to $45 \mathrm{~mm}$ in length ${ }^{[102]}$.

Previous studies have reported two kinds of Tubridge devices. Large Tubridge devices (diameter $\geq 3.5 \mathrm{~mm}$ ) are braided using 62 nickel-titanium microfilaments and 2 platinum-iridium radioopaque microfilaments while the small Tubridge devices (diameter $<3.5 \mathrm{~mm}$ ) are a braid of 46 nitinol microfilaments and 2 platinum-iridium microfilaments. Tubridge flow diverters have a metal coverage rate between $30 \%$ and $35 \%$ when fully deployed and are designed with a gradient in pore size, in which the smallest cell is only $0.040-0.050 \mathrm{~mm}^{2}$ in the middle of the device ${ }^{[53 \mathrm{v}]}$. The flared ends with lower metal coverage are designed to avoid perforator infarction and stent migration during deployment.

\subsection{6 p64 Flow Modulation Device}

The p64 flow modulation device (Phenox, Bochum, Germany) is a fully resheathable, braided tubular implant with controlled mechanical detachment. It is composed of 64 nitinol wires with 2 platinum radiopaque marker wires wrapped around its length. The device can be repositioned or withdrawn until obtaining a satisfactory position, even after completing deployment, a significant advantage ${ }^{[53 \mathrm{w}]}$.

Wires of the p64 device are grouped into bundles of 8 wires at the proximal end with radio-opaque $0.5-\mathrm{mm}$ markers attached to the end of each bundle. The bundles are attached to a slotted crown shape at the end of a $180 \mathrm{~cm}$ stainless steel delivery wire. The crown is covered by a polymer tube which is locked to the delivery wire by a torque 


\section{Submitted to

device to prevent unexpected detachment. The device is compatible with a 0.027 -inch internal diameter microcatheter. The deployment of p64 is similar to traditional stent release, which fully expands the device through a combination of pushing the delivery wire and retrieving the microcatheter. While the p64 is available with and without a distal wire, the distal wire design may increase flexibility and support during delivery and deployment. The porosity of p64 is relatively low, varying from 51\% to $60 \%$ at nominal diameters, with a radial force similar to that of the PED Flex ${ }^{[103 b]}$.

A report showed that the success rate of P64 device placement ranges from 85\%$98 \%$. The stiffness of the implant and its friction within the delivery catheter are the main causes of technical failure ${ }^{[103 a]}$. The P64 device is available between sizes of 2.5$5 \mathrm{~mm}$ in diameter with $0.5 \mathrm{~mm}$ increment and 9-36 $\mathrm{mm}$ length with $3 \mathrm{~mm}$ increment.

\subsubsection{Thin Film Nitinol Flow-Diversion}

In 2009, an animal study demonstrated that pore density (number of pores $/ \mathrm{mm}^{2}$ ), rather than porosity (metal-free area/total area), was an important factor to predict the efficacy of flow-diverting devices. Devices with a high pore density are thought to be more effective ${ }^{[110]}$. In contrast to other flow-diverter devices, the flow diverters based on Thin Film Nitinol (TFN) technology attain a very high pore density (70 pores $/ \mathrm{mm}^{2}$ ) but maintain a similar metal coverage rate. TFN Flow-Diversion (NeuroSigma, Los Angeles, California) has a cylindrical TFN micro-mesh that is attached on a laser-cut nitinol stent. The TFN metal sheets are approximately $5 \mu \mathrm{m}$ thick can be produced in various patterns using techniques commonly used in the microelectronics industry. This device enables high rates of aneurysm occlusion soon after implantation ( 2 weeks), as observed in preclinical testing ${ }^{[111]}$.

Meanwhile, microfabricated TFN membranes show an extreme mechanical bendability (up to $180^{\circ}$ ) and radial stretchability (>500\%) compared with other kinds of flow diverters. However, after the TFN flow-diverter is compressed into a delivery catheter, the TFN membrane undergoes an extreme deformation of 400-500\%, which can easily cause mechanical fracture during its delivery within the microcatheter ${ }^{[112]}$. 


\section{Submitted to

\subsection{Typical intra-saccular flow diverters}

Intra-saccular flow diverter devices represent a different flow diversion approach in which the braided device redirects blood flow at the aneurysm neck after its deployment within the aneurysm sac. These devices are designed to treat bifurcation aneurysms.

\subsubsection{Woven EndoBridge device}

The Woven EndoBridge device (WEB, Sequent Medical, Aliso Viejo, California, USA) was first marketed in 2011. It is composed of a braided nitinol wire that holds the device in a globular shape. WEB provides a neck metal coverage between $35 \%$ and $45 \%$ and yields a "stent-like" adherence to the inside of the aneurysm sac ${ }^{[104 b]}$.

The WEB device has three subtypes: the WEB Single Layer (SL) and WEB Single Layer Sphere (SLS) are both single layer devices made of braided nitinol/platinum wires while the WEB Double Layer (DL) is a mesh sphere made of two layers of braided nitinol wires. The device is available in sizes ranging from $4 \times 3 \mathrm{~mm}$ and $11 \times 9$ $\mathrm{mm}$, and is attached to a flexible delivery wire ${ }^{[113]}$. Proximal, distal and/or middle radiopaque platinum markers are used to facilitate accurate positioning of the device, which is delivered through a 0.027 inch microcatheter and detached electrothermally. The device is fully retrievable.

More recently, Asnafi et al. performed a meta-analysis of 588 aneurysms (22\% ruptured aneurysms) in 565 patients treated with the WEB device. Treatment failure occurred in 3\% of all cases. The initial complete occlusion rate was $59 \%$, and increased to $85 \%$ after 7 months ${ }^{[104 a]}$. Furthermore, the WEB device does not require dual antiplatelet therapy.

\subsubsection{The Luna AES device}

The Luna aneurysm embolization device (AES; NFocus Neuromedical, Palo Alto, California) is a self-expandable, braided ovoid device made from two layers of nitinol wire mesh. Similar to the WEB device, it is designed to disrupt flow from within the aneurysm, and similarly, there is no need for dual antiplatelet therapy. The device can also be delivered through a standard 0.027 inch inner diameter microcatheter ${ }^{[53 z]}$. 


\section{Submitted to

\subsubsection{Medina embolization device}

The Medina embolization device (MED, Medtronic, Irvine, California, USA) is also designed to be an intra-saccular self-expanding flow diverter, consisting of a core wire and memory alloy outer filaments that are shaped into petals along the axis of the structure. As the device is deployed, the three-dimensional filament petal deforms to fill the aneurysm sac and ostium, creating a spherical shape basket and distributing the forces on the aneurysm wall. The MED is delivered via a smaller 0.021 inch microcatheter. During its deployment within the aneurysm sac it can be easily resheathed, redeployed and finally mechanically detached. This happens in a very similar manner as coil manipulation.

The MED potentially has the following advantages over the WEB device: 1) the delivery microcatheter has a smaller profile (0.021 inch ID for MED vs. 0.027 inch ID for WEB), which makes arrival at the target lesion and entry into the aneurysm sac easier; 2) the ability to place multiple MEDs in a Russian doll fashion or standard coils into the aneurysm is likely to cause an increase of packing density rate and earlier aneurysmal occlusion as compared to WEB device. An extremely rapid occlusion of large aneurysms has already reported in early clinical experience ${ }^{[53 q]}$.

\subsubsection{Neck-bridging device}

The eCLIPs Bifurcation Remodelling System (eCLIPs, eVasc Neurovascular Enterprises ULC, eVasc Medical Systems Corp, Vancouver, Canada) device is a selfexpanding, nickel-titanium, fully retrievable, hemi-stent. The device has a leaf segment with moveable ribs, which can immediately disrupt flow in the aneurysm, while also allowing the placement of detachable coils, thus reducing the chance of aneurysm recurrence. The high density of the leaf segment, $23 \%-42 \%$ metal coverage, also provides a scaffold for endothelial cell creeping and progressive neointimal growth to achieve histological repair at the aneurysm neck ${ }^{[114]}$.

\subsection{Clinical applications}

The safety and efficacy of flow-diverting devices have been demonstrated in several well-designed trials and numerous clinical studies. Initially, the Pipeline for Uncoilable and Failed Aneurysms (PUFS) trial prospectively assessed 108 patients with unruptured 


\section{Submitted to

large and giant wide-necked internal carotid artery aneurysms, and reported a high rate of complete occlusion (78 out of $108,73.6 \%$ ) with a low $5.6 \%$ rate of major stroke or neurologic death at 180 days. The technique success rate was $99 \%{ }^{[115]}$. In 2016 , the 3 year angiographic follow-up results from the PUFS cohort showed a progressive complete aneurysm obliteration $(93.4 \%$ cure rate) without delayed aneurysm recanalization and/or growth ${ }^{[116]}$. Even more recently, the five-year results of PUFS trial presented a $95.2 \%(60 / 63)$ rate of aneurysm occlusion. Moreover, no new serious device-related events or recanalization were observed ${ }^{[98 e]}$. In the International Retrospective Study of PED (IntrePED) trial, the largest study on PED for cerebral aneurysms, Kallmes et al. reported on the safety of PED for the treatment of 906 aneurysms in 793 patients, and showed that the neurologic morbidity and mortality rate was $8.4 \%{ }^{[88]}$. Similarly, the prospective Aneurysm Study of Pipeline in an Observational Registry (ASPIRe) reported a combined neurological morbidity/mortality rate of $6.8 \%(13 / 191)$ for patients with unruptured cerebral aneurysms treated with PED, and the complete occlusion rate was $74.8 \%$ (77/103) 8 months later ${ }^{[117]}$.

Similar results are obtained with other commonly used FDDs. A multicenter experience from 24 centers reported that the permanent neurologic morbidity and mortality rates were $6 \%$ and $2.7 \%$, respectively, in 186 intracranial aneurysms that received a Surpass flow diverter treatment. Of these, $75 \%$ of patients had $100 \%$ occlusion after a single Surpass device implant ${ }^{[94]}$. For posterior circulation complex aneurysms, a German multicenter study reported a complete aneurysm occlusion rate of $66 \%$ with the Surpass flow diverter ${ }^{[118]}$.

The most recent experience of 4 Spanish centers of 157 patients treated with a SILK flow-diverter device showed total morbidity and mortality rates of 9.6\% (15/157) and $3.2 \%(5 / 157)$, respectively, at six months after treatment. Complete occlusion was observed in $78.1 \%(100 / 128)$ of cases within one year of the procedure ${ }^{[99 b]}$. However, it is possible that the different designs of flow-diverter devices may slightly influence the rate of complications and occlusions ${ }^{[119]}$.

Others studies have also reported safety and efficacy experiences using off-label PED for treating ruptured aneurysms ${ }^{[120]}$, aneurysms in children ${ }^{[121]}$, and small aneurysms $(\leq$ 


\section{Submitted to

$7 \mathrm{~mm})^{[122]}$. However, the indications of FDD for IA treatment need to be fully defined and these kinds of devices have not yet to be shown to be beneficial for all type of patients with cerebral aneurysms. The Flow Diversion in the Treatment of Intracranial Aneurysm Trial (FIAT) trial, conducted in 3 Canadian hospitals, showed that a significantly higher proportion of patients were dead or dependent at 3 or more months when randomized to flow diversion. Based on those results, the authors concluded that FFDs were not as safe and effective as they had originally hypothesized ${ }^{[123]}$. Currently, the FIAT trial continues to enroll patients for whom flow diversion appears promising. Clinicians should be judicious when offering patients this novel and promising treatment option. Other trials on flow diversion have already been designed ${ }^{[124]}$ since further intensive research needs to be conducted to clarify its clinical efficacy in highly selected patients.

\section{Thrombectomy devices}

\subsection{Overview}

Stroke is currently the most common cause of permanent disability and the third most common cause of death in the world, and it is estimated that about 5.7 million people die of strokes each year ${ }^{[125]}$. The FDA has approved several devices for mechanical thrombectomy to treat acute ischemic stroke (AIS), such as stent retrievers that allow for mechanical thrombectomy at the site of occlusion to immediately restore blood flow $^{[126]}$. As opposed to suction devices, stent retrievers are deployed inside the clot to entrap it by exerting continuous radial force on the clot to embed it into the meshed network, which facilitates clot retrieval. The retention force on the clot by the device is determined by the stent struts that embed and encase the thrombus ${ }^{[127]}$. These devices combine the advantages of temporary reperfusion of the affected territory and mechanical thrombectomy ${ }^{[128]}$. The first generation of stent retriever devices (Merci) was approved by FDA in 2004. Since then, the most popular stent retrievers used in clinic are the Solitaire FR revascularization device (EV3 Neurovascular, Irvine, California) and Trevo Provue Retrieval System (Stryker Neurovascular, Kalamazoo, Michigan). Meanwhile, many other promising devices are undergoing clinical trials to evaluate their performance (Figure 3 and Table 4). 


\section{ADVANCEP subnatertio MATERIALS}

Table 4. Detailed characteristics and parameters of stent retrievers used in thrombectomies for the treatment of acute ischemia stroke

\begin{tabular}{|c|c|c|c|c|c|c|c|c|c|c|c|c|c|c|c|}
\hline $\begin{array}{l}\text { Device } \\
\text { Name }\end{array}$ & $\begin{array}{l}\text { Sub- } \\
\text { types }\end{array}$ & $\begin{array}{l}\text { Compa } \\
\text { ny }\end{array}$ & $\begin{array}{l}\text { Mate } \\
\text { rial }\end{array}$ & Structure design & $\begin{array}{l}\text { Micro } \\
\text { filame } \\
\text { nts }\end{array}$ & $\begin{array}{l}\text { Cell } \\
\text { size }\end{array}$ & $\begin{array}{l}\text { Diam } \\
\text { eter/ } \\
\text { mm }\end{array}$ & $\begin{array}{l}\text { Length } / \mathrm{m} \\
\mathrm{m}\end{array}$ & $\begin{array}{l}\text { Radiopaque } \\
\text { /Marker }\end{array}$ & $\begin{array}{l}\text { Radia } \\
\text { l } \\
\text { force/ } \\
(\mathbf{N} / \mathbf{m} \\
\text { m) }\end{array}$ & $\begin{array}{l}\text { Retri } \\
\text { evabi } \\
\text { lity }\end{array}$ & $\begin{array}{l}\text { Compatible } \\
\text { microcathete } \\
\text { r/deliver } \\
\text { system (inch) }\end{array}$ & $\begin{array}{l}\text { Target } \\
\text { vessel } \\
\text { diamete } \\
\text { r/mm }\end{array}$ & $\begin{array}{l}\text { Indica } \\
\text { tions }\end{array}$ & $\begin{array}{l}\text { Recanali } \\
\text { zation } \\
\text { rate } \\
\text { (TICI } \\
\text { 2b-3) }\end{array}$ \\
\hline Merci & $\begin{array}{l}\text { Merci } \\
X^{[129]}\end{array}$ & $\begin{array}{l}\text { Concent } \\
\text { ric } \\
\text { Medical }\end{array}$ & $\begin{array}{l}\text { Nitin } \\
\text { ol }\end{array}$ & $\begin{array}{l}5 \text { helical tapered } \\
\text { nitinol coil loops } \\
\text { covered with } \\
\text { platinum }\end{array}$ & $\begin{array}{l}0.012- \\
0.014 \\
\text { inch }\end{array}$ & - & $\begin{array}{l}2.5- \\
3.5 \\
\mathrm{~mm}\end{array}$ & $\begin{array}{l}\text { Tip /Loop } \\
\text { length } 7 \\
\text { mm }\end{array}$ & fully visible & - & Yes & $2.4 \mathrm{Fr}$ & NA & AIS & \multirow{3}{*}{$\begin{array}{l}43 \%- \\
69.5 \%\end{array}$} \\
\hline \multirow{5}{*}{$\begin{array}{l}\text { Solitai } \\
\text { re }\end{array}$} & $\begin{array}{l}\text { Merci } \\
\text { L }\end{array}$ & $\begin{array}{l}\text { Concent } \\
\text { ric } \\
\text { Medical }\end{array}$ & $\begin{array}{l}\text { Nitin } \\
\text { ol }\end{array}$ & $\begin{array}{l}\text { 4-6 nontapering } \\
\text { helical nitinol } \\
\text { coil with prolene } \\
\text { filaments }\end{array}$ & $\begin{array}{l}0.012- \\
0.014 \\
\text { inch }\end{array}$ & - & NA & $\begin{array}{l}\text { Tip /Loop } \\
\text { length } 7 \\
\text { mm }\end{array}$ & fully visible & - & Yes & $2.4 \mathrm{Fr}$ & NA & AIS & \\
\hline & $\begin{array}{l}\text { Merci } \\
\text { V }\end{array}$ & $\begin{array}{l}\text { Concent } \\
\text { ric } \\
\text { Medical }\end{array}$ & $\begin{array}{l}\text { Nitin } \\
\text { ol }\end{array}$ & $\begin{array}{l}\text { Slight distal } \\
\text { narrowing helical } \\
\text { nitinol coil with } \\
\text { paolene filaments }\end{array}$ & $\begin{array}{l}0.012- \\
0.014 \\
\text { inch }\end{array}$ & - & $\begin{array}{l}2.0- \\
3.0 \\
\mathrm{~mm}\end{array}$ & $\begin{array}{l}\text { Loop } \\
\text { length } 5-7 \\
\mathrm{~mm}\end{array}$ & fully visible & - & Yes & $2.4 \mathrm{Fr}$ & $2.0-3.5$ & AIS & \\
\hline & $\begin{array}{l}\text { Solitair } \\
\mathrm{e}^{\mathrm{TM}} \\
\mathrm{FR}^{[130]}\end{array}$ & $\begin{array}{l}\text { Medtro } \\
\text { nic }\end{array}$ & $\begin{array}{l}\text { Nitin } \\
\text { ol }\end{array}$ & $\begin{array}{l}\text { folded } \\
\text { architecture of } \\
\text { circumferentially } \\
\text { overlapping } \\
\text { nitinol struts }\end{array}$ & $60 \mu \mathrm{m}$ & $\begin{array}{l}2.6 \\
\times \\
4.5 \\
\mathrm{~mm}\end{array}$ & $4-6$ & $15-30$ & $\begin{array}{l}3-4 \quad \text { distal/1 } \\
\text { proximal } \\
\text { marker }\end{array}$ & $\begin{array}{l}0.011 \\
0 \\
\mathrm{~N} / \mathrm{mm}\end{array}$ & Yes & $0.021-0.027$ & $\begin{array}{l}2.0- \\
4.0(\mathrm{FR} 4 \\
\mathrm{mm}) / \\
3.0- \\
5.5(\mathrm{FR} 6 \\
\mathrm{mm})\end{array}$ & AIS & $\begin{array}{l}78.3 \%- \\
100 \%\end{array}$ \\
\hline & $\begin{array}{l}\text { Solitair } \\
\mathrm{e}^{\mathrm{TM}} \\
\text { Platinu } \\
\mathrm{m}^{[131]}\end{array}$ & $\begin{array}{l}\text { Medtro } \\
\text { nic }\end{array}$ & $\begin{array}{l}\text { Nitin } \\
\text { ol }\end{array}$ & $\begin{array}{l}\text { with addedd } \\
\text { platinum markers } \\
\text { to provide real } \\
\text { time procedural } \\
\text { feedback }\end{array}$ & NA & NA & $4-6$ & $20-40$ & $\begin{array}{l}3-4 \quad \text { distal/3 } \\
\text { body } \quad(\text { every } \\
10 \quad \mathrm{~mm}) / 1 \\
\text { proximal } \\
\text { marker }\end{array}$ & NA & Yes & $0.021-0.027$ & $\begin{array}{l}2.0-4.0 / \\
3.0-5.5\end{array}$ & AIS & - \\
\hline & $\begin{array}{l}\text { Mindfr } \\
\text { ame } \\
\text { Captur } \\
\mathrm{e}^{\mathrm{TM}} \mathrm{LP}\end{array}$ & $\begin{array}{l}\text { Medtro } \\
\text { nic }\end{array}$ & $\begin{array}{l}\text { Nitin } \\
\text { ol }\end{array}$ & $\begin{array}{l}\text { with proprietary } \\
\text { cell geometry that } \\
\text { maximizes } \\
\text { entrapment and } \\
\text { designed to treat } \\
\text { occlusions in } \\
\text { arteries of small } \\
\text { caliber }\end{array}$ & $\begin{array}{l}\sim 54 \\
\mu \mathrm{m}\end{array}$ & $\begin{array}{l}\sim 2.5 \\
\times \\
6.4 \\
\mathrm{~mm}\end{array}$ & $3-4$ & $20-30$ & $\begin{array}{l}2 \text { gold distal/1 } \\
\text { platinum } \\
\text { iridium } \\
\text { proximal } \\
\text { marker }\end{array}$ & $\begin{array}{l}0.005- \\
0.016 \\
\mathrm{~N} / \mathrm{mm}\end{array}$ & Yes & 0.017 & $\begin{array}{l}2.0-3.0 / \\
2.5-4.0\end{array}$ & AIS & - \\
\hline
\end{tabular}




\begin{tabular}{|c|c|c|c|c|c|c|c|c|c|c|c|c|c|c|c|}
\hline \multirow[t]{3}{*}{$\begin{array}{l}\text { Trevo } \\
\text { device }\end{array}$} & $\begin{array}{l}\text { Trevo } \\
\text { provue } \\
\text { 132] }\end{array}$ & Stryker & $\begin{array}{l}\text { Nitin } \\
\text { ol }\end{array}$ & $\begin{array}{l}\text { Closed-cell } \\
\text { nitinol stent-like } \\
\text { retriever with } \\
\text { tapered distal end }\end{array}$ & NA & $\begin{array}{l}13.4 \\
\mathrm{~mm}^{2} \\
*\end{array}$ & 4.0 & 20 & $\begin{array}{lr}\text { Fully visible } \\
\text { with } 4 \mathrm{~mm} \\
\text { distal marker } \\
\text { tip and } \\
\text { proximal } \\
\text { marker }\end{array}$ & $\begin{array}{l}0.014 \\
80 \\
\mathrm{~N} / \mathrm{mm}\end{array}$ & Yes & $2.4 \mathrm{Fr}$ & $\begin{array}{l}1.5- \\
3.5 \mathrm{~mm}\end{array}$ & AIS & $\begin{array}{l}80 \%- \\
92 \%\end{array}$ \\
\hline & $\begin{array}{l}\text { Trevo } \\
\text { XP } \\
\text { ProVue } \\
{[133]}\end{array}$ & Stryker & $\begin{array}{l}\text { Nitin } \\
\text { ol }\end{array}$ & $\begin{array}{l}\text { Closed-cell } \\
\text { nitinol stent-like } \\
\text { retriever with } \\
\text { tapered distal end }\end{array}$ & NA & NA & 6.0 & 20 & $\begin{array}{lr}\text { Fully visible } \\
\text { with } \quad 4 \mathrm{~mm} \\
\text { distal marker } \\
\text { tip and } \\
\text { proximal } \\
\text { marker }\end{array}$ & $\begin{array}{l}0.014 \\
80 \\
\mathrm{~N} / \mathrm{mm}\end{array}$ & Yes & $2.4 \mathrm{Fr}$ & $\begin{array}{l}1.5- \\
4 \mathrm{~mm}\end{array}$ & AIS & $86-91 \%$ \\
\hline & $\begin{array}{l}\text { Trevo } \\
\text { baby [53 } \\
\text { aj, 134] }\end{array}$ & Stryker & $\begin{array}{l}\text { Nitin } \\
\text { ol }\end{array}$ & $\begin{array}{l}\text { Closed-cell } \\
\text { nitinol stent-like } \\
\text { retriever with } \\
\text { tapered distal end }\end{array}$ & NA & NA & 3.0 & 20 & $\begin{array}{lr}\text { Fully visible } \\
\text { with } 4 \mathrm{~mm} \\
\text { distal marker } \\
\text { tip and } \\
\text { proximal } \\
\text { marker }\end{array}$ & $\begin{array}{l}0.006 \\
00 \\
\mathrm{~N} / \mathrm{mm}\end{array}$ & Yes & $1.7 \mathrm{Fr}$ & $\begin{array}{l}1.5- \\
4 \mathrm{~mm}\end{array}$ & AIS & $\begin{array}{l}75 \%- \\
85.7 \%\end{array}$ \\
\hline Revive & $\begin{array}{l}\text { Revive } \\
\text { SE }^{[53 n]}\end{array}$ & $\begin{array}{l}\text { Codman } \\
\text { Neuro }\end{array}$ & $\begin{array}{l}\text { Nitin } \\
\text { ol }\end{array}$ & $\begin{array}{l}\text { Closed-ended } \\
\text { basket of nitinol } \\
\text { stent }\end{array}$ & NA & $\begin{array}{l}\text { decrea } \\
\text { se } \\
\text { from } \\
\text { proxi } \\
\text { mal to } \\
\text { distal } \\
(3.4 \\
\mathrm{mm}^{2} \\
*)\end{array}$ & 4.5 & 30 & $\begin{array}{l}\text { Radiopaque } \\
\text { tip }\end{array}$ & $\begin{array}{l}0.012 \\
7 \\
\mathrm{~N} / \mathrm{mm}\end{array}$ & Yes & $2.4 \mathrm{Fr}$ & $\begin{array}{l}1.5- \\
4 \mathrm{~mm}\end{array}$ & AIS & $\begin{array}{l}79.6 \%- \\
100 \%\end{array}$ \\
\hline $\begin{array}{l}\text { Embol } \\
\text { us } \\
\text { Retrie } \\
\text { ver } \\
\text { with } \\
\text { Interli } \\
\text { nked } \\
\text { Cages }\end{array}$ & $\begin{array}{l}\text { Embol } \\
\text { us } \\
\text { Retriev } \\
\text { er with } \\
\text { Interlin } \\
\text { ked } \\
\text { Cages }{ }^{[5} \\
\text { 3p, 135] }\end{array}$ & $\begin{array}{l}\text { Microve } \\
\text { ntion }\end{array}$ & $\begin{array}{l}\text { Nitin } \\
\text { ol }\end{array}$ & $\begin{array}{l}3-5 \quad \text { spherical } \\
\text { nitinol wire cages }\end{array}$ & NA & NA & $3-6$ & $15-44$ & $\begin{array}{l}\text { Tantalum } \\
\text { radiopaque tip } \\
(5 \mathrm{~mm})\end{array}$ & $\begin{array}{l}0.011 \\
00- \\
0.018 \\
5 \mathrm{~N} / \mathrm{m} \\
\mathrm{m}\end{array}$ & Yes & $1.7 \mathrm{Fr}$ & NA & AIS & $\begin{array}{l}79.4 \%- \\
86 \%\end{array}$ \\
\hline
\end{tabular}




\section{Submitted to

\subsection{Typical thrombectomy devices}

\subsubsection{Merci device}

The Merci clot retrieval device (Concentric Medical, Mountain View, CA) is the first FDA cleared embolectomy device for removing clot in AIS patients. It achieved a $69.5 \%$ vessel recanalization rate with adjuvant intra-arterial recombinant tissue plasminogen activator (rtPA) usage ${ }^{[129 b]}$. The Merci Retrieval System includes the Merci retriever device, a microcatheter, and a balloon guide catheter.

The first generation of the nitinol retriever device (models X4, X5 and X6) is a flexible shape-memory wire with 5 helical tapered coil loops at the distal end in a corkscrew shape. The diameter of its distal loops taper from $2.7 \mathrm{~mm}$ to $1.1 \mathrm{~mm}$. The device is covered with platinum to improve visibility under fluoroscopy. The X6 is slightly stiffer than the X5. The Merci X series are available in 2.5, 3.0 and $3.5 \mathrm{~mm}$ diameters and are inserted through a $2.4 \mathrm{~F}$ Merci microcatheter ${ }^{[136]}$. Once deployed distally to the clot, the device takes on its natural corkscrew shape to ensnare and extract the clot into the Merci balloon catheter, which is placed in the cervical segment of the internal carotid artery.

The L series and V series devices were later introduced in 2006 and 2008, respectively. The Merci second-generation L-series (L4, L5, and L6) devices were redesigned into a non-tapering helical nitinol coil with additional arched prolene filaments from the distal to the proximal end of the helix to increase clot entrapment. The cylindrical helix coil-like design enables optimal vessel wall apposition, and it is at a 90-degree angle with respect to the proximal catheter. The third generation V-series ( V 2.0, V 2.5, and V 3.0) device is a hybrid design of the earlier two series. The V retrievers have a linear, non-angular design with a slight distal narrowing, but it is also covered with filaments to increase surface area to facilitate clot extraction. The device 


\section{Submitted to

is delivered through a Merci microcatheter 18L. Merci devices with a loop diameter of $2.0 \mathrm{~mm}$ are intended for more distal vessels (M2 segment of MCA), $2.5 \mathrm{~mm}$ for moderately sized vessels (M1 segment of MCA, vertebral artery), and $3.0 \mathrm{~mm}$ for large vessels (ICA, basilar artery) ${ }^{[137]}$.

One disadvantage of the Merci Retriever is that the curved loops can unwind and slide through the clot rather than tightly engaging the target thrombus during pull back $^{[138]}$. Despites differences in design, recanalization rates have not been reported to substantially differ between generations of these retriever devices ${ }^{[129 b]}$. However, according to the SWIFT and TREVO 2 trials, the Solitaire and Trevo devices introduced next both achieve better blood flow recanalization than the Merci device ${ }^{[132 b \text {, }}$ 133b].

\subsubsection{Solitaire FR device}

The Solitaire stent retriever (CE marked since July 2009) is the most regularly used device in recent thrombectomy trials. The device is a laser-cut, self-expandable nitinol stent with an electrically detachable, closed cell design. It is cut from a nitinol sheet into a honeycomb pattern with constant cell dimensions of $2.6 \times 4.5 \mathrm{~mm}$. The device has a folded architecture of circumferentially overlapping struts with a longitudinal split section, which engages and pushes the clot against the vessel wall, with multiple planes of contact ${ }^{[139]}$.

Currently, four sizes of devices are available: $4 \mathrm{~mm}$ diameter with $15 \mathrm{~mm}$ or $20 \mathrm{~mm}$ working lengths, and $6 \mathrm{~mm}$ diameter with $20 \mathrm{~mm}$ or $30 \mathrm{~mm}$ working lengths. The Solitaire FR $6 \mathrm{~mm}$ at any length has a larger radial force than the FR $4 \mathrm{~mm}$. As the working length of Solitaire FR increases, the contact area with the vessel wall also increases ${ }^{[140]}$. In general, the working length should be at least the length of the thrombus.

This device is delivered by a 0.021 to 0.027 inch microcatheter via a $180 \mathrm{~cm}$ long, 0.016 inch nitinol pusher wire ${ }^{[141]}$. The recommended vessel diameter is $2-4 \mathrm{~mm}$ for the $4 \times 15 / 4 \times 20 \mathrm{~mm}$ versions, or $3-5.5 \mathrm{~mm}$ for the $6 \times 20 / 6 \times 30 \mathrm{~mm}$ versions $^{[130 \mathrm{a}]}$. 


\section{Submitted to

\subsubsection{Trevo device}

The Trevo Retriever (Stryker Neurovascular, Mountain View, CA) is a selfexpanding, laser cut, hydrophilic coated, closed-cell nitinol stent-like retriever thrombectomy device which was approved in Europe in 2010. Clinical trials in US first enrolled patients in $2011^{[133 b]}$.

The distal end has a $4 \mathrm{~mm}$ soft and floppy radiopaque tip wire that allows stable deployment and enhances fluoroscopic visualization. The distal end is tapered over a distance of $10 \mathrm{~mm}$, which provides a smooth transition from the radiopaque tip to the active area, which has higher radial force; the taper facilitates release of the device into more distal and smaller vessels ${ }^{[53 a i]}$. Like other retrieval devices, this device is also deployed by unsheathing the microcatheter, leaving the device directly in the thrombus and allowing it to immediately begin expanding and incorporating into the thrombus. This passive stent opening process may help attenuate potential vascular injury. Its structural design also evenly distributes the radial force of the whole device throughout the many stent struts along the device length ${ }^{[133 b]}$. Flattened stent struts oriented orthogonally to the device promote clot incorporation ${ }^{[142]}$. The device is permanently attached to a flexible 0.018 -inch pusher wire that is $180 \mathrm{~cm}$ at the proximal end with a taper transition to $75 \mathrm{~cm}$, which effectively prevents any accidental detachment while pulling back. The overall length of the Trevo device is $44 \mathrm{~mm}$, with a working length of $20 \mathrm{~mm}$ and a diameter of $4 \mathrm{~mm}$. Each Trevo device can be used in 1.5 to $3.5 \mathrm{~mm}$ vessels for a maximum of six retrievals ${ }^{[143]}$.

\subsubsection{Trevo ProVue Retriever}

The Trevo ProVue is a fully radiopaque version of the Trevo device that was released in November 2012 ${ }^{[53 \mathrm{a} i]}$. The newer generation Trevo device is also constructed of a cylindrical nitinol hypotube with wide cells oriented in a helical way. Platinum is incorporated throughout the entire retriever structure. This fully structurally radiopaque design enables the operator to visualize strut compression in images, which reflects the progress of clot integration. Furthermore, the strut behavior may indicate the stiffness of the clot, or whether there may have been an underlying stenosis ${ }^{[144]}$. Like the original Trevo, this device also has a perpendicular strut orientation, which, in theory, should improve thrombus integration and extraction ${ }^{[133 b]}$. 


\section{Submitted to

This device is $4 \times 40 \mathrm{~mm}$ with a working length of $20 \mathrm{~mm}$. It is recommended for use in intracranial vessels with a diameter between $1.5 \mathrm{~mm}$ to $4 \mathrm{~mm}$ and the device requires the use of a 0.021 inch or larger microcatheter ${ }^{[141]}$.

\subsubsection{Trevo XP ProVue Retriever}

The Trevo XP ProVue $3 \times 20 \mathrm{~mm}$ device (Baby Trevo) is the newest generation of the Trevo devices. It is specifically built to retrieve clots from smaller intracranial vessels and has a $36 \mathrm{~mm}$ total length that includes a $20 \mathrm{~mm}$ clot capture area (working length) and a $3 \mathrm{~mm}$ diameter.

According to the manufacturer, the Baby Trevo should have a lower radial force than previous models $(0.00600 \mathrm{~N} / \mathrm{mm}$ compared with $0.01480 \mathrm{~N} / \mathrm{mm})$, which is supposed to minimize endothelial and arterial wall damage, especially in vessels of smaller caliber $(\leq 3 \mathrm{~mm})^{[132 \mathrm{c}, 145]}$. However, clot retriever efficacy is directly proportional to the radial force, so the higher radial force Solitaire device may have a theoretical advantage over the Baby Trevo design by enabling immediate recanalization upon deployment ${ }^{[146]}$. An optimized platinum alignment in the device allows for more efficient compression within the catheter to facilitate smooth delivery while a larger cell area improves embolus integration ${ }^{[144]}$. Bench test results showed that the Baby Trevo can provide much larger cell sizes than the Trevo device when deployed in small vessels. Cell size was $217 \%$ larger when deployed in a $2 \mathrm{~mm}$ vessel and $57 \%$ larger in a $3 \mathrm{~mm}$ vessel than $4 \times 20 \mathrm{~mm}$ Trevo device ${ }^{[53 \mathrm{aj}, 134]}$.

The updated design removes the distal tip and taper of the ProVue Retriever. These design improvements decrease the length of the device that needs to be placed distally to the clot. Its distal end is softer than that of the Solitaire FR $4 \times 20 \mathrm{~mm}$ by at least $48 \%$, and the short landing zone may be beneficial while passing through or releasing tortuous anatomies, vessel bifurcations or in small caliber vessels. The stent retriever is fully radiopaque, with one proximal and two distal radiopaque markers to facilitate accurate positioning. It can be delivered through a small 0.017 inch microcatheter ${ }^{[134]}$. The device has a total length of $190 \mathrm{~cm}$, and pusher wire has been narrowed to 0.015 inch to make it compatible with smaller microcatheters than the original device and suitable for distal arteries arrival. 


\section{Submitted to

\subsubsection{Revive device}

The Revive device (Codman, Raynham, Massachusetts, USA) is a self-expanding, nondetachable nitinol stent for intracranial thrombectomy. The distal end of this stent has an innovative closed-ended basket with smaller cells to enhance capture of clots and large fragments.

The Revive device has various cell shapes that spiral around the longitudinal axis of the stent. Additionally, it has a high radial force and decreasing cell size from the proximal to the distal retrieval zone. The basket design is optimized for centering within the vessel lumen and preventing further distal embolization during deployment and retrieval. Once device positioned across the occlusion, the displaced clot engages with the basket and is then retracted into the guiding catheter under simultaneous aspiration.

Its narrow and tall strut design provides better penetration and engagement with clots. However, a previous study suggests that the small cell size may be the reason for weak clot engagement between the filaments ${ }^{[142]}$. The stent only has one size $(4.5 \times 22$ $\mathrm{mm})$ and is can be delivered by 0.021 or 0.027 inch inner diameter microcatheters ${ }^{[53 \mathrm{n}]}$. The single size design is compatible with most segments of the MCA or Vertebrobasilar artery; however, it is too small to be used in the distal ICA.

\subsubsection{Embolus Retriever with Interlinked Cages device}

The tubular design of typical stent retriever devices has a risk of clot fragmentation, migration or distal embolism. Additionally, a large contact area of metal retriever with the vessel wall may lead to endothelial injuries and/or vessel wall vasospasm during retraction $^{[147]}$. The Embolus Retriever with Interlinked Cages (ERIC, MicroVention, Tustin, California) device is a new stent retriever designed to overcome these challenges ${ }^{[135]}$. Depending on the size, it consists of 3-5 spherical nitinol wire cages that are linked together in a linear array specifically for reducing clot fragmentation and distal emboli. Meanwhile, the limited vessel wall contact areas may reduce vascular damage.

ERIC is also designed for immediate thrombus retrieval with little or no delay, while other stent retrievers require a 3-5 minute wait for clot integration ${ }^{[53 p]}$. The device is available in sizes from $3 \mathrm{~mm}$ to $6 \mathrm{~mm}$ and the number of linked spheres range from 


\section{Submitted to

3 to 5 . The available working lengths range from $15 \mathrm{~mm}$ to $44 \mathrm{~mm}$. ERIC can be delivered through a low profile 0.017 inch microcatheter regardless of the device size used. The recanalization rate reported for ERIC is about $80 \%$ to $85 \%{ }^{[53 \mathrm{p}]}$.

\subsection{Clinical applications}

Acute ischemic stroke is a major cause of death or disability worldwide. Intravenous recombinant tissue plasminogen activator (rtPA) treatments for occlusion of intracranial large vessels often have a low recanalization rate, with only $10 \%$ to $15 \%$ of ICA occlusions and $25 \%$ to $50 \%$ of proximal MCA occlusions recanalized, and only $35 \%$ to $40 \%$ of patients achieving good clinical functional independence outcomes ${ }^{[148]}$. Mechanical treatment approaches for acute ischemic stroke aim for fast and efficient reperfusion with short procedure times. After placing a femoral artery sheath, a microcatheter is then inserted into the intracranial vessels and passed through the occlusion segment with the support of a guidewire. After using contrast injection to confirm its arrival at the distal normal vessel lumen, mechanical thrombectomy devices can be introduced via microcatheters, advanced to the affected artery, and then deployed under fluoroscopic guidance. Thrombectomy can be performed with or without proximal balloon occlusion to reduce the risk of distal embolization during the procedure.

The first generation of thrombectomy devices approved by FDA were the Merci and Penumbra (aspiration catheter) devices. These devices had differing mechanisms to remove clots: (1) the Merci device is a coil-shaped retriever that can be delivered within the microcatheter as a wire to engage and bind the clot before being pulled back through the guiding catheter along with the thrombus; (2) the Penumbra system is a catheter aspiration device that applies suction to remove the thrombus. The Interventional Management of Stroke (IMS) III trial compared IV rtPA with mechanical thrombectomy; $45 \%$ of the included patients received clot removal using the Merci or Penumbra devices ${ }^{[148 b]}$. However, the results revealed no significant differences in 
long-term functional outcome between IV rtPA and mechanical thrombectomy treatments. Both sub-groups also had a similar mortality rate at 90 days and a similar proportion of patients with symptomatic intracerebral hemorrhage. The Intra-arterial Versus Systemic Thrombolysis for Acute Ischemic Stroke (SYNTHESIS EXPANSION) trial randomized 362 patients with acute ischemic stroke into either a standard IV rtPA group $(n=181)$ or a mechanical thrombectomy or intra-arterial therapy group $(n=181)$ within 4.5 hours of symptom onset. In this trial, no benefit of endovascular therapy was observed when comparing primary outcomes (vessel recanalization), survival without disability at 90 days, symptomatic intracranial hemorrhage, and mortality ${ }^{[149]}$. Thus, early trials using first-generation devices failed to show any clinical benefit to acute stroke patients with regard to mortality and morbidity improvement despite successful recanalization rates in the technique itself. Possible reasons for the discrepancy include: 1) Merci or Penumbra devices were still not able to promise a high rate of recanalization; 2) no strict image selection such as computed tomographic angiography (CTA) or computed tomographic perfusion (CTP) was performed to confirm large vessel occlusion or to identify areas of hyper-perfusion or any collateral circulation compensation; 3) the study did not strictly follow the rule of "time is brain" to select recanalization patients and did not strictly control the time from symptom onset to reperfusion.

Recently published randomized clinical trials revealed that catheter-based thrombectomy using retrievable stents significantly improves therapeutic outcomes for patients with large vessel occlusion compared to IV rtPA alone ${ }^{[126 f, 150]}$. The key attribute for success identified in the recent clinical trials is their fast reperfusion time. The time from the onset of symptoms to vessel reperfusion averaged from 4.0 hours to 5.5 hours. Clinical success can also be ascribed to the application of stent retriever devices. In most randomized, multi-center clinical trials, the Solitaire stent was the most wildly used stent. Besides the Multicenter Randomized Clinical Trial of Endovascular 


\section{Submitted to

Treatment for Acute Ischemic Stroke in the Netherlands (MR CLEAN) trial, which didn't specify a particular type of stent to use, the proportion of patients who receive a thrombectomy using the Solitaire stent in the Endovascular Treatment for Small Core and Anterior Circulation Proximal Occlusion with Emphasis on Minimizing CT to Recanalization Times (ESCAPE), the Randomized Trial of Revascularization with Solitaire FR® Device vs. Best Medical Therapy in the Treatment of Acute Stroke Due to Anterior Circulation Large Vessel Occlusion Presenting within Eight-Hours of Symptom Onset (REVASCAT), Solitaire ${ }^{\mathrm{TM}}$ FR With the Intention For Thrombectomy as Primary Endovascular Treatment for Acute Ischemic Stroke (SWIFT PRIME) and Extending the Time for Thrombolysis in Emergency Neurological Deficits-IntraArterial (EXTEND-IA) trials were $76.9 \%, 100 \%, 100 \%$ and $100 \%$ respectively. The total thrombectomy technique success rate can reach up to $72-100 \%$ and grade 2 or 3 reperfusion of Thrombolysis in cerebral infarction (TICI) was achieved in 79.6-94.3\% of occlusions, while the symptomatic intracranial hemorrhage rate was only $0-6.4 \%$. At the 90-day follow up, the rate of good modified Rankin scores of 0-2 was between 53\%71\%. The TREVO device is the second most popular stent retriever device used for thrombectomy in clinic. The Trevo versus Merci retrievers for Thrombectomy Revascularisation of Large Vessel Occlusions in Acute Ischaemic Stroke (TREVO 2) clinical trial revealed that the technique recanalization rate for Trevo device is $86 \%$, and the 90-day good outcome rate with a modified Rankin score $0-2$ was $40 \%$, with a symptomatic intracranial hemorrhage rate of $7 \%$, which is slightly higher than the Solitaire stent ${ }^{[133 b]}$. The recently-published DWI or CTP Assessment with Clinical Mismatch in the Triage of Wake-Up and Late Presenting Strokes Undergoing Neurointervention with Trevo (DAWN) and The Endovascular Therapy Following Imaging Evaluation for Ischemic Stroke (DEFUSE-3) studies found that if the clinical symptom-infarction or hyperperfusion-infarction areas are mismatched, patients can benefit from receiving thrombectomy treatment, which has a good (45-49\%) functional 


\section{Submitted to

independence rate at 90 days compared with $13 \%$ to $17 \%$ in the control group, where thrombectomy was performed between 6-16 or 6-24 hours after the onset of ischemic stroke $^{[151]}$. The REVIVE SE Device is the latest marketed thrombectomy devices and it permits a better and faster recanalization in patient with a stroke. The REVIVE SE Device is designed to ease navigation through small diameter or tortuous intracranial vessels. Presently, several clinical trials are still being undertaken to fully investigate its efficacy and safety for clinical application. In 2011, Rohde et al. were the first to report that all lesions were successfully recanalized in 10 patients with acute large vessel occlusions who received the Revive device treatment. However, two patients had symptomatic intracranial hemorrhage and one of them was fatal ${ }^{[53 n]}$. Overall, thrombectomy using stent retriever devices has already evolved as a standard technical for the treatment of acute ischemia stroke in strictly selected patients with anterior large vessel occlusions in clinic.

\section{Biosafety for metal device insertion in cerebrovasculature}

\subsection{Overview}

Biosafety is one of the most important issues that needs to be fully investigated after metal device insertion. Device related biosafety can be divided into immediate and long-term stages based on its different insertion periods. The immediate biosafety stage (from immediately post-insertion to a few days after) is mainly affected by the device insertion procedure, and the typical risks include arterial wall spasms, thrombosis, distal embolism or side branch occlusion. Chances of their occurrence greatly depend on the inserted device's mechanical properties, including passing performance, flexibility, and the amount of dilation in the vessel lumen. More importantly, proper device selection by the operators will minimize the immediate risks. Generally speaking, the better the mechanical performance of the device and the better its size matches the vessel 


\section{Submitted to

geometry, the less damage is caused by its delivery and insertion. Long-term biosafety mainly depends on the body response or biocompatibility of the metal material. Considering that metal devices have already been widely used in clinic for a long time, their biological response has been proved stable in most cases. However, the local disease environment may contribute to the devices' long-term biosafety. Endothelization is a standard way to judge if the metal device has become completely incorporated into the natural vasculature; any delayed endothelization exposes the device surface and increases the risks of thrombosis or intima over-proliferation, which can cause lumen restenosis ${ }^{[152]}$.

\subsection{Spasm}

Cerebral vasospasm is defined as the narrowing of the major cerebral arteries following subarachnoid hemorrhage caused by aneurysm rupture, arteriovenous malformation rupture, or brain tumor resection ${ }^{[153]}$. Vasospasm is detected in $67 \%$ of patients with subarachnoid hemorrhage (SAH) and is a major cause of morbidity and mortality ${ }^{[154]}$. Vasospasm has a biphasic course after SAH. The acute phase typically begins 3 to 4 hours after hemorrhage begins, and often rapidly or spontaneously resolves after hemorrhage stops. Then, the chronic phase begins 3 to 5 days later and resolves after about 14 days, with maximum narrowing typically occurring between days 6 and $8^{[155]}$. Besides cerebral vasospasm caused by a natural history of the disease, mechanical stimulation caused by device insertion can induce cerebral vasospasm in intra- or extracranial arteries whether or not a patient has SAH. Cerebral artery catheterization, balloon dilation, and stent insertion, especially when stent needs to be repositioned in the arterial lumen, are all capable of causing damage to the vessel wall that induces vasospasm. Vasospasm caused by device insertion belongs to the acute phase of response as it typically begins within minutes. Stent retriever devices have been confirmed to induce severe vasospasm due to vascular injury and autopsy studies have found pathologic inflammation reactions such as fibrin thrombi containing large 


\section{Submitted to

numbers of neutrophils and neutrophil invasion into the internal elastic lamina ${ }^{[156]}$. Possible vasospasm mechanisms following SAH have already been well-studied. The central event of vasospasm is medial vascular smooth muscle contraction caused by an increased concentration of intracellular calcium and activated calmodulin and myosin light chain kinase (MLCK). Catecholamines, which can be degraded by Catechol-Omethyltransferase (COMT) were also found to promote acute vasospasm following $\mathrm{SAH}^{[157]}$. Furthermore, SAH leads to increased phosphorylation of endothelial nitric oxide synthase (eNOS), an enzyme that synthesizes NO and plays a protective role against vasospasm; phosphorylation decreases NO availability and increases superoxide production, which may deplete residual NO even more by further reacting to form peroxynitrite ${ }^{[158]}$. Inflammation is often considered a factor associated with the chronic stage of vasospasm. For example, elevated levels of matrix-metalloproteinase9 (MMP-9) and VEGF following an inflammation reaction are associated with vasospasm $^{[159]}$. These results were all obtained from studies of vasospasm following SAH; however, mechanical injury to arterial walls caused by device insertion might induce vasospasm by different mechanisms and further investigation is needed.

Since vasospasm related to metal device implantation has a higher occurrence rate in SAH patients, triple " $\mathrm{H}$ " therapy (hypertension, hypervolemia, hemodilution) is basic conservative treatment to prevent or reduce its occurrence rate in SAH patients. Meanwhile, intra-arterial or intravenous injection of vasodilators, like papaverine, magnesium sulfate, erythropoietin, fasudil hydrochloride, endothelin-1 antagonists, nitric oxide progenitors, sildenafil and nimodipine are currently employed to manage device- and/or SAH-related vasospasm ${ }^{[160]}$. However, for high risk vasospasm, such as vasospasm occurring immediately after stent insertion or stent retriever push, there is a high chance of inducing thrombosis if the vasospasm is not resolved immediately. In these situations, balloon angioplasty may be applied ${ }^{[161]}$. 


\section{Submitted to

\subsection{Thrombosis or thromboembolism}

Thrombosis or thromboembolism related to device insertion describes the presence of a thrombus or clot that originated in the device and/or fell off into distal vessel lumen. As an exogenetic transplant, metal device insertion into cerebral arteries has the problem of blood compatibility. Thus, patients are required to receive dual antiplatelet aggregation or anticoagulant therapy to reduce their risk of thrombosis or thromboembolic events. However, patients who have aspirin or clopidogrel resistance or who are in a hypercoagulable state may have a higher risk of induced thrombosis within devices.

Thrombosis or thromboembolic events can be triggered by the metallic device, or its polymer or drug coatings, varying from benign reactions to excessive inflammation and in-device thrombosis. Depending on when it occurs, thrombosis can be categorized into early (<30 days), late ( $>30$ days) and very late ( $>1$ year) stages, and early thromboembolic events can be further categorized into intraprocedural (during the procedure) and subacute (from the end of the procedure to 30 days thereafter) ${ }^{[162]}$. The one-month cumulative incidence of stent thrombosis ranges from $0.4 \%$ to $5 \%^{[163]}$. However, over $80.0 \%$ of angiographically confirmed thromboembolic events occur within 2 days of the procedure ${ }^{[164]}$. After 30 days, the risk reduces for bare metal stent due to complete endothelialization within this period of time ${ }^{[165]}$.

Diabetes, chronic kidney disease, hypercoagulable status, small vessels, multiple stents, bifurcation lesions and chronic total occlusion are all potential risk factors for thromboembolic events ${ }^{[166]}$. Device factors affecting thromboembolic event may include: 1) characteristics of the device, as its structural design might influence the risk of platelet activation after deployment. Higher metal coverage rates, closed cell designs, and balloon expandable deployment methods can increase the risk of thrombosis or thromboembolism, while lower metal coverage rates, open cell designs, and self- 
expandable release via microcatheter may reduce the risk. Functional material drug elution coatings or covering material may also increase the risk of thrombosis or thromboembolism. A previous study suggested that both the polymer coating and the medication it contains might influence the propensity for thrombosis ${ }^{[167]}$. 2) Anatomic characteristics of cerebral arteries, including their smaller vessel diameter, tortuous shape and arterial wall injuries such as thrombus-containing lesions and dissections ${ }^{[168]}$ may also increase the risk of thrombosis in the lumen of the segment implanted with a device. 3) In some circumstances, device manipulation, such as using a stent retriever device, can cause arterial wall damage and induce thrombosis via the extrinsic coagulation pathway.

Basic drugs including dual antiplatelet therapy and anticoagulant therapy are the essential treatments to prevent thromboembolic events. Antiplatelet agents such as GP IIb/IIIa inhibitors play an important role during treatment of thrombosis, as GP IIb/IIIa inhibitor application, either intravenously or intraarterially, is associated with increased reperfusion and decreased recurrence of stent thromboembolism. Both experimental and human autopsy data have revealed that thrombi within the stent contain very little fibrin and instead consist of mostly platelets ${ }^{[169]}$. This fact provides a strong argument for treatment with GP IIb/IIIa inhibitors. Some studies show the reperfusion success rate can reach up to around 90\% when IIb/IIIa inhibitors are used along with mechanical recanalization ${ }^{[170]}$. Moreover, the use of GP IIb/IIIa inhibitors is the only known predictor that decreases the recurrence of in-stent thrombosis after an initially successful recanalization treatment ${ }^{[171]}$.

Thrombolytic drugs can directly be applied to dissolve thrombi, and urokinase and rtPA are two of the most frequently used thrombolytic drugs. They are applied via catheter thrombolysis during interventional procedures. However, considering the low rate of fibrin in the stent thrombi, thrombolytic drugs often not very effective at achieving reperfusion in this setting. Instead, mechanical recanalization is often 


\section{Submitted to

required and this method includes the use of guide wire mechanical fragmentation, catheter suction, balloon dilation and stent retrievers. For in situ thrombosis within the implanted devices, guide wire mechanical fragmentation and balloon dilation are often applied, and care should be taken to avoid further damage to the arterial wall, which might result in thrombus aggravation. Meanwhile, catheter suction or stent retriever methods are often considered for distal vessel thromboembolism. After restoration of antegrade blood flow, combination therapy with thrombolytic drugs or GP IIb/IIIa inhibitors may prompt residual thrombolysis or prevent thrombus recurrence.

\section{3 Side branch occlusions}

One of the anatomic characteristics of the cerebral artery is its multiple perforator vessels or side branches. These perforator vessels or side branches are ending feeder vessels and once occluded, a brain infarction is likely to occur. After metal devices insertion, vessel wall contact with a high metal coverage or materials coating the outside of the device (as in covered stents), arterial dissection or tearing, and thrombus migration can all cause occlusion of perforator vessels or side branches leading to ischemic stroke. As the metal coverage rate of a conventional stent is only $6-8 \%$, its insertion does not need to consider coverage of perforator or side branches. However, for flow diverters, whose metal coverage goes up to $45-70 \%$, and for covered stents, whose coating material can cover the whole segment of stented artery, the risk of occluding perforator vessels or side branches runs much higher.

Generally, PEDs are recommended to be inserted into cerebral arteries with branches or perforators. The PED device has a unique risk profile that includes occlusion of both side branches and perforator vessels. Side branch occlusion has been reported at a particularly high rate at the ophthalmic artery ${ }^{[172]}$. Another study detected no immediate postoperative occlusions in the 127 arterial branches covered by PEDs, and 
angiographic follow-up (mean 10 months, range 3-34.7 months) revealed 13 (15.8\%) arterial side branches that were occluded out of 82 cases, including 2 anterior cerebral arteries, 8 ophthalmic arteries, and 3 posterior communicating arteries. However, no anterior choroidal artery occlusion was observed and no neurological symptoms were experienced in patients with branch occlusions ${ }^{[173]}$.

The main issue with the covered stent usage in the cerebrovasculature is the possible blockage of side branches or perforating arteries due to the stented segment. Thus, covered stents are mostly not considered for intracranial vessels because distal cerebral arteries (like middle cerebral artery or basilar artery) have many perforating branches, which means they run a high risk of ischemia after a covered stent deployment. Such stents can, however, be successfully used to treat intracranial aneurysms located at the ICA or VA. Another reason they are not use intracranially may be that the stiffness of the covered stent system may not allow it to arrive at distal cerebral arteries. Instead, for vessels at the skull, covered stents can be applied if coverage of important side branches can be avoided. Important side branches like the anterior choroidal artery, the posterior communicating artery, the fetal type posterior cerebral artery, the anterior and posterior inferior cerebellar arteries and the primary trigeminal artery should not be covered $^{[174]}$. In a previous study, covering the ophthalmic artery in one patient resulted in acute vision loss, which might be due to insufficient compensation of lateral branches by the ipsilateral external carotid artery ${ }^{[175]}$. If the ophthalmic artery or posterior communicating artery is suspected to be covered, caution is advised when performing a balloon occlusion test at the coverage segment.

\subsection{Endothelization, Neointima and Restenosis}

Metal devices inserted into a vessel lumen, such as a stent or flow diver device, will experience the progression of neointimal coverage and endothelization. Neointimal 


\section{Submitted to \\ ADVANCEDS
MATERIALS}

hyperplasia refers to thickening of arterial walls due to the migration and proliferation of vascular smooth muscle cells (SMCs), primarily in the media or tunica intima, before endothelization completes. During endothelization, endothelial cells gradually creep and cover the metal struts, which inhibits platelet and leukocyte activation and maintains vascular SMCs in a nonproliferative state ${ }^{[176]}$. Active substances in the vessel such as NO and prostagtandin (PGI) are secreted by endothelial cells to regulate and maintain the balance of vessel contraction and dilation, and the coagulative and fibrinolytic systems, as well as control cell proliferation and inflammation reactions. Thus, complete endothelization has a close relationship to biosafety with regards to metal device insertion.

\subsubsection{Problems of neointimal hyperplasia and restenosis}

If the inserted devices have a low metal coverage rate and cause little damage to the vessel wall, then neointima proliferation is often mild with a quick normal endothelization and will run a low risk of causing intra-luminal restenosis. However, if the metal devices have a high metal coverage rate and induce severe damage to arterial wall, such as endothelial cell denudation, atherosclerotic plaque disruption, arterial wall dissection, and even stretching of the entire artery, then excessive neointimal hyperplasia or restenosis can occur. Post angioplasty restenosis is thought to mainly be caused by vascular smooth muscle cell (VSMC) migration and proliferation and excessive extracellular matrix production. Other possible reasons include elastic recoil of the vessel, negative remodeling or contraction, and thrombus formation at the site of injury $^{[177]}$. In addition, VSMC over-proliferation and migration thickens arterial walls and decreases arterial lumen space ${ }^{[178]}$. The in-stent stenosis rate (ISR) is classified into four types based on the length of restenosis compared to the stented arterial length: (i) focal restenosis no more than $10 \mathrm{~mm}$ in length, (ii) diffuse lesions with more than 10 $\mathrm{mm}$ of restenosis within the stent, (iii) proliferative restenosis more than $10 \mathrm{~mm}$ in length that extends outside of the stent, and (iv) occlusive lesions longer than $10 \mathrm{~mm}$ in 


\section{Submitted to

the stent ${ }^{[179]}$. These criteria are adopted from the coronary stent standards. Considering that the brain vasculature has its own histological features like underdeveloped SMC in the media and different lengths of stented arteries, ISR classifications focused on the cerebro vasculature to be further developed.

Device-related restenosis or neointimal over-proliferation can be influenced by the following factors:

1) Device design: features that seem to have more favorable ISR rates include open cell structures, suitable radial force against the arterial wall, shorter device length and fewer implanted devices. Meanwhile, stent strut design may also impact the endothelization or intimal hyperplasia by altering the stream of blood flow (Figure 6).

2) Degree of the damage to the vessel wall: intraluminal stenosis related to device insertion is a type of arterial wall healing response to arterial injury. VSMC proliferation is closely related with rupture of the internal elastic layer. Experimental studies of RNA extraction 30 min after arterial wall injury caused by balloon dilation demonstrated that as inflation pressure increases, c-fos expression, neointimal formation and proliferation are stimulated ${ }^{[180]}$.

3) Degree of neointimal proliferation: Such proliferation is proportional to the degree of injury. Metal device insertion into a normal vessel often induces mild arterial wall injury while for a severely stenotic artery, angioplasty by stent insertion often needs to dilate the diseased artery and tear the intima, media or even the entire vessel wall. In this situation, severe arterial wall injury often results in an aggressive repair reaction and over proliferation of SMCs to induce stenosis.

4) Inflammation reaction: Vascular inflammation, neointimal proliferation, and restenotic obstruction at the stented lumen induced by endovascular treatment are the result of complex interactions between vascular cells and the dysregulation of vascular repair under particular pathological conditions. Platelets, neutrophils, and monocytes 


\section{Submitted to \\ ADVANCEDS}

play essential roles in inflammatory response ${ }^{[181]}$. Platelet and fibrin deposition at the site of injury triggers expression of cell adhesion molecules that recruit leukocytes ${ }^{[182]}$. Leukocytes then attach to platelets through the combination of leukocyte integrin Mac1 (CD11b/CD18) with platelet glycoprotein Ib-alpha ${ }^{[183]}$ or when fibrinogen binds with platelet glycoprotein IIb/IIIa ${ }^{[184]}$. Experimental and clinical studies have revealed that leukocyte adhesion mediated by Mac-1 and platelets is the main mechanism that results in vascular inflammation and restenosis after coronary stenting ${ }^{[185]}$. Sometimes the intensity of infiltration by the inflammatory cells can release inflammatory mediators and cytokines such as platelet-derived growth factor (PDGF) and transforming growth factor-b (TGF-b) to induce VSMC migration and proliferation ${ }^{[186]}$. Previous studies have already revealed that VSMCs or myofibroblasts in the neointimal migrate from the media or adventitia in response to $\operatorname{PDGF}^{[187]}$.

5) Anatomic and hemodynamic factors: Considering the extremely tortuous course of the cerebral vasculature, blood flow in the highly curved vessels often presents complicated hemodynamic characteristics. When a metal device is inserted into a curved vessel, the greater and lesser curvature sides of the vessel wall may have different metal coverage rate. The lesser curvature side is more likely to have higher metal packing or kinking, especially in open cell stents that further disturb the blood flow. Deformation of the inserted device in a tortuous artery also makes for unequally distributed radial force, which can cause differing extents of vessel wall injury and vessel repair that result in stenosis. The complicated hemodynamics in curved vessels include an asymmetrical distribution of wall shear stress which will directly affect the process of endothelial cell coverage and neointimal hyperplasia (Figure 7). Previous research indicated that in the curved vessels, the walls with greater and lesser curvature are subjected to higher wall shear stress; thus, the creeping of endothelial cells from adjacent normal arterial walls and the deposition of endothelial progenitor cells were affected and delayed endothelization progress was observed ${ }^{[53 a g]}$. 


\section{Submitted to \\ ADVANCEDS}

6) Disease of the arterial wall: Arterial wall atherosclerosis is another important factor that encourages intimal hyperplasia. The pathology of atheroselerotic plaque includes subintimal lipid deposition, proliferation of SMCs and deposition of ECM, so injury of the atheroselerotic artery caused by metal device insertion has a larger chance of resulting in over intimal hyperplasia and lumen stenosis. 7) Patients with a history of diabetes or restenosis may run a higher risk of $\operatorname{ISR}^{[188]}$. Meanwhile, patients displaying systemic markers of inflammation, such as midkine, have a higher risk of intimal hyperplasia due to macrophage accumulation caused by stent insertion ${ }^{[189]}$.

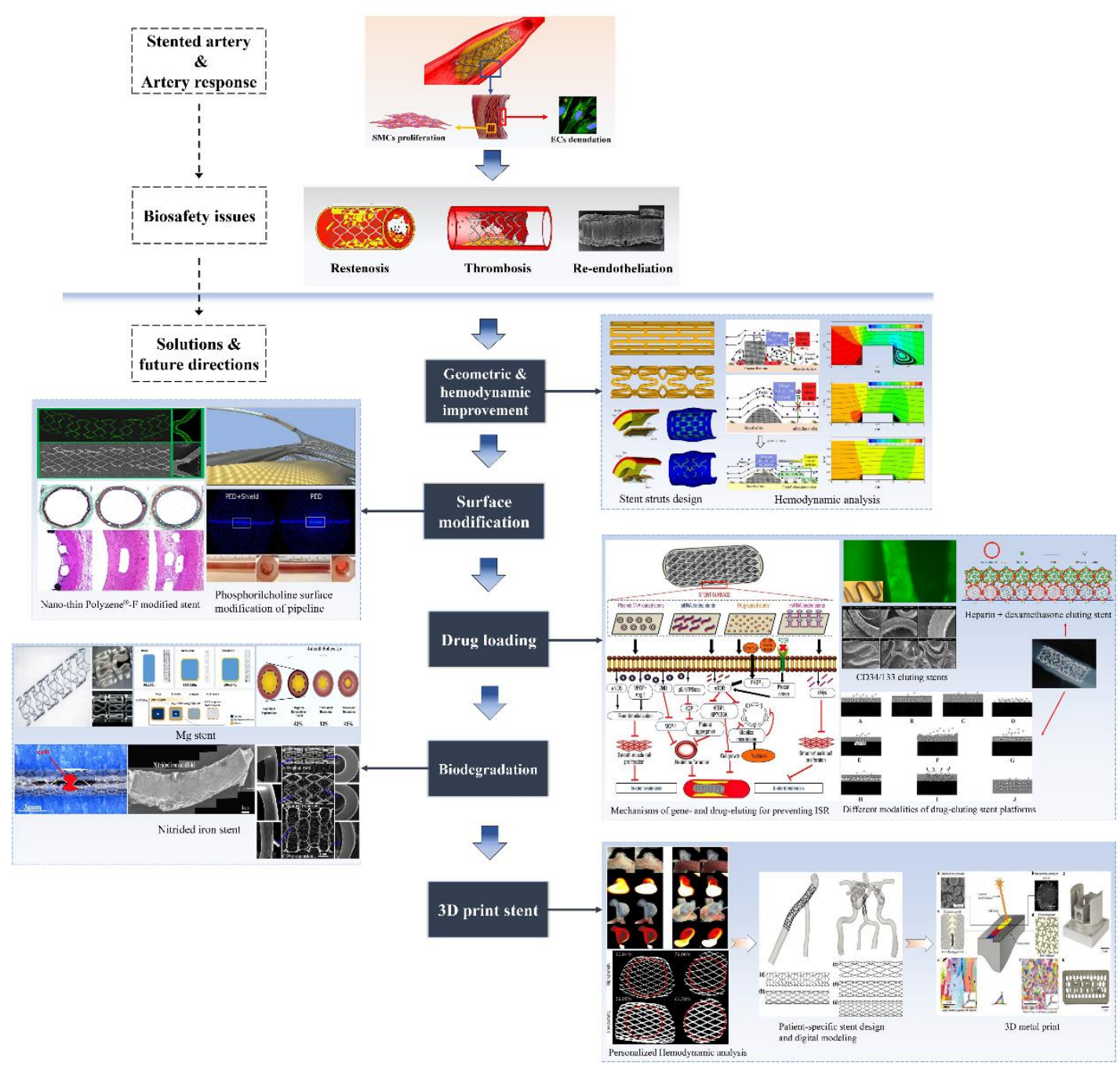

Figure 6. Diagram of the biosafety issues for metal stents insertion into the arterial lumen and the potential solutions and future directions to reduce these risks ${ }^{[190]}$. 


\section{ADVANCED \\ Submitted to}

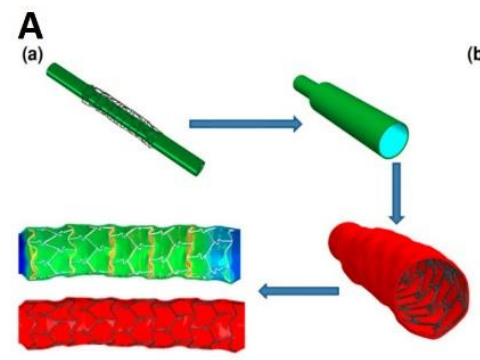

(c)

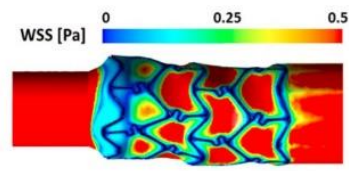

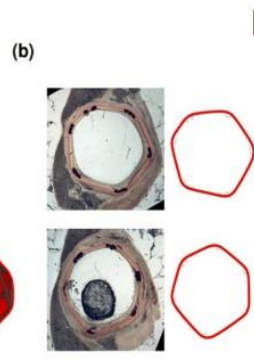

(d)

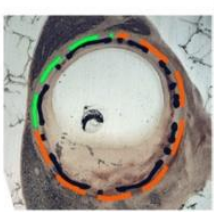

B

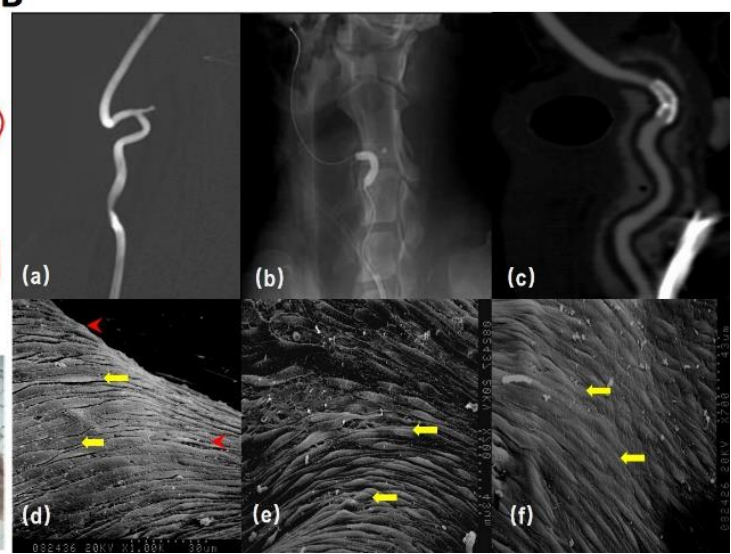

Figure 7. The complicated hemodynamics in curved vessels. (A) The effect of stenting on vascular anatomy and computational fluid dynamics analysis found good correlation between low WSS areas (orange lines) and the in-stent restenosis after 14 days on histological observation. (B) Histological observation after using a covered sent to treat curved cervical artery aneurysm (a-c) showed at 6 months, endothelial cells (yellow arrows) become tightly arranged to cover the stent strut (red arrows) (Bd) or form a whirlpool in the curved segment (B-e), while at 12 months, the endothelial cells have completely matured and are arranged even more tightly $(B-f)^{[53 a g, 191]}$

\subsubsection{Mechanism of neointimal hyperplasia}

Molecular or genetic mechanisms related to neointimal hyperplasia or in-stent restenosis have been carefully studied since the clinical application of stent insertion. Both the MAPK and the cAMP-protein kinase A (PKA) signaling pathways have been found to inhibit intima proliferation and formation after balloon-induced injury. In particular, cAMP/PKA activation markedly inhibits VSMC proliferation ${ }^{[192]}$. Amplifying or stimulating the cAMP/PKA pathway in VSMCs at the molecular level, such as by overexpressing the A kinase anchor protein, resulted in the activation of 


\section{Submitted to \\ ADVANCEDS}

cAMP-induced transcription through anchoring the PKA regulatory subunit to subcellular membranes. These biochemical reactions increase levels of p27kip1 and suppress not only VSMC growth in vitro but also neointimal hyperplasia in vivo ${ }^{[193]}$. Meanwhile, inactivating cellular ras proteins, which are key transducers of mitogenic signals, in balloon-injured rats significantly reduced neointima formation (by approximately 55\%) 14 days after balloon injury ${ }^{[194]}$. (Figure 8a)

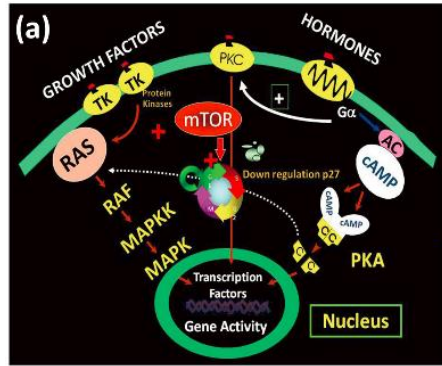

(c)

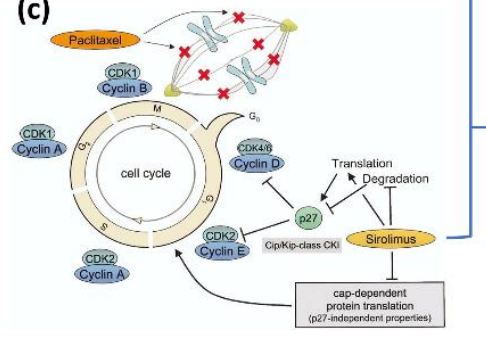

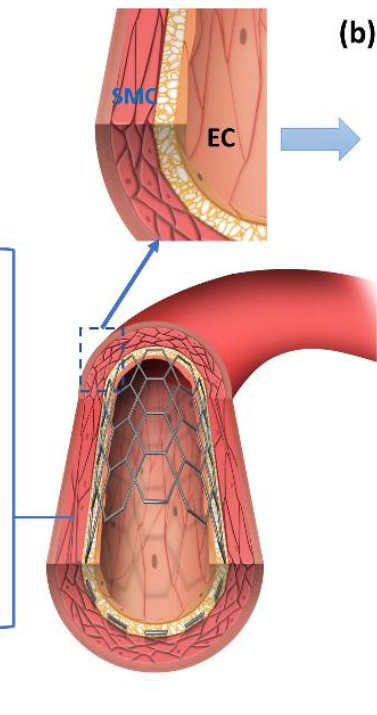

(b)

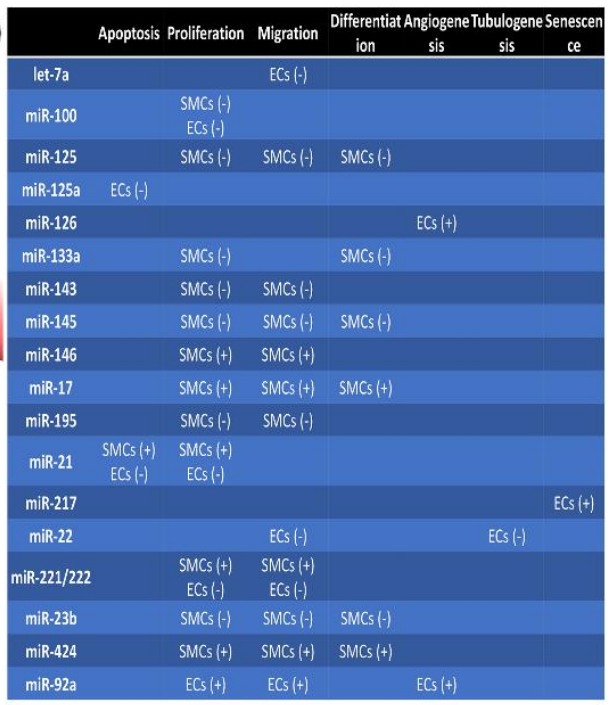

Figure 8. Several aspects of the vascular response to injury. (a) Molecular mechanisms of vascular smooth muscle cell proliferation and selected intracellular targets for antiproliferative strategies $^{[195]}$. (b) miRNAs expression involved in response to vascular injury. (+): induction; (-): inhibition; SMCs: smooth muscle cells; ECs: endothelial cells. (c) Schematic diagram of the VSMC cycle and its regulatory mediators ${ }^{[196]}$. CDK: cyclin-dependent kinase; CKI: cyclin-kinase inhibitor; G1: Gap 1; G2: Gap 2; M: Mitosis; S: Synthesis.

MicroRNAs (miRNAs) also play a key role to regulate the pathophysiological processes of neointimal hyperplasia or restenosis and have largely been investigated for their potential to function as both biomarkers and therapeutic targets ${ }^{[197]}$. Since 


\section{Submitted to

miRNAs mediate communication between endothelial cells (ECs) and vascular SMCs, monocytes, pericytes, or platelets, they play an important role in modulating the vascular response to injury. Generally, repair induced by vascular injury may result in the upregulation of a certain group of miRNAs (such as miR-21, miR-146, miR221/222 and miR-424) and downregulation of another group of miRNAs (such as miR145, miR-143, miR-125 and miR-23b), which together regulate the apoptosis, proliferation, migration and differentiation of both SMCs and ECs. (Figure 8b) In humans, miR-21 is highly expressed in atherosclerotic lesions or after vascular injury ${ }^{[198]}$. Upregulation of miR-21 also enhances VSMC growth both in vitro and in vivo after vascular injury. This effect is mediated by PTEN, a tumor suppressor that is a direct target of miR-21. Meanwhile, the miRNA also indirectly targets Bcl-2, indicating that it can modulate VSMC growth through different pathways ${ }^{[198 a]}$. A similar regulation effect is seen in miR-146a when it binds the Krüppel-like factor 4 (KLF-4), which is a key transcription factor that regulates the phenotypic switch of VSMCs: they can regulate each other ${ }^{[199]}$. High expression of the miR-221/222 cluster has also been found to control proliferation, migration, and apoptosis in VSMCs as well as in $\mathrm{ECs}^{[200]}$. Since these miRNAs target $\mathrm{p} 27$ and $\mathrm{p} 57$, their overexpression results in excessive neointimal growth, whereas their downregulation can reduce neointima formation by approximately $40 \%$ in a rat model ${ }^{[201]}$. Furthermore, miR-221/222 upregulation inhibits EC proliferation by targeting the proto-oncogene c-kit. Meanwhile, miR-424 exhibits a completely different way of modulating VSMC proliferation than other miRNAs. Despite its increased levels after injury, miR-424 works by directly targeting cyclin D1 to cause a G1/S transition, and thus arresting VSMC proliferation $^{[202]}$. The major modulators of SMC phenotype to maintain VSMC differentiation are miR-143 and miR-145, and their overexpression prevents neointimal hyperplasia $^{[203]}$. Their expression can be upregulated by introducing a serum response factor such as myocardin or by the jag-1/Notch axis ${ }^{[204]}$. Downregulation caused by 


\section{Submitted to \\ ADVNANED
MAAERRALAS}

vascular injury, hemodynamic stress or in atherosclerotic vessels ${ }^{[205]}$ promote the VSMCs to transition from a synthetic phenotype to a contractile phenotype. Like miR146a, miR-145 directly targets KLF-4, but it also interacts with KLF-5, an inhibitor of myocardin $^{[203]}$, calmodulin kinase II $\delta$, and several other factors involved in serum response factor activity ${ }^{[206]}$. By contrast, miR-143 functions mainly by targeting Elk$1^{[204 a]}$. Similar to miR-143 and miR-145, miR-195 is another modulator of VSMC phenotypes to prevent VSMC proliferation and migration. Overexpression of miR-195 decreases cell proliferation and migration by downregulating Rho-GTPase Cdc42, FGF1, and cyclin D1 ${ }^{[207]}$.

\subsubsection{Neointimal hyperplasia prevention or treatment}

Despite intimal hyperplasia after metal device insertion being an inevitable pathological response, different measures can be taken to minimize the response and to reduce restenosis risks caused by intimal hyperplasia. These methods include: 1) Modification of the metal surfaces with polymers. A nitinol surface using polyhedral oligomeric silsesquioxanes and poly(carbonate-urea) urethane can result in a nanocomposite polymer which has antithrombogenic, nonbiodegradable, and in situ endothelialization properties $^{[208]}$. Surface modification of metal devices to construct a buffer layer is important for long-term biocompatibility. 2) Consistent anti-inflammation drug elution on the device surface via a polymer carrier. By releasing drugs that target VSMC proliferation from the polymer-coated stent struts, drug-eluting stents (DES) have very successfully reduced ISR in coronary arteries since they were introduced in $2002^{[195]}$. 3) Promotion of the process of re-endothelialization. Stent strut surface modifications with thromboresistant biomolecules encourages the attachment of the vascular cells to the stent, which is the first step of endothelialization. Substantially promising bioactive materials include heparin, albumin, phosphorylcholine, aptamers, elastininspired polymers, thrombomodulin and anti-CD34 antibody ${ }^{[190 i]}$. A heparin/collagen multilayer coating functionalized with Anti-CD34 antibody successfully achieves rapid 


\section{Submitted to \\ ADVANCEDS
MATERIALS}

endothelialization and prevents restenosis, which indicates that the combination of an EC-specific ligand with a suitable matrix can promote in situ endothelialization and may inhibit ISR. VEGF has also been proven to promote the process of endothelialization. VEGF can be bound on the surface of a stent by static electricity to stimulate EC migration and proliferation. Another method to prompt EC adhesion or proliferation includes integrating adhesion proteins, like collagen, fibronectin, gelatin and nanofibers constructed by fibrin glue, with PLLA-CL on a metal surface to simulate the configuration or chemical environment of the extracellular matrix. Meanwhile, a polypeptide such as heparin and peptides arginine-glycine-aspartic acid (RGD) can also have similar effect to prompt ECs migration and proliferation.

Intracranial vessel lumen restenosis or reocclusion induced by metal device implantation is a clinical dilemma as no satisfactory methods exist to resolve this issue. For peripheral arterial restenosis, many endovascular treatments such as plain balloons, rotational atherectomy, brachytherapy, drug coated balloons, cutting balloons and drug eluting stents are optional methods associated with of less need for target lesion revascularization and a reduced risk major adverse events compared with treatments using bare metal stents ${ }^{[209]}$. However, for intracranial application, a mechanical treatment such as percutaneous transluminal angioplasty dilation is the most commonly applied treatment. Treatment outcomes are associated with vessel lumen size, length of ISR, vessel curvature and whether or not it was completely occluded. Surgical treatment is an option for the treatment of extra-cranial restenosis, as the extra-cranial artery has a larger diameter and an easy access path that allows direct incision to remove the metal device, thrombus, plaque or hyperplastic intima. Sometimes bypass surgery can also be used to restore blood flow reperfusion for distal vessels and brain tissues. However, surgical treatment for intracranial restenosis is often difficult in technique, as the small lumen hinders direct surgical open surgery for cerebrovascular ISR. Moreover, due to 
its deep location in brain, for most of the diseased artery, there is no proper vessel that can be used for bypass surgery.

\section{Future directions of intracranial metal devices}

Devices based on metal materials such as platinum and nitinol alloys have been widely applied in the brain vasculature for the treatment of cerebrovascular diseases. Novel structural designs have mostly focused on enhancing device flexibility and providing better occlusion, isolation or reconstruction performance during treatment for vascular diseases. However, many challenges remain and further investigation is needed to make intracranial devices safer and more effective. Drug elution and 3D printing techniques are well-studied and have been successfully incorporated into the cardiac and peripheral vasculatures; such innovations also have potential value to be applied to cerebrovascular disease treatment ${ }^{[210]}$.

\subsection{Biodegradable metal materials for intracranial devices}

Compared to biodegradable polymers or synthetic polymers, absorbable metals typically have excellent stiffness and strength, and can often be made into a much smaller size. Thus, they are very attractive for intracranial applications. Current research on metals for vascular applications includes alloys based on magnesium $(\mathrm{Mg})^{[211]}$, iron $(\mathrm{Fe})^{[212]}$, and zinc $(\mathrm{Zn} ; \mathrm{Zn}-\mathrm{Mg}, \mathrm{Zn}-\mathrm{Al})^{[213]}$. Magnesium is generally considered a neuro-protective element for acute ischemic stroke. Since magnesium, iron, and zinc all naturally exist in the body, $\mathrm{Mg}$-, Fe- or $\mathrm{Zn}$-based alloys have demonstrated good biocompatibility and non-toxic biodegradation, and are promising metals for absorbable stents. Mg stents have already been applied in the treatment of atherosclerotic stenosis in the coronary and inferior genicular arteries ${ }^{[214]}$. The main limitation of bio-absorbable $\mathrm{Mg}$ stents is its fast degradation rate in vivo; it can only reliably provide mechanical support for up to 3 months. Surface modification is one method to increase surface corrosion resistance, which prolongs the stent degradation time. One such modification is a coating of poly (3-hydroxybutyrate-co-3- 


\section{Submitted to \\ ADVANCEDS}

Hydroxyhexanoate) (PHBHHx) or poly (1, 3-trimethylene carbonate) (PTMC) $)^{[215]}$ on $\mathrm{Mg}$ alloy. In dynamic degradation tests, the speed of degradation of PHBHHx- or PTMC-coated Mg alloys was found to be reduced by one and three orders of magnitude compared to PCL-coated and bare Mg alloys, respectively. PHBHHx- or PTMC-coated $\mathrm{Mg}$ alloys also exhibited less volume loss and generated fewer corrosion products than PCL-coated and bare Mg alloys after 52 weeks in rats. Research also suggests that micro-arc oxidation can reduce the speed of Mg alloy degradation ${ }^{[216]}$. Finally, making new alloys that combine different proportions of $\mathrm{Mg}$ mixed with other metals is another way to tune the degradation rate and corrosion control while enhancing biocompatibility. Examples of such alloys include Mg ZK60 alloy (Z= Zinc, K= Zirconium $)^{[217]}$, AZ61 (A= Aluminium, $Z=$ Zirconium $)^{[218]}, \mathrm{ZM} 21(\mathrm{Z}=$ Zirconium, $\mathrm{M}=$ Manganese $)^{[219]}, \mathrm{AE} 21(\mathrm{~A}=\text { Aluminium, } \mathrm{E}=\mathrm{Rare} \text { earth })^{[220]}, \mathrm{AZ} 31^{[221]}$.

Other biodegradable metals such as bio-corrodible Fe scaffolds can provide longer term reliable mechanical support (at least 12-18 months), have a slower biodegradation process, and inhibit inflammation reactions compared to $\mathrm{Mg}$ stents ${ }^{[222]}$. A biocorrodible iron scaffold is produced by laser cutting a pure $\mathrm{Fe}(>99.8 \%)$ tube into a design similar to a Nitinol stent under a nitrogen environment to prevent premature corrosion. A mid-term angiographic patient follow up study after 6-18 months indicated that it is a feasible technique with no significant in-stent neointimal hyperplasia or inflammatory reactions around the stent struts, and no iron toxicity ${ }^{[222 a]}$. Corrosion of the iron-based stent in tissue was observed over 4 weeks ${ }^{[222 b]}$. Research on $\mathrm{Mg}$ - or Febased alloys shows mechanical characteristics equal to or higher than stainless steel, but their degradation speed is still an unresolved issue. A study of $\mathrm{Mg}$-based alloys showed that their degradation rate was too fast. In contrast, Fe-based alloys have good mechanical performance but unsatisfactorily slow biodegradation rate. The introduction of $\mathrm{Zn}$ and its alloys in 2013 represented a breakthrough in the field of biodegradable metallic stents. $\mathrm{Zn}$ alloys, including $\mathrm{Zn}-\mathrm{Mg}$ and $\mathrm{Zn}-\mathrm{Al}$, display slower corrosion and degradation rates of $\sim 0.02 \mathrm{~mm} . \mathrm{y}^{-1}$, about half that of standard pure $\mathrm{Mg}$, making them ideal for stent applications ${ }^{[223],[224]}$. Zn alloys are fabricated with new casting process: First, they are extruded at $250^{\circ} \mathrm{C}$ followed by homogenization at $350^{\circ} \mathrm{C}$ for $48 \mathrm{~h}$. Then, a $\mathrm{Zn}$ alloy tube with a wall thickness of $2.5 \mathrm{~mm}$ is made by extrusion at $300^{\circ} \mathrm{C}$. Hot extrusion is a critical treatment that transforms the corrosion mechanism 


\section{Submitted to

from localized pitting to a more uniform erosion. Currently, $\mathrm{Zn}-0.5 \mathrm{Mg}$ seems to be the most ideal material for biodegradable stent, as the grain size and orientation do not change during the final cutting process (Table 5).

Despite the promising research, several important issues need to be clarified before using biodegradable metals in the clinic. One major concern is that the $\mathrm{Mg}$ or $\mathrm{Fe}$ alloys do not share the self-expandable properties of nitinol alloys, so they can only be assembled on balloon catheters for delivery and release. This is likely to increase the system profile and decrease its flexibility. Furthermore, metal biodegradation and its end products may impart toxic effects to healthy neurons or result in distal vessel embolization. Lastly, the process of metal degradation is likely to cause more severe inflammation, which may result in intimal hyperplasia or delayed endothelization. 
Table 5. Key properties and aspects of potential non-biodegradable and biodegradable metals for medical cerebrovascular device applications

\begin{tabular}{|c|c|c|c|c|c|}
\hline & 316L stainless & Co-Cr alloys & Nitinol alloys & Fe alloys & Mg alloys \\
\hline Radiopaque & Yes & Yes & No & No & No \\
\hline Self-expandable & No & No & Yes & No & No \\
\hline Radial force & Good & Excellent & Good & - & - \\
\hline Flexibility & Good & Good & Excellent & Good & Good \\
\hline $\begin{array}{l}\text { Essential trace } \\
\text { element }\end{array}$ & Yes & Yes & Yes & Yes & Yes \\
\hline $\begin{array}{l}\text { Recommended } \\
\text { daily intake }\end{array}$ & - & 60-350ug/day & 25-35ug/day & $6-20 \mathrm{mg}$ & $375-500 \mathrm{mg}$ \\
\hline Blood serum level & - & $0.4 \mathrm{ug} / \mathrm{L}$ & $26 \mathrm{ug} / \mathrm{L}$ & $5.0-17.6 \mathrm{~g} / \mathrm{L}$ & $0.73-1.06 \mathrm{mM}$ \\
\hline $\begin{array}{l}\text { In vivo long-term } \\
\text { overdose effects }\end{array}$ & - & $\begin{array}{l}\text { Heart failure, shock, } \\
\text { goiter, myocarditis. }\end{array}$ & $\begin{array}{l}\text { Skin herpes, } \\
\text { erythema, ulceration, } \\
\text { hair whitening. }\end{array}$ & $\begin{array}{l}\text { Damage of lipid membranes, proteins and } \\
\text { DNA; stimulus for inflammations; } \\
\text { increase of free radicals }\end{array}$ & $\begin{array}{l}\text { Excessive } \mathrm{Mg} \text { leads to nausea; reduction of } \\
\text { the excitability of neuromuscular, smooth } \\
\text { muscular and cardiac regions }\end{array}$ \\
\hline $\begin{array}{l}\text { Effect on local pH } \\
\text { during } \\
\text { degradation }\end{array}$ & Alkalescent & Acidic & Alkalescent & Alkalescent & Alkalescent \\
\hline Corrosion mode & Localized corrosion & $\begin{array}{l}\text { Mostly localized and } \\
\text { piting }\end{array}$ & $\begin{array}{l}\text { Mostly localized and } \\
\text { piting }\end{array}$ & Localized corrosion & Mostly localized and piting \\
\hline $\begin{array}{l}\text { Expected gaseous } \\
\text { corrosion } \\
\text { products }\end{array}$ & NA & NA & NA & None & Hydrogen \\
\hline $\begin{array}{l}\text { Expected solid } \\
\text { corrosion } \\
\text { products }\end{array}$ & NA & NA & NA & $\mathrm{Fe}(\mathrm{OH})_{2}, \alpha-\mathrm{FeO}(\mathrm{OH}), \mathrm{Fe}_{3} \mathrm{O}_{4}$ & $\begin{array}{l}\mathrm{Mg}(\mathrm{OH})_{2}, \quad \mathrm{MgO}, \quad \mathrm{MgCl}_{2}, \quad\left(\mathrm{Ca}_{1}-\right. \\
\left.\mathrm{xMg}_{\mathrm{x}}\right)_{10}(\mathrm{PO} 4)_{6} \mathrm{OH}_{2}\end{array}$ \\
\hline
\end{tabular}

Fr = French $; \mathrm{NA},-$ = data not available; 


\section{Submitted to

\subsection{Drug elution techniques for intracranial devices}

Devices and designs that are effective in one particular specialty can quickly inspire and prompt innovations in other specialties. For example, the field of neurointerventional surgery has been dramatically influenced by the areas of cardiac and peripheral intervention. At present, drug-eluting stents (DES) have been routinely used in coronary arteries to prevent intimal hyperplasia and restenosis. However, this technique may also have a bright future in intracranial applications, especially when a stent is inserted into arteriosclerotic arteries. Metal device insertion provides a platform to carry polymers that enable the continuous release of drugs. Degradation rate is an effective index to judge drug release performance as it can be affected by polymer itself, passivation, and the fabrication process ${ }^{[225]}$. A number of polymers are commonly considered for use, such as polylactic acid (PLA), poly-L-lactic acid (PLLA), poly-Dlactic acid (PDLA), polyglycolic acid (PGA), polyethylene glycol (PEG) and poly( $\varepsilon^{-}$ caprolactone) (PCL). However, mixtures of two polymers to make a drug carrier for controlled release are more frequently used. For example, devices have been developed using poly(d,l-lactic-co-glycolic acid) (PLGA) ${ }^{[226]}$, poly-D,L-lactic acid and polycaprolactone (PDLLA-PCL) ${ }^{[227]}$, poly (3-hydroxybutyrate-co-3-hydroxyhexanoate) $(\mathrm{PHBHHx})^{[215 b]}$, poly(1,3-trimethylene carbonate) $(\mathrm{PTMC})^{[215 a]}$, poly(ethylene glycol)poly( $\left(\varepsilon\right.$-caprolactone) (PEG-PCL) ${ }^{[228]}$, and poly(vinyl alcohol)- $g$-PLGA (PVA- $g$ PLGA $)^{[229]}$. The drugs used for DESs are mainly anti-cell proliferation drugs including: Sirolimus (Rapamycin), Pacilitaxel, and derivatives of Sirolimus (Everolimus, Zotarolimus, Novolimus and Biolimus A9) ${ }^{[226 a]}$. (Figure 8c) The DESs under clinical investigation or currently in clinical use are listed in Table 6. 
Table 6. The drug-eluting stents in clinical research or use.

\begin{tabular}{|c|c|c|c|c|c|c|c|c|c|}
\hline \multirow{2}{*}{$\begin{array}{l}\text { Genera } \\
\text { tion }\end{array}$} & \multirow{2}{*}{$\begin{array}{l}\text { Polyme } \\
\text { r type }\end{array}$} & \multirow[b]{2}{*}{ Stent name } & \multirow{2}{*}{$\begin{array}{l}\text { Platform } \\
\text { material }\end{array}$} & \multicolumn{2}{|c|}{ Thickness } & \multirow{2}{*}{$\begin{array}{l}\text { Drug } \\
\text { (concertation) }\end{array}$} & \multirow[b]{2}{*}{ Drug release } & \multirow[b]{2}{*}{ Polymer material } & \multirow{2}{*}{$\begin{array}{l}\text { Degradati } \\
\text { on time }\end{array}$} \\
\hline & & & & $\begin{array}{l}\text { Strut } \\
(\mu \mathrm{m})\end{array}$ & $\begin{array}{l}\text { Coating } \\
(\mu \mathrm{m})\end{array}$ & & & & \\
\hline \multirow{2}{*}{ First } & \multirow{2}{*}{ Durable } & BX velocity ${ }^{[230]}$ & Stainless steel & 140 & 5 & $\begin{array}{l}\text { Sirolimus } \\
\left(140 \mu \mathrm{g} / \mathrm{cm}^{2}\right)\end{array}$ & $\begin{array}{l}100 \% \text { over } 15 \\
\text { days }\end{array}$ & nonerodable polymers & None \\
\hline & & $\begin{array}{l}\text { TAXUS } \\
\text { NIRx }^{[231]}\end{array}$ & Stainless steel & N/A & N/A & Paclitaxel $\left(1 \mu \mathrm{g} / \mathrm{cm}^{2}\right)$ & $\begin{array}{l}80 \% \text { over } 48 \\
\text { hours }\end{array}$ & $\begin{array}{l}\text { hydrocarbon-based } \\
\text { elastomer }\end{array}$ & None \\
\hline \multirow{7}{*}{ Second } & \multirow{7}{*}{ Durable } & XIENCE V ${ }^{[232]}$ & $\begin{array}{l}\text { Cobalt- } \\
\text { Chromium }\end{array}$ & 87 & 7.8 & $\begin{array}{l}\text { Everolimus } \\
\left(100 \mu \mathrm{g} / \mathrm{cm}^{2}\right)\end{array}$ & $\begin{array}{lll}80 \% & \text { over } & 30 \\
\text { days } & & \end{array}$ & PBMA and PVDF & None \\
\hline & & $\begin{array}{l}\text { Endeavour } \\
\text { Resolute }^{[233]}\end{array}$ & $\begin{array}{l}\text { Cobalt- } \\
\text { Chromium }\end{array}$ & 91 & 6 & $\begin{array}{l}\text { Zotarolimus } \\
\left(160 \mu \mathrm{g} / \mathrm{cm}^{2}\right)\end{array}$ & 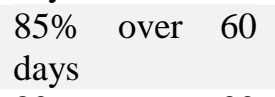 & $\begin{array}{l}\text { PBMA, PHMA, PVP, } \\
\text { PVA }\end{array}$ & None \\
\hline & & $\begin{array}{l}\text { Promus } \\
\text { Element }^{[234]}\end{array}$ & $\begin{array}{l}\text { Platimun- } \\
\text { Chromium }\end{array}$ & 81 & 8 & $\begin{array}{l}\text { Everolimus }(100 \mu \mathrm{g} / \mathrm{c} \\
\left.\mathrm{m}^{2}\right)\end{array}$ & 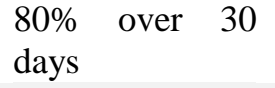 & PBMA and PVDF & None \\
\hline & & DESyne $^{[235]}$ & $\begin{array}{l}\text { Cobalt- } \\
\text { Chromium }\end{array}$ & 80 & $<3$ & $\begin{array}{l}\text { Novolimus } \\
(5 \mu \mathrm{g} / \mathrm{mm})\end{array}$ & $\begin{array}{lll}80 \% & \text { over } & 90 \\
\text { days } & & \end{array}$ & PBMA & None \\
\hline & & $\begin{array}{l}\text { Resolute } \\
\text { Integrity }\end{array}$ & Cobalt alloy & 91 & 5.6 & $\begin{array}{l}\text { Zotarolimus } \\
\left(1.6 \mu \mathrm{g} / \mathrm{mm}^{2}\right)\end{array}$ & $\begin{array}{l}100 \% \text { after } 6 \\
\text { months }\end{array}$ & BioLinx-Parylene & None \\
\hline & & Partner $^{[237]}$ & Stainless steel & 90 & 6 & Sirolimus & controlled & PBMA/PEVA & None \\
\hline & & $\begin{array}{l}\text { TAXUS Element } \\
(\mathrm{ION})^{[238]}\end{array}$ & $\begin{array}{l}\text { Platimun- } \\
\text { Chromium }\end{array}$ & 81 & 7 & Paclitaxel $\left(1 \mu \mathrm{g} / \mathrm{mm}^{2}\right)$ & 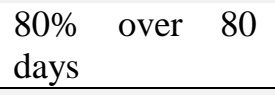 & Translute & None \\
\hline \multirow{5}{*}{ Third } & \multirow{5}{*}{$\begin{array}{l}\text { Biodegr } \\
\text { adable }\end{array}$} & BuMA $^{[239]}$ & Stainless steel & 100 & N/A & $\begin{array}{l}\text { Sirolimus }(1.4 \mu \mathrm{g} / \mathrm{mm} \\
\text { 2) }\end{array}$ & $\begin{array}{l}100 \% \text { over } 30 \\
\text { days }\end{array}$ & PLGA & N/A \\
\hline & & $\operatorname{NOYA}^{[240]}$ & $\begin{array}{l}\text { Cobalt- } \\
\text { Chromium }\end{array}$ & 81 & 6 & $\begin{array}{l}\text { Sirolimus }(8.8 \mu \mathrm{g} / \mathrm{mm} \\
\left.{ }^{2}\right)\end{array}$ & $\begin{array}{l}100 \% \text { over } 30 \\
\text { days }\end{array}$ & PDLLA & N/A \\
\hline & & BioMatrix Flex ${ }^{[241]}$ & Stainless steel & 112 & 10 & $\begin{array}{l}\text { BiolimusA9 } \\
(15.6 \mu \mathrm{g} / \mathrm{mm})\end{array}$ & $\begin{array}{ll}45 \% & \text { over } 30 \\
\text { days } & \end{array}$ & PDLLA & 6-9 months \\
\hline & & Coracto SES ${ }^{[242]}$ & Stainless steel & N/A & 4 & $\begin{array}{l}\text { Rapamycin }(1.7 \mu \mathrm{g} / \mathrm{m} \\
\left.\mathrm{m}^{2}\right)\end{array}$ & $\begin{array}{l}\text { Sirolimus }(3.9 \mu \mathrm{g} \\
\left./ \mathrm{mm}^{2}\right)\end{array}$ & PLGA & $\begin{array}{l}10- \\
12 \text { weeks }\end{array}$ \\
\hline & & $\begin{array}{l}\text { Elixir } \\
\text { Myolimus }^{[243]}\end{array}$ & $\begin{array}{l}\text { Cobalt- } \\
\text { Chromium }\end{array}$ & 80 & $<3$ & Myolimus $(3 \mu \mathrm{g} / \mathrm{mm})$ & $\begin{array}{ll}90 \% & \text { over } 90 \\
\text { days } & \end{array}$ & PDLLA & 6-9months \\
\hline
\end{tabular}




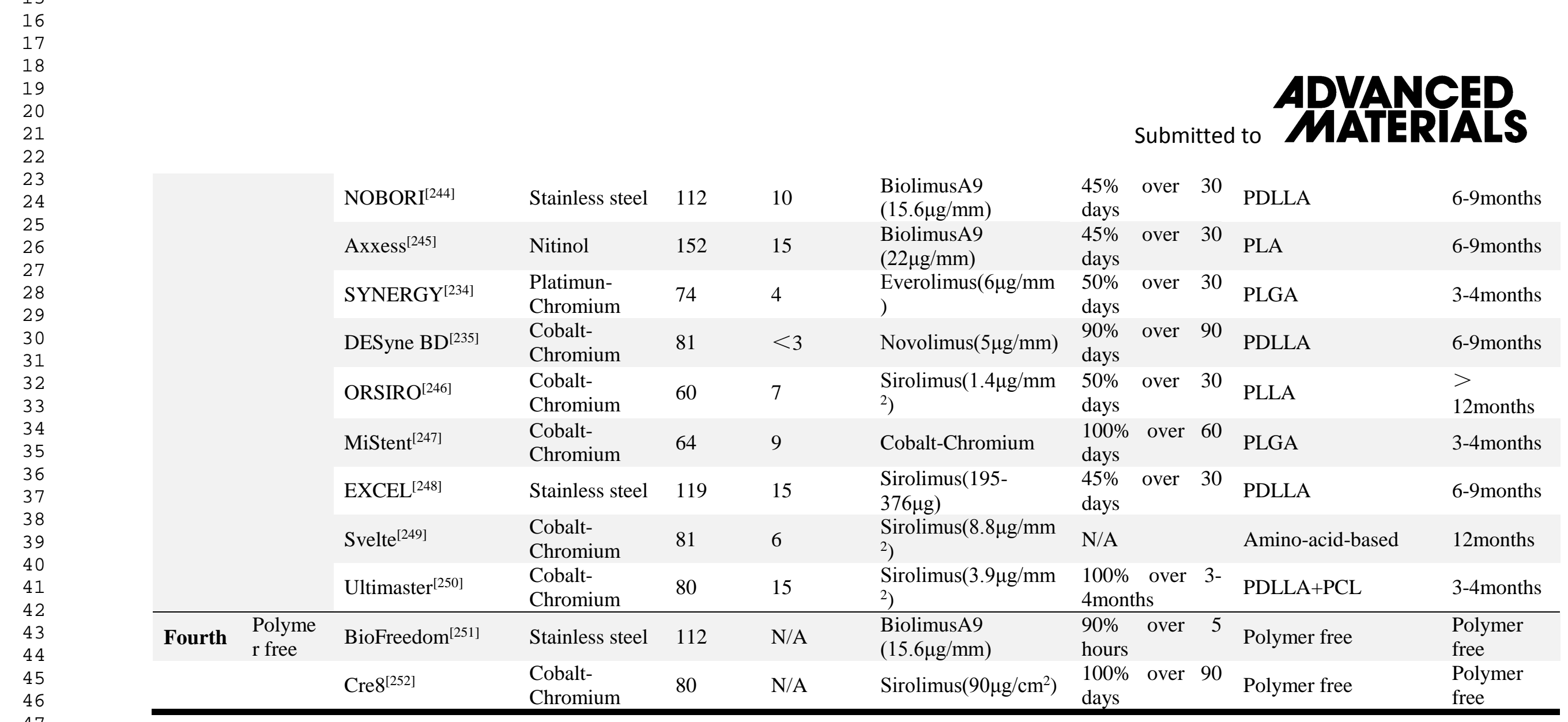

PBMA: polybutyl methacrylate; PHMA: polyhexyl methacrylate; PDLLA: poly-(D,L)-lactic acid; PLGA: polylactic-co-glycolic acid; PVA: polyvinyl alcohol; PVDF: polyvinylidene fluoride; PVO: polyvinyl octal; PVP: polyvinyl pyrrolidone; PLC: polymer liquid crystal; PLA: polylactic acid; PLLA: poly-L-lactic acid; N/A: not applicable. 


\section{Submitted to \\ ADNAMEED
MAATKRAAS}

The first-generation of drug eluting stents, such as the Cypher DES, are often made with durable polymer coatings to release paclitaxel or sirolimus ${ }^{[226 a}$. (Figure 9a) The first-generation DES significantly reduces neointimal response, but one major limitation is a durable polymer remnant that causes persistent inflammatory response due to the lack of biocompatibility. This often results in late and very late stent thrombosis (ST) rates and an increased risk of late in-stent restenosis (ISR), which is considered a "late catch-up" phenomenon $^{[253]}$. Second-generation DESs, such as zotarolimus-eluting and everolimuseluting stents, are designed to have improved critical components to increase safety and efficacy $^{[232]}$. The most distinct changes between first- and second-generation DESs are stent frame design and polymer composition. Several studies show that a thinner stent frame can reduce restenosis, endothelialization and thrombogenicity ${ }^{[254]}$. Therefore, the stent materials transitioned from stainless steel to $\mathrm{CoCr}^{[233]}$ and $\mathrm{PtCr}^{[234]}$, which enable the fabrication of thinner stent platforms that preserve the radial strength and recoil properties. For example, the XIENCE V stent uses a Multi-Link Vision's cobaltchromium $(\mathrm{CoCr})$ stent platform coated with a thin layer of drug polymer. The thicknesses of the strut and polymer are $87 \mu \mathrm{m}$ and $7.8 \mu \mathrm{m}$, respectively. A more biologically compatible polymer coating reduces the incidence of late ST; however, this technology is limited by the presence of a permanent polymer, which evokes hypersensitivity reactions, chronic inflammation and neo-atherosclerosis.

The long-term complications of the first- and second- generation of DES are mostly related to permanent polymeric materials. There are several strategies in development for newer generation DESs, such as biodegradable polymer (BP) DESs, polymer-free (PF) DESs, and fully biodegradable DESs ${ }^{[255]}$. Third-generation DESs with biodegradable polymers, such as the BioMatrix Flex stent (Biolimus-eluting stents), have demonstrated less in-stent late lumen loss and neointimal response ${ }^{[241,256]}$. Although BPs are less inflammatory than DPs, they still can induce an inflammatory response. Therefore, the fourth-generation polymer-free DESs (PF-DES) have been promoted as an ideal solution to this problem ${ }^{[251-252,257]}$. The platform material of PF-DES is stainless steel with a microporous surface, and the anti-proliferative drug is released from the struts. Four types of PF-DES are currently under clinical evaluation: microporous DES, DES with reservoir technology, nanoparticle-based DES, and drug filled stents. 


\section{Submitted to \\ ADNAMEED
MAATERAAS}

One alternative to permanent stent insertion, where polymers or stent struts can cause complications, may be to develop completely bio-resorbable vascular scaffolds (BVS). BVSs have some important advantages: (1) they are completely bio-resorbable, leave no residual materials in the vessel wall, and do not damage the integrity of the vascular structure, (2) sufficient mechanical flexibility to adapt to the vessel geometry, which may have favorable effects on blood flow ${ }^{[258]}$, (3) the vasomotor and physiological function of the scaffold segment is regained within a few months after implantation, and (4) they introduce no imaging artifacts to noninvasive imaging modalities such as MR or CT scans $^{[259]}$. Several types of materials are being investigated for $\mathrm{BVS}^{[225 b]}$, among which PLLA and magnesium are the most promising. Other materials suitable for BVS may include iron alloys ${ }^{[222 a]}$ and PLLA/PDLA/L-lactic-co- $\varepsilon$-caprolactone ${ }^{[260]}$.

Drug eluting techniques have already profoundly influenced coronary heart disease treatment, and the use of drug-eluting stents or balloons has become the first line treatment to handle restenosis clinically. In cerebral artery atherosclerosis, the SAMMPRIS trial clearly revealed better outcomes for symptomatic intracranial stenosis with aggressive medical management than with percutaneous angioplasty and metallic stenting $^{[66 a]}$. As a result, metallic stents to treat intracranial stenosis should only be used for patients who have failed in medical therapy or who have high risk factors ${ }^{[66 b]}$. However, the selection of patients and intervention procedures was considered to be deficient in the SAMMPRIS trial; thus, several additional studies have been carried out to determine if drug eluting stents might bring better treatment outcomes for intracranial atherosclerosis. Although the studies have already revealed that the restenosis rate is significantly reduced compared to the bare metal stent treatment, all drug eluting stents applied in cerebral arteries so far have been coronary stents ${ }^{[261]}$. More flexible drug eluting stents need to be developed to improve safety in the cerebrovasculature. Presently, the drug eluting technique is also being applied in flow diverters. The PED 3 flow diverter uses a surface modification of phosphorilcholine. These surface modified flow diverters are reported to cause less thrombus formation than bare FDDs. Additionally, the clot 


\section{Submitted to \\ ADNAMEED
MAATERAAS}

incidence rate for the classic PED is 1.72 times higher than for the Pipeline Flex with Shield Technology ${ }^{[262]}$.

Nevertheless, safety is still the primary concern about applying drug eluting techniques in brain vasculature. Sustained release of anti-proliferation drugs carried by the metal devices may cause damage to neurons, and moreover, materials can fall off during stent inflation or drug carrier degradation, which may increase the risk of distal vessel embolization to cause a brain infarction. Furthermore, delayed endothelization or suppressed inflammation reaction by drugs runs a high risk of thrombosis and other complications (Figure $9 b$ ).

(a)

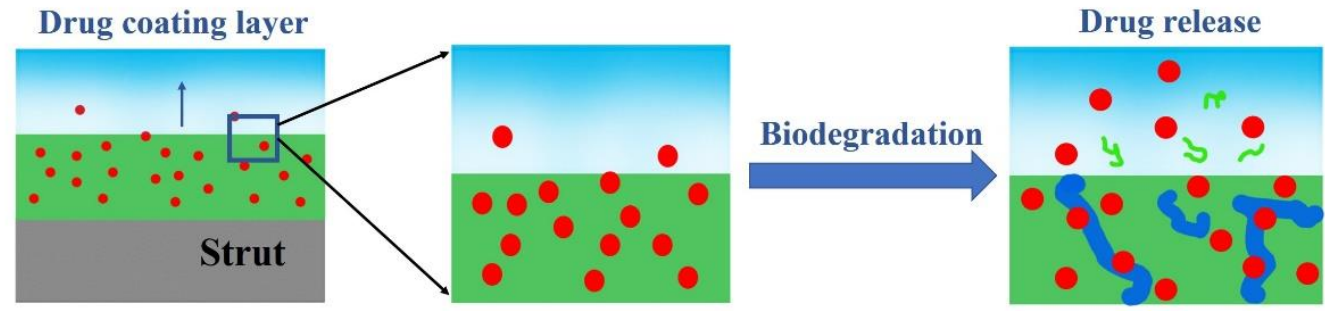

(b)

TAXUS stent insertion
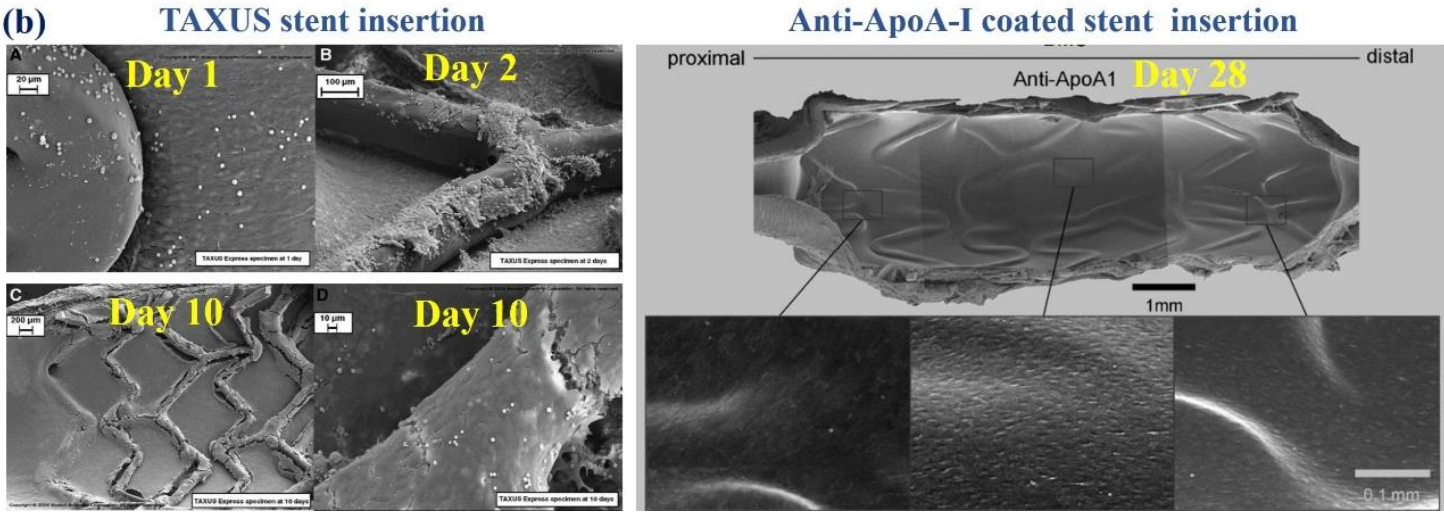

Figure 9. Controlled drug releasing schematic diagram and endothelization process of the drug eluting stents. (a) Two-stage drug release of the polymer degradation and erosion. Stage 1: slow release by diffusion through the polymer; Stage 2: enhanced release contributed by polymer degradation and erosion. (b) Characteristic images of endothelial coverage were assessed by scanning electron microscopy at 1 and 2 days $(A)$ and 10 days of a paclitaxel-eluting stent (TAXUS) and at 28 days of an anti-ApoA1 coated stent. $^{[263]}$ 


\section{Submitted to \\ ADVANECD
MAATERRALS}

\subsection{Personalized device manufacture for intracranial devices}

$3 \mathrm{D}$ printing is becoming a new option in manufacturing to enable simultaneous customization and enhanced functionality. Increasingly, this technology can help satisfy the great need for patient-specific artificial organs, implants or devices, especially in surgery applications ${ }^{[264]}$. Innovation in $3 \mathrm{D}$ printing techniques and the development of multifunctional printable materials can drive the future application of 3D printing in many fields. Many medical devices are currently manufactured using metals and/or their alloys. For long-term tissue replacement therapy, they are usually designed as implants or fixtures to undertake loads because of their excellent strength and ductility ${ }^{[265]}$. The metals and their alloys that can be 3D printed for medical applications are generally: conventional metals and their alloys, shape memory alloys, and biodegradable metals.

The two commonly used methods of 3D printing are Directed Energy Deposition (DED) and Powder Bed Fusion (PBF). The working principle of DED and PBF differs in one fundamental way: in DED, a continuous stream of metal powder or wire is melted by a high power-density laser as it is deposited onto the substrate, whereas PBF pre-deposits a layer of metal powder and then melts it at the desired location under a focused laser beam with selectively controlled thermal energy ${ }^{[266]}$.. The quantity directly affects the printing resolution in a DED manufacturing process. Several processes have been created based on PBF technology, including selective laser sintering (SLS) and selective laser melting (SLM), direct metal laser sintering (DMLS), laser cussing and electron beam melting (EBM). DMLS generally uses both metal powder and a high power laser to sinter together a target structure, so it is an additive manufacturing (AM) or rapid prototyping (RP) process. This process can be used to produce dense parts, but post-treatment is often required to make it gas- or pressure-tight. In fact, many tradenames (laser sintering, cussing, etc.) describe the same process with the same technologies ${ }^{[190 a]}$. 


\section{Submitted to \\ ADVANCEDS}

3D printed metal devices that can provide anatomically-personalized hemodynamic intervention treatments may have an especially bright future in the treatment of cerebrovascular disease ${ }^{[267]}$. Metal devices used in the brain, such as stents and flow diverters, especially stand to benefit from the application of 3D printing techniques. As each cerebral vasculature has its unique tortuous course, different patients or diseases may require the stent to have custom-designed 3D angles or diameters in different stent segments. Thus, 3D printed stents promise improved adaptation to the vascular wall to reduce damage to the arterial wall related to device insertion, which may in turn reduce the risk of thrombosis or late in-stent restenosis. Furthermore, considering that arterial stenosis, occlusion and aneurysms are all hemodynamics-related diseases, enhancing the occlusion rate of a flow diverter or the dilating strength of a stent may improve the treatment outcomes. 3D printing may improve the performance of these metal devices in the following ways: 1) Vascular stents: as intracranial stents often require both mechanical support and high flexibility, we can design and 3D print a patient-specific nitinol alloy stent with an enhanced number or thickness of the stent struts, or increase the diameter in the diseased artery to improve the hemodynamics after stenting; meanwhile, we can adjust the design for a normal artery lumen by reducing the stent diameter or the number or thickness of the stent to enhance its flexibility. These patientspecific stent designs cannot be efficiently manufactured by laser cutting or weaving techniques ${ }^{[268]}$. 2) Flow diverters: a flow diverter at the aneurysm neck needs high metal coverage to produce a maximal flow re-direction, while in normal vessel lumens, the metal coverage should be low to maintain the patency of vessel branches. Current designs of flow diverters are braided using nitinol wires, so it is impossible to create different metal coverage rates in different stent segments, while 3D print can easily produce this type of design ${ }^{[269]}$.

The great advantage of 3D printing technology is that it provides easy customization of implant design to improve functionality. In the surgical fields, 3D printing technology 


\section{Submitted to \\ ADNAMECEP
MATEKRALA}

promises artificial organs, implants or devices that are patient-specific ${ }^{[270]}$. Although much progress has already been made, the future of 3D printing technology will require continued development in both printing technology and novel printable materials.

\section{Conclusion and future perspectives}

In summary, endovascular metal device insertion is already a revolutionary technology for the treatment of cerebral vascular diseases, including ischemic or hemorrhagic stroke. The wide application of this technology has made it possible to treat previously untreatable diseases, and promoted the transition from traditional open surgery to less invasive catheter-based interventions. However, some challenges remain when using metal devices in the cerebral vasculature. These future directions may lead to potential solutions to these problems:

i) Devices used in brain vasculature often require excellent mechanical performance, such as high flexibility or radial force. The mechanical properties of currently available metal materials restrict their application in smaller or distal cerebral vasculature (with diameter $<2 \mathrm{~mm}$ ). Thus, new metal alloys or novel structural designs must be developed to improve the devices' mechanical performance and reduce their profile.

ii) Permanent metal device insertion faces challenges of device-related acute thrombosis or long-term vessel lumen restenosis. Drug-eluting techniques have been widely applied in the coronary or peripheral vasculatures to prevent long-term lumen loss after stent insertion, but its safety and efficacy in intracranial vessels still needs further investigation. The main concerns about the safety of drug-elution technology center on drug neurotoxicity and risks related to the drug carrier when applied in the brain. Thus, further research in this area is primarily focused on the following aspects: 1) finding safer drugs or other bio-active materials like proteins, polypeptides, molecules or even genes 


\section{Submitted to \\ ADVANCED
MATERIALS}

to prevent device-induced complications and reduce neurotoxicity; 2) optimizing drug loading techniques to achieve sustained drug release while minimizing the carrier fall off risk. Moreover, the risk of acute thrombosis or inflammation caused by nonbiodegradable or biodegradable carriers should be fully considered.

iii) As metal device insertion is permanent, risks like restenosis, inflammation and thrombus formation cannot be completely avoided. The ideal model is to have a device that is inserted to treat the disease, and that completely biodegrades after treatment is completed without further interruption to the normal vasculature. Biodegradable polymers or metals have already been used in the coronary or peripheral vasculatures in the clinic, but too-short or too-long degradation periods, degradation induced by inflammation response, and unsatisfactory mechanical performance are major limitations. Thus, further research to find more suitable biodegradable materials that have excellent mechanical properties and appropriate biodegradation modes is the future direction. Also important is to avoid distal vessel embolization or acute thrombosis during the biodegradation period; a combination of drug-elution techniques on biodegradable material surfaces may be an effective way to reduce inflammation during degradation.

iv) In view of the unique set of anatomies, vessel lumen diameters, and vessel wall structures comprising the cerebral vasculature of each person, individualized devices require both flexibility of structure and mechanical strength. Meanwhile, flow dynamics and tissue response to devices are also different from person to person, so only a personalized device can guarantee maximized treatment outcomes and reduced complications. With the development of 3D printing technology, images collected from computed tomographic angiography (CTA), magnetic resonance angiography (MRA) or digital subtraction angiography (DSA) can be processed to obtain a 3D digital vessel model or image that can then be used to design a personalized metal device. These technologies will be certainly applied in clinical to enhance treatment outcomes in the near future. 


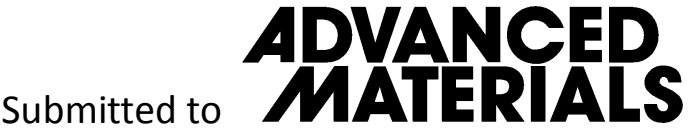

\section{Acknowledgments}

This study was supported by grants from the National Natural Science Foundation of China (81771943，81571773 and 51873107), Shanghai Pujiang Program (16PJD036), Shanghai Municipal Education Commission-Gaofeng Clinical Medicine Grant Support (No.20152528 and 20171906); Three-year plan program by Shanghai Shen Kang Hospital Development Center (16CR3043A); Shanghai Science and Technology Commission of Shanghai Municipality Program (14DZ1941206 and 18ZR1434200); Shanghai municipal health and Family Planning Commission (201840027). Prof. H. Zhang acknowledges Jane and Aatos Erkko Foundation (4704010), Academy of Finland (decision no. 297580) and Sigrid Juselius Foundation (grant no. 28001830K1) for financial support. Prof. H. A. Santos acknowledges financial support from the University of Helsinki Research Funds, the HiLIFE Research Funds, the Sigrid Jusélius Foundation (decision no. 4704580), and the European Research Council under the European Union's Seventh Framework Programme (FP/2007-2013, Grant No. 310892).

\section{References}

[1] in Health, United States, 2016: With Chartbook on Long-term Trends in Health, Hyattsville (MD) 2017. [2] http://www.who.int/gho/mortality_burden_disease/causes_death/top_10/en/

[3] A. S. Go, D. Mozaffarian, V. L. Roger, E. J. Benjamin, J. D. Berry, W. B. Borden, D. M. Bravata, S. Dai, E. S. Ford, C. S. Fox, S. Franco, H. J. Fullerton, C. Gillespie, S. M. Hailpern, J. A. Heit, V. J. Howard, M. D. Huffman, B. M. Kissela, S. J. Kittner, D. T. Lackland, J. H. Lichtman, L. D. Lisabeth, D. Magid, G. M. Marcus, A. Marelli, D. B. Matchar, D. K. McGuire, E. R. Mohler, C. S. Moy, M. E. Mussolino, G. Nichol, N. P. Paynter, P. J. Schreiner, P. D. Sorlie, J. Stein, T. N. Turan, S. S. Virani, N. D. Wong, D. Woo, M. B. Turner, Circulation 2013, 127, e6.

[4] A. S. Go, M. Dariush, V. L. Roger, E. J. Benjamin, J. D. Berry, W. B. Borden, D. M. Bravata, D. Shifan, E. S. Ford, C. S. Fox, Circulation 2013, 127, 143.

[5] J. Broderick, S. Connolly, E. Feldmann, D. Hanley, C. Kase, D. Krieger, M. Mayberg, L. Morgenstern, C. S. Ogilvy, P. Vespa, M. Zuccarello, Circulation 2007, 116, e391.

[6] F. A. Serbinenko, Voprosy Neǐrokhirurgii 1971, 35, 3.

[7] G. Guglielmi, F. Vinuela, J. Dion, G. Duckwiler, J Neurosurg 1991, 75, 8.

[8] (a) R. W. Ryan, A. S. Khan, R. Barco, A. Choulakian, Neurosurg Focus 2017, 42, E11; (b) J. B. White, C. G. Ken, H. J. Cloft, D. F. Kallmes, AJNR Am J Neuroradiol 2008, 29, 1242; (c) L. Touma, K. B. 


\section{Submitted to \\ ADNAMEED
MAATERAAS}

Filion, L. H. Sterling, R. Atallah, S. B. Windle, M. J. Eisenberg, JAMA Neurol 2016, 73, 275.

[9] (a) C. Y. Lien, C. R. Huang, W. C. Tsai, C. W. Hsu, N. W. Tsai, C. C. Chang, C. H. Lu, C. C. Chien, W.

N. Chang, J Clin Neurosci 2017; (b) T. Sorenson, W. Brinjikji, G. Lanzino, J Neurosurg Sci 2016, 60, 116.

[10] (a) A. K. Wakhloo, M. J. Deleo, 3rd, M. M. Brown, Stroke 2009, 40, e305; (b) M. Piotin, R. Blanc, Front Neurol 2014, 5, 41; (c) Y. Q. Zhu, M. H. Li, F. Lin, D. L. Song, H. Q. Tan, B. X. Gu, H. Q. Zhang, B. Leng, P. L. Zhang, Eur Radiol 2013, 23, 287; (d) M. Zanaty, N. Chalouhi, S. I. Tjoumakaris, R. H. Rosenwasser, L. F. Gonzalez, P. Jabbour, Front Neurol 2014, 5, 21.

[11] A. Cowley, B. Woodward, Platin Met Rev 2011, 55, 98.

[12] M. H. Han, O. K. Kwon, C. J. Yoon, B. J. Kwon, S. H. Cha, K. H. Chang, AJNR Am J Neuroradiol 2003, 24, 539.

[13] B. R. Bendok, R. J. Rahme, G. Complex Registry, J Neurointerv Surg 2013, 5, 54.

[14] M. T. Koltz, N. Chalouhi, S. Tjoumakaris, L. Fernando Gonzalez, A. Dumont, D. Hasan, R. Rosenwasser, P. Jabbour, J Clin Neurosci 2014, 21, 148.

[15] D. H. Lee, A. Arat, H. Morsi, L. D. Jou, M. E. Mawad, Interv Neuroradiol 2009, 15, 29.

[16] C. A. Taschner, L. Thines, M. El-Mahdy, H. Rachdi, J. Y. Gauvrit, J. P. Lejeune, J. P. Pruvo, X. Leclerc, Neuroradiology 2009, 51, 45.

[17] G. Jindal, T. Miller, M. Iyohe, R. Shivashankar, V. Prasad, D. Gandhi, J Vasc Interv Neurol 2016, 9, 46.

[18] M. S. Teleb, A. Ver Hage, J. Carter, M. V. Jayaraman, R. A. McTaggart, J Neurointerv Surg 2017, 9, 122.

[19] G. Dabus, L. Hacein-Bey, B. Varjavand, R. D. Tomalty, P. P. Han, V. Yerokhin, I. Linfante, J. Mocco, T. Oxley, A. Spiotta, M. I. Chaudry, R. D. Turner, A. S. Turk, J Neurointerv Surg 2017, 9, 419.

[20] C. G. McDougall, S. C. Johnston, A. Gholkar, S. L. Barnwell, J. C. Vazquez Suarez, J. Masso Romero, J. C. Chaloupka, A. Bonafe, A. K. Wakhloo, D. Tampieri, C. F. Dowd, A. J. Fox, S. J. Imm, K. Carroll, A. S. Turk, M. Investigators, AJNR Am J Neuroradiol 2014, 35, 935.

[21] B. Gory, F. Turjman, Acta Neurochir (Wien) 2014, 156, 831.

[22] K. M. Fargen, S. Blackburn, E. M. Deshaies, J. S. Carpenter, P. Jabbour, W. J. Mack, A. T. Rai, A. H. Siddiqui, R. D. Turner, J. Mocco, J Neurointerv Surg 2015, 7, 40.

[23] A. J. Molyneux, A. Clarke, M. Sneade, Z. Mehta, S. Coley, D. Roy, D. F. Kallmes, A. J. Fox, Stroke 2012, 43, 2544.

[24] B. Waldau, K. M. Fargen, W. J. Mack, N. M. Wilson, A. Khaldi, B. L. Hoh, J. Mocco, Interv Neuroradiol 2012, 18, 200.

[25] A. Waseem, I. Ahmed, S. Hadeel, J Stroke Cerebrovasc Dis 2018, 20, S1052.

[26] S. Fujimura, H. Takao, T. Suzuki, C. Dahmani, H. Mamori, M. Yamamoto, Y. Murayama, Conf Proc IEEE Eng Med Biol Soc 2016, 2016, 3298.

[27] H. W. Jeong, S. C. Jin, J Cerebrovasc Endovasc Neurosurg 2015, 17, 295.

[28] (a) D. F. Kallmes, N. H. Fujiwara, AJNR Am J Neuroradiol 2002, 23, 1580; (b) H. J. Cloft, AJNR Am J Neuroradiol 2006, 27, 289.

[29] X. B. Guo, Y. M. Fan, J. N. Zhang, Eur J Radiol 2011, 79, e42.

[30] C. A. Taschner, R. Chapot, V. Costalat, P. Machi, P. Courtheoux, X. Barreau, J. Berge, L. Pierot, K. 


\section{Submitted to \\ ADVANCEDS
MATERIALS}

Kadziolka, B. Jean, R. Blanc, A. Biondi, H. Brunel, S. Gallas, A. Berlis, D. Herbreteau, J. Berkefeld, H. Urbach, S. El Shikh, J. Fiehler, H. Desal, E. Graf, A. Bonafe, Neuroradiology 2016, 58, 777.

[31] J. W. Speirs, T. H. Burke, S. Y. Lee, B. D. Ala, J Neurointerv Surg 2013, 5 Suppl 3, iii72.

[32] M. Killer, D. Kallmes, R. Jones, Y. Ding, M. Vestal, T. Hauser, R. Virmani, G. Cruise, Minim Invasive Neurosurg 2010, 53, 97.

[33] G. Guglielmi, F. Vinuela, I. Sepetka, V. Macellari, J Neurosurg 1991, 75, 1.

[34] (a) A. J. Molyneux, R. S. Kerr, L. M. Yu, M. Clarke, M. Sneade, J. A. Yarnold, P. Sandercock, Lancet 2005, 366, 809; (b) A. J. Molyneux, R. S. Kerr, J. Birks, N. Ramzi, J. Yarnold, M. Sneade, J. Rischmiller, Lancet Neurol 2009, 8, 427.

[35] (a) F. Vinuela, G. Duckwiler, M. Mawad, J Neurosurg 1997, 86, 475; (b) C. Cognard, A. Weill, L. Castaings, A. Rey, J. Moret, Radiology 1998, 206, 499.

[36] L. Pierot, L. Spelle, F. Vitry, Stroke 2008, 39, 2497.

[37] I. S. o. U. I. A. Investigators, N Engl J Med 1998, 339, 1725.

[38] M. J. Slob, W. J. van Rooij, M. Sluzewski, AJNR Am J Neuroradiol 2005, 26, 901.

[39] H. J. Cloft, D. F. Kallmes, AJNR Am J Neuroradiol 2004, 25, 60.

[40] H. J. Cloft, AJNR Am J Neuroradiol 2007, 28, 152.

[41] P. M. White, S. C. Lewis, A. Gholkar, R. J. Sellar, H. Nahser, C. Cognard, L. Forrester, J. M. Wardlaw, Lancet 2011, 377, 1655.

[42] C. Taschner, R. Chapot, V. Costalat, P. Courtheoux, X. Barreau, J. Berge, L. Pierot, K. Kadziolka, B. Jean, R. Blanc, A. Biondi, H. Brunel, S. Gallas, A. Berlis, D. Herbreteau, J. Berkefeld, C. Groden, H. Urbach, S. El Shikh, E. Graf, A. Bonafe, Neuroradiology 2015, 57, 599.

[43] K. M. Fargen, S. Blackburn, J. S. Carpenter, P. Jabbour, W. J. Mack, A. T. Rai, A. H. Siddiqui, R. D. Turner, J. Mocco, J Neurointerv Surg 2014, 6, 495.

[44] H. S. Kang, M. H. Han, B. J. Kwon, O. K. Kwon, S. H. Kim, S. H. Choi, K. H. Chang, AJNR Am J Neuroradiol 2005, 26, 1921.

[45] (a) A. Vance, B. G. Welch, Neurol Res 2014, 36, 356; (b) I. Rezek, G. Mousan, Z. Wang, M. H. Murad,

D. F. Kallmes, AJNR Am J Neuroradiol 2013, 34, 1769.

[46] J. Moret, C. Cognard, A. Weill, L. Castaings, A. Rey, Interv Neuroradiol 1997, 3, 21.

[47] B. D. Jagadeesan, F. Siddiq, A. W. Grande, R. P. Tummala, J Neurointerv Surg 2014, 6, 704.

[48] L. Pierot, C. Cognard, R. Anxionnat, F. Ricolfi, Radiology 2011, 258, 546.

[49] L. Pierot, L. Spelle, X. Leclerc, C. Cognard, A. Bonafe, J. Moret, Radiology 2009, 251, 846.

[50] M. Shapiro, J. Babb, T. Becske, P. K. Nelson, AJNR Am J Neuroradiol 2008, 29, 1777.

[51] Y. Matsuda, J. Chung, K. Keigher, D. Lopes, J Neurointerv Surg 2018, 10, 274.

[52] N. Ebrahimi, B. Claus, C. Y. Lee, A. Biondi, G. Benndorf, AJNR Am J Neuroradiol 2007, $28,823$.

[53] (a) K. J. Becker, T. G. Brott, Stroke 2005, 36, 400; (b) A. M. Spiotta, A. Miranpuri, M. I. Chaudry, R. D. t. Turner, A. S. Turk, J Neurointerv Surg 2013, 5 Suppl 3, iii79; (c) C. Roth, D. Junk, P. Papanagiotou, A. Keuler, H. Korner, M. Schumacher, W. Reith, AJNR Am J Neuroradiol 2012, 33, 1317; (d) D. Fiorella, P. Lylyk, I. Szikora, M. E. Kelly, F. C. Albuquerque, C. G. McDougall, P. K. Nelson, J Neurointerv Surg 2009, 1, 56; (e) H. Henkes, A. Bose, S. Felber, E. Miloslavski, E. Berg-Dammer, D. Kuhne, Interv Neuroradiol 2002, 8, 107; (f) K. Kallenberg, L. Solymosi, C. A. Taschner, J. Berkefeld, M. Schlamann, O. Jansen, S. Arnold, B. Tomandl, M. Knauth, B. Turowski, J Neurointerv Surg 2016, 8, 834; (g) D. J. 


\section{ADVANCEDS
subnited to MATERIALS}

Padalino, A. Singla, W. Jacobsen, E. M. Deshaies, Surg Neurol Int 2013, 4, 9; (h) Z. Kulcsar, U. Ernemann, S. G. Wetzel, A. Bock, S. Goericke, V. Panagiotopoulos, M. Forsting, D. A. Ruefenacht, I. Wanke, Stroke 2010, 41, 1690; (i) C. P. Kealey, Y. J. Chun, F. E. Vinuela, K. P. Mohanchandra, G. P. Carman, F. Vinuela, D. S. Levi, J Biomed Mater Res B Appl Biomater 2012, 100, 718; (j) P. Mordasini, N. Frabetti, J. Gralla, G. Schroth, U. Fischer, M. Arnold, C. Brekenfeld, AJNR Am J Neuroradiol 2011, 32, 294; (k) R. T. Higashida, V. V. Halbach, C. F. Dowd, L. Juravsky, S. Meagher, AJNR Am J Neuroradiol 2005, 26, 1751; (1) T. Liebig, C. Kabbasch, C. Strasilla, A. Berlis, W. Weber, L. Pierot, T. Patankar, X. Barreau, J. Dervin, A. Kursumovic, S. Rath, B. Lubicz, J. Klisch, AJNR Am J Neuroradiol 2015, 36, 1721; (m) R. D. Turner, A. Turk, I. Chaudry, J Neurointerv Surg 2013, 5, 157; (n) S. Rohde, S. Haehnel, C. Herweh, M. Pham, S. Stampfl, P. A. Ringleb, M. Bendszus, Stroke 2011, 42, 2954; (o) T. Kahles, C. Garcia-Esperon, S. Zeller, M. Hlavica, J. Anon, M. Diepers, K. Nedeltchev, L. Remonda, AJNR Am J Neuroradiol 2016, 37, 114; (p) H. Raoult, H. Redjem, R. Bourcier, A. Gaultier-Lintia, B. Daumas-Duport, J. C. Ferre, F. Eugene, R. Fahed, B. Bartolini, M. Piotin, H. Desal, J. Y. Gauvrit, R. Blanc, J Neurointerv Surg 2017, 9, 574; (q) M. Aguilar Perez, P. Bhogal, R. Martinez Moreno, H. Bazner, O. Ganslandt, H. Henkes, J Neurointerv Surg 2017, 9, 77; (r) C. Ulfert, M. Pham, M. Sonnberger, F. Amaya, J. Trenkler, M. Bendszus, M. A. Mohlenbruch, J Neurointerv Surg 2018, 20, pii: neurintsurg; (s) M. H. Li, Y. D. Li, B. L. Gao, C. Fang, Q. Y. Luo, Y. S. Cheng, Z. Y. Xie, Y. L. Wang, J. G. Zhao, Y. Li, W. Wang, B. L. Zhang, M. Li, AJNR Am J Neuroradiol 2007, 28, 1579; (t) D. F. Kallmes, Y. H. Ding, D. Dai, R. Kadirvel, D. A. Lewis, H. J. Cloft, Stroke 2007, 38, 2346; (u) J. De Vries, J. Boogaarts, A. Van Norden, A. K. Wakhloo, Stroke 2013, 44, 1567; (v) Y. Zhou, P. F. Yang, Y. B. Fang, Y. Xu, B. Hong, W. Y. Zhao, Q. Li, R. Zhao, Q. H. Huang, J. M. Liu, AJNR Am J Neuroradiol 2014, 35, 2326; (w) F. Briganti, G. Leone, M. Marseglia, D. Cicala, F. Caranci, F. Maiuri, J Neurointerv Surg 2016, 8, 173; (x) Y. Ding, D. Dai, D. F. Kallmes, D. Schroeder, C. P. Kealey, V. Gupta, A. D. Johnson, R. Kadirvel, AJNR Am J Neuroradiol 2016, 37, 497; (y) J. M. Pumar, M. Blanco, F. Vazquez, J. A. Castineira, L. Guimaraens, A. Garcia-Allut, AJNR Am J Neuroradiol 2005, 26, 2573; (z) S. C. Kwon, Y. H. Ding, D. Dai, R. Kadirvel, D. A. Lewis, D. F. Kallmes, AJNR Am J Neuroradiol 2011, 32, 602; (aa) J. Hartman, J Neurointerv Surg 2011, 3, 207; author reply 207; (ab) F. Gao, B. Du, X. T. Xu, Y. J. Wang, W. J. Jiang, J Endovasc Ther 2009, 16, 642; (ac) R. Jahan, AJNR Am J Neuroradiol 2010, 31, 1938; (ad) J. Klisch, C. Eger, V. Sychra, C. Strasilla, S. Basche, J. Weber, Neurosurgery 2009, 65, 258; (ae) R. M. Starke, A. Turk, D. Ding, R. W. Crowley, K. C. Liu, N. Chalouhi, D. M. Hasan, A. S. Dumont, P. Jabbour, C. R. Durst, R. D. Turner, J Neurointerv Surg 2016, 8, 135; (af) O. Diaz, T. L. Gist, G. Manjarez, F. Orozco, R. Almeida, J Neurointerv Surg 2014, 6, 614; (ag) Y. Q. Zhu, M. H. Li, J. Xie, H. Q. Tan, Y. S. Cheng, J. B. Wang, Eur Radiol 2010, 20, 1974; (ah) H. Henkes, E. Miloslavski, S. Lowens, J. Reinartz, T. Liebig, D. Kuhne, Neuroradiology 2005, 47, 222; (ai) R. G. Nogueira, E. I. Levy, M. Gounis, A. H. Siddiqui, J Neurointerv Surg 2012, 4, 295; (aj) D. C. Haussen, A. Lima, R. G. Nogueira, J Neurointerv Surg 2016, 8, 295; (ak) Y. H. Ding, D. A. Lewis, R. Kadirvel, D. Dai, D. F. Kallmes, AJNR Am J Neuroradiol 2011, $32,607$.

[54] (a) Y. Kadkhodayan, N. Rhodes, S. Blackburn, C. P. Derdeyn, D. T. Cross, 3rd, C. J. Moran, AJR Am J Roentgenol 2013, 200, 872; (b) R. P. Benitez, M. T. Silva, J. Klem, E. Veznedaroglu, R. H. Rosenwasser, Neurosurgery 2004, 54, 1359; (c) Y. Kadkhodayan, C. T. Somogyi, D. T. Cross, 3rd, C. P. Derdeyn, G. J. Zipfel, M. R. Chicoine, K. M. Rich, R. L. Grubb, Jr., R. G. Dacey, Jr., C. J. Moran, J 


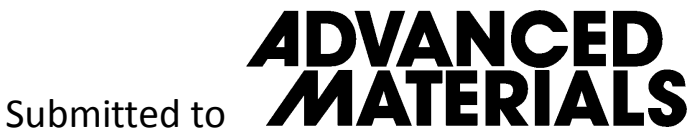

Neurointerv Surg 2012, 4, 368.

[55] (a) O. O. Zaidat, R. Klucznik, M. J. Alexander, J. Chaloupka, H. Lutsep, S. Barnwell, M. Mawad, B. Lane, M. J. Lynn, M. Chimowitz, N. I. H. M.-c. W. I. S. R. S. Group, Neurology 2008, 70, 1518; (b) W. J. Jiang, W. Yu, B. Du, F. Gao, L. Y. Cui, Stroke 2011, 42, 1971; (c) M. I. Chimowitz, M. J. Lynn, C. P. Derdeyn, T. N. Turan, D. Fiorella, B. F. Lane, L. S. Janis, H. L. Lutsep, S. L. Barnwell, M. F. Waters, B. L. Hoh, J. M. Hourihane, E. I. Levy, A. V. Alexandrov, M. R. Harrigan, D. Chiu, R. P. Klucznik, J. M. Clark, C. G. McDougall, M. D. Johnson, G. L. Pride, Jr., M. T. Torbey, O. O. Zaidat, Z. Rumboldt, H. J. Cloft, S. T. Investigators, $N$ Engl J Med 2011, 365, 993; (d) D. Fiorella, E. I. Levy, A. S. Turk, F. C. Albuquerque, D. B. Niemann, B. Aagaard-Kienitz, R. A. Hanel, H. Woo, P. A. Rasmussen, L. N. Hopkins, T. J. Masaryk, C. G. McDougall, Stroke 2007, 38, 881.

[56] (a) X. Wang, Z. Wang, C. Wang, Y. Ji, X. Ding, Y. Zang, Turk Neurosurg 2016, 26, 69; (b) Z. Feng, G.

Duan, P. Zhang, L. Chen, Y. Xu, B. Hong, W. Zhao, J. Liu, Q. Huang, BMC Neurol 2015, 15, 187; (c) Z. Vajda, E. Schmid, T. Guthe, C. Klotzsch, A. Lindner, L. Niehaus, W. Sperber, J. Peters, G. Arnold, H. Bazner, H. Henkes, Neurosurgery 2012, 70, 91; (d) J. Mocco, K. V. Snyder, F. C. Albuquerque, B. R. Bendok, S. B. Alan, J. S. Carpenter, D. J. Fiorella, B. L. Hoh, J. U. Howington, B. T. Jankowitz, K. M. Liebman, A. T. Rai, R. Rodriguez-Mercado, A. H. Siddiqui, E. Veznedaroglu, L. N. Hopkins, E. I. Levy, J Neurosurg 2009, 110, 35; (e) K. Y. Lee, D. Y. Chen, H. L. Hsu, C. J. Chen, Y. C. Tseng, Interv Neuroradiol 2016, 22, 187.

[57] (a) R. Juszkat, S. Nowak, S. Smol, W. Kociemba, T. Blok, A. Zarzecka, Interv Neuroradiol 2007, 13, 255; (b) B. Lubicz, A. Kadou, R. Morais, B. Mine, Neuroradiology 2017, 59, 271; (c) K. Aydin, A. Arat, S. Sencer, M. Barburoglu, S. Men, AJNR Am J Neuroradiol 2015, 36, 1934.

[58] (a) J. Klisch, C. Clajus, V. Sychra, C. Eger, C. Strasilla, S. Rosahl, R. Gerlach, I. Bar, H. Hoch, U. Herbon, L. Borota, P. Jonasson, T. Liebig, Neuroradiology 2010, 52, 349; (b) H. W. Ye, Y. Q. Liu, Q. J. Wang, T. Zheng, X. B. Cui, Y. Y. Gao, L. F. Lai, X. Zhang, X. F. Li, S. X. Su, X. Y. He, C. Z. Duan, Exp Ther Med 2015, 10, 145; (c) H. W. Jeong, W. B. Seung, J Cerebrovasc Endovasc Neurosurg 2015, 17, 301; (d) C. Clajus, V. Sychra, C. Strasilla, J. Klisch, Neuroradiology 2013, 55, 629.

[59] (a) X. Zhang, J. Zhong, H. Gao, F. Xu, N. C. Bambakidis, J Neurointerv Surg 2017, 9, 553; (b) D. Behme, A. Weber, A. Kowoll, A. Berlis, T. H. Burke, W. Weber, J Neurointerv Surg 2015, 7, 281; (c) M. Mohlenbruch, C. Herweh, L. Behrens, L. Jestaedt, H. Amiri, P. A. Ringleb, M. Bendszus, M. Pham, Neuroradiology 2014, 56, 389.

[60] W. J. Jiang, X. T. Xu, M. Jin, B. Du, K. H. Dong, J. P. Dai, AJNR Am J Neuroradiol 2007, $28,830$.

[61] M. H. Li, Y. D. Li, H. Q. Tan, Q. Y. Luo, Y. S. Cheng, Radiology 2009, 253, 470.

[62] B. King, S. Vaziri, A. Singla, K. M. Fargen, J. Mocco, J Neurointerv Surg 2015, 7, 905.

[63] W. J. Lee, C. S. Cho, J Cerebrovasc Endovasc Neurosurg 2012, 14, 247.

[64] M. F. M. Ten Brinck, J. de Vries, R. Bartels, J. A. Grotenhuis, H. D. Boogaarts, Neurosurgery 2018. [65] (a) T. Zhao, W. Y. Zhu, X. Y. Xiong, J. Li, L. Wang, H. Y. Ding, F. Wei, Y. Zhou, Z. L. Gong, S. Y. Cheng, Y. Liu, J. Shuai, Q. W. Yang, J Stroke Cerebrovasc Dis 2016, 25, 2368; (b) M. Levesque, P. Salami, C. Behr, M. Avoli, Epilepsia 2013, 54, 596.

[66] (a) C. P. Derdeyn, M. I. Chimowitz, M. J. Lynn, D. Fiorella, T. N. Turan, L. S. Janis, J. Montgomery, A. Nizam, B. F. Lane, H. L. Lutsep, S. L. Barnwell, M. F. Waters, B. L. Hoh, J. M. Hourihane, E. I. Levy, A. V. Alexandrov, M. R. Harrigan, D. Chiu, R. P. Klucznik, J. M. Clark, C. G. McDougall, M. D. 


\section{Submitted to \\ ADNAMEED
MATERRALAS}

Johnson, G. L. Pride, Jr., J. R. Lynch, O. O. Zaidat, Z. Rumboldt, H. J. Cloft, Lancet 2014, 383, 333; (b) H. M. Kwon, M. J. Lynn, T. N. Turan, C. P. Derdeyn, D. Fiorella, B. F. Lane, J. Montgomery, L. S. Janis, Z. Rumboldt, M. I. Chimowitz, JAMA Neurol 2016, 73, 36.

[67] S. O. Safety, P. Benefit, 2004.

[68] A. Liu, T. Peng, Z. Qian, Y. Li, C. Jiang, Z. Wu, X. Yang, J Neuroradiol 2015, 42, 298.

[69] (a) S. R. Dashti, D. Fiorella, M. M. Toledo, Y. Hu, C. G. McDougall, F. C. Albuquerque, J Neurointerv Surg 2010, 2, 356; (b) B. Gao, A. M. Malek, AJNR Am J Neuroradiol 2010, 31, E85.

[70] S. W. Kim, S. O. Sung, K. S. Chae, H. S. Park, S. H. Lee, J Cerebrovasc Endovasc Neurosurg 2015, $17,149$.

[71] (a) C. C. Wang, W. Li, AJNR Am J Neuroradiol 2017, 38, 1163; (b) J. A. Grossberg, R. A. Hanel, G. Dabus, K. Keigher, D. C. Haussen, E. Sauvageau, I. Linfante, D. Gonsales, P. Aguilar Salinas, M. Bouslama, M. Mayich, R. G. Nogueira, D. K. Lopes, J Neurointerv Surg 2017, 9, 1098.

[72] H. Q. Tan, M. H. Li, Y. D. Li, C. Fang, J. B. Wang, W. Wang, J. Wang, P. L. Zhang, Y. Q. Zhu, Cerebrovasc Dis 2011, 31, 154.

[73] (a) B. Kis, W. Weber, P. Berlit, D. Kuhne, Neurosurgery 2006, 58, 443; (b) W. Poncyljusz, P. Bilinski, K. Safranow, J. Baron, M. Zbroszczyk, M. Jaworski, S. Bereza, T. H. Burke, J Neurointerv Surg 2015, $7,524$.

[74] A. Bose, M. Hartmann, H. Henkes, H. M. Liu, M. M. Teng, I. Szikora, A. Berlis, J. Reul, S. C. Yu, M. Forsting, M. Lui, W. Lim, S. P. Sit, Stroke 2007, 38, 1531.

[75] (a) K. M. Fargen, B. L. Hoh, B. G. Welch, G. L. Pride, G. Lanzino, A. S. Boulos, J. S. Carpenter, A. Rai, E. Veznedaroglu, A. Ringer, R. Rodriguez-Mercado, P. Kan, A. Siddiqui, E. I. Levy, J. Mocco, Neurosurgery 2012, 71, 239; (b) I. L. Maldonado, P. Machi, V. Costalat, T. Mura, A. Bonafe, AJNR Am J Neuroradiol 2011, 32, 131.

[76] M. Piotin, R. Blanc, L. Spelle, C. Mounayer, R. Piantino, P. J. Schmidt, J. Moret, Stroke 2010, 41, 110. [77] M. Shapiro, T. Becske, D. Sahlein, J. Babb, P. K. Nelson, AJNR Am J Neuroradiol 2012, 33, 159.

[78] C. Islak, N. Kocer, S. Albayram, O. Kizilkilic, O. Uzma, O. Cokyuksel, AJNR Am J Neuroradiol 2002, $23,1589$.

[79] I. Saatci, H. S. Cekirge, M. H. Ozturk, A. Arat, F. Ergungor, Z. Sekerci, E. Senveli, U. Er, S. Turkoglu, O. E. Ozcan, T. Ozgen, AJNR Am J Neuroradiol 2004, 25, 1742.

[80] M. H. Li, Y. Q. Zhu, C. Fang, W. Wang, P. L. Zhang, Y. S. Cheng, H. Q. Tan, J. B. Wang, AJNR Am J Neuroradiol 2008, 29, 1395.

[81] W. Wang, M. H. Li, Y. D. Li, B. X. Gu, H. T. Lu, Neurosurgery 2016, 79, 794.

[82] C. Banerjee, M. I. Chimowitz, Circ Res 2017, 120, 502.

[83] T. M. Sundt, Jr., H. C. Smith, J. K. Campbell, R. E. Vlietstra, R. F. Cucchiara, A. W. Stanson, Mayo Clin Proc 1980, 55, 673.

[84] (a) P. D. Purdy, M. D. Devous, Sr., D. H. Unwin, C. A. Giller, H. H. Batjer, AJNR Am J Neuroradiol 1990, 11, 878; (b) R. Kachel, G. Endert, S. Basche, K. Grossmann, F. H. Glaser, Cardiovasc Intervent Radiol 1987, 10, 142; (c) H. Touho, J Neurosurg 1995, 82, 953; (d) R. L. Feldman, L. Trigg, J. Gaudier, J. Galat, Cathet Cardiovasc Diagn 1996, 38, 316.

[85] O. O. Zaidat, B. F. Fitzsimmons, B. K. Woodward, Z. Wang, M. Killer-Oberpfalzer, A. Wakhloo, R. Gupta, H. Kirshner, J. T. Megerian, J. Lesko, P. Pitzer, J. Ramos, A. C. Castonguay, S. Barnwell, W. S. 


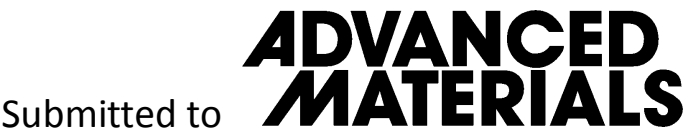

Smith, D. R. Gress, Jama 2015, 313, 1240.

[86] P. Gao, Z. Zhao, D. Wang, J. Wu, Y. Cai, T. Li, W. Wu, H. Shi, W. He, F. Zhu, L. Jiao, F. Ling, Interv Neuroradiol 2015, 21, 196.

[87] G. Benndorf, U. Herbon, W. P. Sollmann, A. Campi, AJNR Am J Neuroradiol 2001, 22, 1844.

[88] D. F. Kallmes, R. Hanel, D. Lopes, E. Boccardi, A. Bonafe, S. Cekirge, D. Fiorella, P. Jabbour, E. Levy,

C. McDougall, A. Siddiqui, I. Szikora, H. Woo, F. Albuquerque, H. Bozorgchami, S. R. Dashti, J. E. Delgado Almandoz, M. E. Kelly, R. t. Turner, B. K. Woodward, W. Brinjikji, G. Lanzino, P. Lylyk, AJNR Am J Neuroradiol 2015, 36, 108.

[89] B. N. Roszelle, L. F. Gonzalez, M. H. Babiker, J. Ryan, F. C. Albuquerque, D. H. Frakes, Neuroradiology 2013, 55, 751.

[90] A. C. Tsang, A. Y. Tang, W. C. Chung, G. K. Leung, K. W. Chow, Clin Neuroradiol 2016, 26, 477.

[91] T. M. Liou, Y. C. Li, J Biomech 2008, 41, 1174.

[92] D. Ma, T. M. Dumont, H. Kosukegawa, M. Ohta, X. Yang, A. H. Siddiqui, H. Meng, Ann Biomed Eng 2013, 41, 2143.

[93] K. Wang, Q. Huang, B. Hong, Z. Li, X. Fang, J. Liu, Neuroradiology 2012, 54, 607.

[94] A. K. Wakhloo, P. Lylyk, J. de Vries, C. Taschner, J. Lundquist, A. Biondi, M. Hartmann, I. Szikora,

L. Pierot, N. Sakai, H. Imamura, N. Sourour, I. Rennie, M. Skalej, O. Beuing, A. Bonafe, F. Mery, F. Turjman, P. Brouwer, E. Boccardi, L. Valvassori, S. Derakhshani, M. W. Litzenberg, M. J. Gounis, AJNR Am J Neuroradiol 2015, 36, 98.

[95] R. Kadirvel, Y. H. Ding, D. Dai, I. Rezek, D. A. Lewis, D. F. Kallmes, Radiology 2014, 270, 394.

[96] M. G. Safain, M. Roguski, R. S. Heller, A. M. Malek, Stroke 2016, 47, 789.

[97] M. Shapiro, E. Raz, T. Becske, P. K. Nelson, AJNR Am J Neuroradiol 2014, 35, 727.

[98] (a) O. Petr, W. Brinjikji, H. Cloft, D. F. Kallmes, G. Lanzino, AJNR Am J Neuroradiol 2016, 37, 1106; (b) M. Martinez-Galdamez, S. Perez, A. Vega, P. Ruiz, J. L. Caniego, E. Barcena, P. Saura, J. C. Mendez, F. Delgado, S. Ortega-Gutierrez, A. Romance, T. Diaz, E. Gonzalez, A. Gil, E. Murias, P. Vega, J Neurointerv Surg 2016, 8, 396; (c) M. A. Mooney, K. Moon, B. A. Gross, A. F. Ducruet, F. C. Albuquerque, J Neurointerv Surg 2017, 9, 571; (d) G. Girdhar, J. Li, L. Kostousov, J. Wainwright, W. L. Chandler, J Thromb Thrombolysis 2015, 40, 437; (e) T. Becske, W. Brinjikji, M. B. Potts, D. F. Kallmes, M. Shapiro, C. J. Moran, E. I. Levy, C. G. McDougall, I. Szikora, G. Lanzino, H. H. Woo, D. K. Lopes, A. H. Siddiqui, F. C. Albuquerque, D. J. Fiorella, I. Saatci, S. H. Cekirge, A. L. Berez, D. J. Cher, Z. Berentei, M. Marosfoi, P. K. Nelson, Neurosurgery 2017, 80, 40; (f) M. Martinez-Galdamez, S. M. Lamin, K. G. Lagios, T. Liebig, E. F. Ciceri, R. Chapot, L. Stockx, S. Chavda, C. Kabbasch, G. Farago, H. Nordmeyer, T. Boulanger, M. Piano, E. P. Boccardi, J Neurointerv Surg 2017, 9, 772; (g) A. S. Puri, F. Massari, T. Asai, M. Marosfoi, P. Kan, S. Y. Hou, M. Howk, M. Perras, C. Brooks, F. Clarencon, M. J. Gounis, A. K. Wakhloo, Neuroradiology 2016, 58, 267; (h) M. W. Hagen, G. Girdhar, J. Wainwright, M. T. Hinds, J Neurointerv Surg 2016, 9, 1006; (i) L. M. Lin, G. P. Colby, M. T. Bender, R. Xu, J. Huang, R. J. Tamargo, A. L. Coon, J Neurointerv Surg 2017, 9, 689.

[99] (a) J. J. Shankar, D. Tampieri, D. Iancu, M. Cortes, R. Agid, T. Krings, J. Wong, P. Lavoie, J. Ghostine, B. Shettar, K. Ritchie, A. Weill, J Neurointerv Surg 2016, 8, 273; (b) J. M. Pumar, A. Banguero, H. Cuellar, L. Guimaraens, J. Masso, S. Miralbes, M. Blanco-Ulla, F. Vazquez-Herrero, M. Souto, M. Gelabert-Gonzalez, Neurosurgery 2017, 81, 595; (c) S. Maimon, L. Gonen, E. Nossek, I. Strauss, R. 


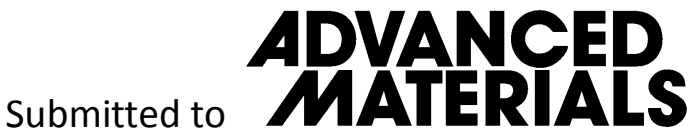

Levite, Z. Ram, Acta Neurochir (Wien) 2012, 154, 979.

[100] G. P. Colby, L. M. Lin, J. M. Caplan, B. Jiang, B. Michniewicz, J. Huang, R. J. Tamargo, A. L. Coon, J Neurointerv Surg 2016, 8, 279.

[101] (a) J. P. Cruz, T. Marotta, C. O'Kelly, M. Holtmannspotter, G. Saliou, R. Willinsky, T. Krings, R. Agid, AJNR Am J Neuroradiol 2014, 35, 1954; (b) H. Luecking, T. Engelhorn, AJNR Am J Neuroradiol 2017, 38, 596; (c) M. A. Mohlenbruch, C. Herweh, L. Jestaedt, S. Stampfl, S. Schonenberger, P. A. Ringleb, M. Bendszus, M. Pham, AJNR Am J Neuroradiol 2015, 36, 1155; (d) F. Drescher, W. Weber, AJNR Am J Neuroradiol 2017, 38, 105.

[102] Y. B. Fang, W. L. Wen, P. F. Yang, Y. Zhou, Y. N. Wu, B. Hong, Y. Xu, W. Y. Zhao, J. M. Liu, Q. H. Huang, Clin Neuroradiol 2017, 27, 345.

[103] (a) R. Morais, B. Mine, P. J. Bruyere, G. Naeije, B. Lubicz, Neuroradiology 2017, 59, 263; (b) S. Fischer, M. Aguilar-Perez, E. Henkes, W. Kurre, O. Ganslandt, H. Bazner, H. Henkes, AJNR Am J Neuroradiol 2015, 36, 2082.

[104] (a) S. Asnafi, A. Rouchaud, AJNR Am J Neuroradiol 2016, 37, 2287; (b) L. Pierot, J. Klisch, C. Cognard, I. Szikora, B. Mine, K. Kadziolka, V. Sychra, I. Gubucz, A. C. Januel, B. Lubicz, Neurosurgery 2013, 73, 27; (c) B. Mine, L. Pierot, B. Lubicz, Expert Rev Med Devices 2014, 11, 315; (d) B. Lubicz, B. Mine, L. Collignon, D. Brisbois, G. Duckwiler, C. Strother, AJNR Am J Neuroradiol 2013, 34, 1209. [105] M. Piotin, A. Biondi, N. Sourour, C. Mounayer, M. Söderman, T. Andersson, S. Mangiafico, M. Jaworski, R. Anxionnat, P. Goffette, J Neurointerv Surg 2015, 7, A13.2.

[106] M. Kojima, K. Irie, K. Masunaga, Y. Sakai, M. Nakajima, M. Takeuchi, T. Fukuda, F. Arai, M. Negoro, Med Biol Eng Comput 2016, 54, 831.

[107] G. P. Colby, L. M. Lin, J Neurointerv Surg 2016, 8, 702.

[108] B. A. Gross, K. U. Frerichs, J Neurol Neurosurg PS 2013, 84, 244.

[109] B. P. Walcott, C. J. Stapleton, O. Choudhri, A. B. Patel, JAMA Neurol 2016, 73, 1002.

[110] C. Sadasivan, L. Cesar, J. Seong, A. Rakian, Q. Hao, F. O. Tio, A. K. Wakhloo, B. B. Lieber, Stroke 2009, 40, 952.

[111] Y. Ding, D. Dai, AJNR Am J Neuroradiol 2016, 37, 497.

[112] Y. Chen, C. Howe, Y. Lee, S. Cheon, W. H. Yeo, Y. Chun, Sci Rep 2016, 6, 23698.

[113] D. Fiorella, A. Molyneux, A. Coon, I. Szikora, I. Saatci, F. Baltacioglu, A. Sultan, A. Arthur, J Neurointerv Surg 2017, 9, 1191.

[114] A. H. Chiu, J. De Vries, C. J. O'Kelly, H. Riina, I. McDougall, J. Tippett, M. Wan, A. L. de Oliveira Manoel, T. R. Marotta, J Neurosurg 2018, 128, 482.

[115] T. Becske, D. F. Kallmes, I. Saatci, C. G. McDougall, I. Szikora, G. Lanzino, C. J. Moran, H. H. Woo, D. K. Lopes, A. L. Berez, D. J. Cher, A. H. Siddiqui, E. I. Levy, F. C. Albuquerque, D. J. Fiorella, Z. Berentei, M. Marosfoi, S. H. Cekirge, P. K. Nelson, Radiology 2013, 267, 858.

[116] T. Becske, M. B. Potts, M. Shapiro, D. F. Kallmes, W. Brinjikji, I. Saatci, C. G. McDougall, I. Szikora, G. Lanzino, C. J. Moran, H. H. Woo, D. K. Lopes, A. L. Berez, D. J. Cher, A. H. Siddiqui, E. I. Levy, F. C. Albuquerque, D. J. Fiorella, Z. Berentei, M. Marosfoi, S. H. Cekirge, P. K. Nelson, J Neurosurg 2017, 127,81 .

[117] D. F. Kallmes, W. Brinjikji, E. Boccardi, E. Ciceri, O. Diaz, R. Tawk, H. Woo, P. Jabbour, F. Albuquerque, R. Chapot, A. Bonafe, S. R. Dashti, J. E. Delgado Almandoz, C. Given, 2nd, M. E. Kelly, 


\section{ADVNACED
Mathento}

D. T. Cross, 3rd, G. Duckwiler, N. Razack, C. J. Powers, S. Fischer, D. Lopes, M. R. Harrigan, D.

Huddle, R. t. Turner, O. O. Zaidat, L. Defreyne, V. M. Pereira, S. Cekirge, D. Fiorella, R. A. Hanel, P.

Lylyk, C. McDougall, A. Siddiqui, I. Szikora, E. Levy, Interv Neurol 2016, 5, 89.

[118] C. A. Taschner, S. Vedantham, AJNR Am J Neuroradiol 2017, 38, 582.

[119] G. Zhou, M. Su, Y. L. Yin, M. H. Li, Neurosurg Focus 2017, 42, E17.

[120] J. W. Yoon, A. H. Siddiqui, T. M. Dumont, E. I. Levy, L. N. Hopkins, G. Lanzino, D. K. Lopes, R.

Moftakhar, J. T. Billingsley, B. G. Welch, A. S. Boulos, J. Yamamoto, R. G. Tawk, A. J. Ringer, R. A. Hanel, Neurosurgery 2014, 75, 419.

[121] R. Navarro, B. L. Brown, A. Beier, N. Ranalli, P. Aldana, R. A. Hanel, J Neurosurg Pediatr 2015, 15, 276.

[122] N. Chalouhi, M. Zanaty, A. Whiting, S. Yang, S. Tjoumakaris, D. Hasan, R. M. Starke, S. Hann, C.

Hammer, D. Kung, R. Rosenwasser, P. Jabbour, J Neurosurg 2015, 122, 1498.

[123] J. Raymond, J. C. Gentric, T. E. Darsaut, D. Iancu, M. Chagnon, A. Weill, D. Roy, J Neurosurg 2017, $127,454$.

[124] (a) F. Turjman, O. Levrier, X. Combaz, A. Bonafe, A. Biondi, H. Desal, S. Bracard, C. Mounayer, R. Riva, F. Chapuis, L. Huot, X. Armoiry, B. Gory, Neuroradiology 2015, 57, 49; (b) A. S. Turk, 3rd, R. H. Martin, D. Fiorella, J. Mocco, A. Siddiqui, A. Bonafe, AJNR Am J Neuroradiol 2014, 35, 1341.

[125] P. M. Rothwell, A. J. Coull, L. E. Silver, J. F. Fairhead, M. F. Giles, C. E. Lovelock, J. N. Redgrave, L. M. Bull, S. J. Welch, F. C. Cuthbertson, L. E. Binney, S. A. Gutnikov, P. Anslow, A. P. Banning, D. Mant, Z. Mehta, Lancet 2005, 366, 1773.

[126] (a) P. W. Vinny, V. Y. Vishnu, D. Khurana, N Engl J Med 2015, 372, 2363; (b) B. C. Campbell, G. A. Donnan, S. M. Davis, N Engl J Med 2013, 368, 2431; (c) T. G. Jovin, A. Chamorro, E. Cobo, M. A. de Miquel, C. A. Molina, A. Rovira, L. San Roman, J. Serena, S. Abilleira, M. Ribo, M. Millan, X. Urra, P. Cardona, E. Lopez-Cancio, A. Tomasello, C. Castano, J. Blasco, L. Aja, L. Dorado, H. Quesada, M. Rubiera, M. Hernandez-Perez, M. Goyal, A. M. Demchuk, R. von Kummer, M. Gallofre, A. Davalos, $N$ Engl J Med 2015, 372, 2296; (d) J. L. Saver, M. Goyal, A. Bonafe, H. C. Diener, E. I. Levy, V. M. Pereira, G. W. Albers, C. Cognard, D. J. Cohen, W. Hacke, O. Jansen, T. G. Jovin, H. P. Mattle, R. G. Nogueira, A. H. Siddiqui, D. R. Yavagal, B. W. Baxter, T. G. Devlin, D. K. Lopes, V. K. Reddy, R. du Mesnil de Rochemont, O. C. Singer, R. Jahan, NEngl J Med 2015, 372, 2285; (e) S. Bracard, X. Ducrocq, J. L. Mas, M. Soudant, C. Oppenheim, T. Moulin, F. Guillemin, Lancet Neurol 2016, 15, 1138; (f) M. Goyal, A. M. Demchuk, B. K. Menon, M. Eesa, J. L. Rempel, J. Thornton, D. Roy, T. G. Jovin, R. A. Willinsky, B. L. Sapkota, D. Dowlatshahi, D. F. Frei, N. R. Kamal, W. J. Montanera, A. Y. Poppe, K. J. Ryckborst, F. L. Silver, A. Shuaib, D. Tampieri, D. Williams, O. Y. Bang, B. W. Baxter, P. A. Burns, H. Choe, J. H. Heo, C. A. Holmstedt, B. Jankowitz, M. Kelly, G. Linares, J. L. Mandzia, J. Shankar, S. I. Sohn, R. H. Swartz, P. A. Barber, S. B. Coutts, E. E. Smith, W. F. Morrish, A. Weill, S. Subramaniam, A. P. Mitha, J. H. Wong, M. W. Lowerison, T. T. Sajobi, M. D. Hill, N Engl J Med 2015, 372, 1019. [127] J. Gralla, G. Schroth, L. Remonda, K. Nedeltchev, J. Slotboom, C. Brekenfeld, Stroke 2006, $37,3019$. [128] P. Papanagiotou, C. Roth, S. Walter, S. Behnke, M. Politi, K. Fassbender, A. Haass, W. Reith, Circulation 2010, 121, 2605.

[129] (a) Y. P. Gobin, S. Starkman, G. R. Duckwiler, T. Grobelny, C. S. Kidwell, R. Jahan, J. Pile-Spellman, A. Segal, F. Vinuela, J. L. Saver, Stroke 2004, 35, 2848; (b) W. S. Smith, G. Sung, J. Saver, R. Budzik, 


\section{Submitted to \\ ADVANCED
MATERIALS}

G. Duckwiler, D. S. Liebeskind, H. L. Lutsep, M. M. Rymer, R. T. Higashida, S. Starkman, Y. P. Gobin, D. Frei, T. Grobelny, F. Hellinger, D. Huddle, C. Kidwell, W. Koroshetz, M. Marks, G. Nesbit, I. E. Silverman, Stroke 2008, 39, 1205; (c) W. S. Smith, G. Sung, S. Starkman, J. L. Saver, C. S. Kidwell, Y. P. Gobin, H. L. Lutsep, G. M. Nesbit, T. Grobelny, M. M. Rymer, I. E. Silverman, R. T. Higashida, R. F. Budzik, M. P. Marks, M. T. Investigators, Stroke 2005, 36, 1432.

[130] (a) F. Miteff, K. C. Faulder, A. C. Goh, B. S. Steinfort, C. Sue, T. J. Harrington, AJNR Am J Neuroradiol 2011, 32, 1078; (b) A. Mpotsaris, M. Bussmeyer, C. Loehr, M. Oelerich, H. Buchner, W. Weber, J Neurol Neurosur PS 2012, 83, 117; (c) F. Dorn, S. Stehle, H. Lockau, C. Zimmer, T. Liebig, Cerebrovasc Dis 2012, 34, 70; (d) J. W. Choi, H. G. Roh, W. J. Moon, N. R. Kim, S. G. Moon, C. H. Kang, Y. I. Chun, H. S. Kang, Korean J Radiol 2011, 12, 662.

[131] A. G. Chartrain, A. J. Awad, J. R. Mascitelli, H. Shoirah, T. J. Oxley, R. Feng, M. Gallitto, R. De Leacy, J. T. Fifi, C. P. Kellner, Neurosurg Focus 2017, 42, E12.

[132] (a) V. M. Pereira, J. Gralla, A. Davalos, A. Bonafe, C. Castano, R. Chapot, D. S. Liebeskind, R. G. Nogueira, M. Arnold, R. Sztajzel, T. Liebig, M. Goyal, M. Besselmann, A. Moreno, G. Schroth, Stroke 2013, 44, 2802; (b) J. L. Saver, R. Jahan, E. I. Levy, T. G. Jovin, B. Baxter, R. G. Nogueira, W. Clark, R. Budzik, O. O. Zaidat, Lancet 2012, 380, 1241; (c) P. Machi, F. Jourdan, D. Ambard, C. Reynaud, K. Lobotesis, M. Sanchez, A. Bonafe, V. Costalat, J Neurointerv Surg 2017, 9, 257.

[133] (a) A. T. Rai, Y. Jhadhav, J. Domico, G. R. Hobbs, Cardiovasc Inter Rad 2012, 35, 1332; (b) R. G.

Nogueira, H. L. Lutsep, R. Gupta, T. G. Jovin, G. W. Albers, G. A. Walker, D. S. Liebeskind, W. S. Smith, Lancet 2012, 380, 1231.

[134] A. L. Kuhn, A. K. Wakhloo, J. D. Lozano, F. Massari, K. De Macedo Rodrigues, M. G. Marosfoi, M.

Perras, C. Brooks, M. Howk, D. E. Rex, M. J. Gounis, A. S. Puri, J Neurointerv Surg 2017, 9, 541.

[135] H. Steglich-Arnholm, D. Kondziella, A. Wagner, M. E. Cronqvist, K. Hansen, T. C. Truelsen, L. H.

Krarup, J. L. S. Hojgaard, S. Taudorf, H. K. Iversen, D. W. Krieger, M. Holtmannspotter, AJNR Am J Neuroradiol 2017, 38, 1356.

[136] A. Alshekhlee, D. J. Pandya, J. English, O. O. Zaidat, N. Mueller, R. Gupta, R. G. Nogueira, Neurology 2012, 79, S126.

[137] M. S. Tenser, A. P. Amar, W. J. Mack, World Neurosurg 2011, 76, S16.

[138] J. Y. Chueh, A. K. Wakhloo, M. J. Gounis, AJNR Am J Neuroradiol 2012, 33, 1998.

[139] V. M. Pereira, J. Gralla, A. Davalos, A. Bonafé, C. Castaño, R. Chapot, D. S. Liebeskind, R. G. Nogueira, M. Arnold, R. Sztajzel, Stroke 2013, 44, 2802.

[140] B. Gory, D. Bresson, I. Kessler, M. L. Perrin, A. Guillaudeau, K. Durand, S. Ponsonnard, C. Couquet,

C. Yardin, C. Mounayer, AJNR Am J Neuroradiol 2013, 34, 2192.

[141] N. C. Beadell, H. Lutsep, Curr Atheroscler Rep 2013, 15, 333.

[142] K. J. Wenger, J. Berkefeld, M. Wagner, Clin Neuroradiol 2014, 24, 251.

[143] O. Jansen, J. M. Macho, M. Killer-Oberpfalzer, D. Liebeskind, N. Wahlgren, Cerebrovasc Dis 2013, $36,218$.

[144] H. C. Prince, A. J. Saliba, J. Wheeler, S. Bruder, Ann N Y Acad Sci 2014, 1329, 107.

[145] G. W. Peitz, C. A. Sy, R. Grandhi, Neurosurg Focus 2017, 42, E12.

[146] N. Mendonca, A. Flores, J. Pagola, M. Rubiera, D. Rodriguez-Luna, M. A. De Miquel, P. Cardona, H. Quesada, P. Mora, J. Alvarez-Sabin, C. Molina, M. Ribo, J Neuroimaging 2014, 24, 167. 


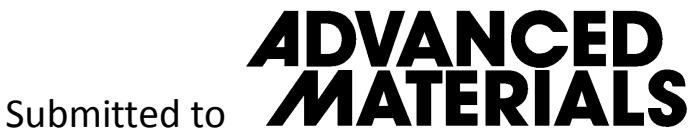

[147] D. Arai, A. Ishii, H. Chihara, H. Ikeda, S. Miyamoto, J Neurointerv Surg 2016, 8, 992.

[148] (a) R. G. Gonzalez, K. L. Furie, G. V. Goldmacher, W. S. Smith, S. Kamalian, S. Payabvash, G. J. Harris, E. F. Halpern, W. J. Koroshetz, E. C. Camargo, W. P. Dillon, M. H. Lev, Stroke 2013, 44, 3109; (b) J. P. Broderick, Y. Y. Palesch, A. M. Demchuk, S. D. Yeatts, P. Khatri, M. D. Hill, E. C. Jauch, T. G. Jovin, B. Yan, F. L. Silver, R. von Kummer, C. A. Molina, B. M. Demaerschalk, R. Budzik, W. M. Clark, O. O. Zaidat, T. W. Malisch, M. Goyal, W. J. Schonewille, M. Mazighi, S. T. Engelter, C. Anderson, J. Spilker, J. Carrozzella, K. J. Ryckborst, L. S. Janis, R. H. Martin, L. D. Foster, T. A. Tomsick, N Engl J Med 2013, 368, 893; (c) N Engl J Med 1995, 333, 1581; (d) W. Hacke, M. Kaste, E. Bluhmki, M. Brozman, A. Davalos, D. Guidetti, V. Larrue, K. R. Lees, Z. Medeghri, T. Machnig, D. Schneider, R. von Kummer, N. Wahlgren, D. Toni, N Engl J Med 2008, 359, 1317.

[149] (a) A. Ciccone, L. Valvassori, M. Nichelatti, A. Sgoifo, M. Ponzio, R. Sterzi, E. Boccardi, N Engl J Med 2013, 368, 904; (b) A. Ciccone, L. Valvassori, N Engl J Med 2013, 368, 2433.

[150] (a) O. A. Berkhemer, P. S. Fransen, D. Beumer, L. A. van den Berg, H. F. Lingsma, A. J. Yoo, W. J. Schonewille, J. A. Vos, P. J. Nederkoorn, M. J. Wermer, M. A. van Walderveen, J. Staals, J. Hofmeijer, J. A. van Oostayen, G. J. Lycklama a Nijeholt, J. Boiten, P. A. Brouwer, B. J. Emmer, S. F. de Bruijn, L. C. van Dijk, L. J. Kappelle, R. H. Lo, E. J. van Dijk, J. de Vries, P. L. de Kort, W. J. van Rooij, J. S. van den Berg, B. A. van Hasselt, L. A. Aerden, R. J. Dallinga, M. C. Visser, J. C. Bot, P. C. Vroomen, O. Eshghi, T. H. Schreuder, R. J. Heijboer, K. Keizer, A. V. Tielbeek, H. M. den Hertog, D. G. Gerrits, R. M. van den Berg-Vos, G. B. Karas, E. W. Steyerberg, H. Z. Flach, H. A. Marquering, M. E. Sprengers, S. F. Jenniskens, L. F. Beenen, R. van den Berg, P. J. Koudstaal, W. H. van Zwam, Y. B. Roos, A. van der Lugt, R. J. van Oostenbrugge, C. B. Majoie, D. W. Dippel, M. C. Investigators, N Engl J Med 2015, 372, 11; (b) B. C. Campbell, P. J. Mitchell, T. J. Kleinig, H. M. Dewey, L. Churilov, N. Yassi, B. Yan, R. J. Dowling, M. W. Parsons, T. J. Oxley, T. Y. Wu, M. Brooks, M. A. Simpson, F. Miteff, C. R. Levi, M. Krause, T. J. Harrington, K. C. Faulder, B. S. Steinfort, M. Priglinger, T. Ang, R. Scroop, P. A. Barber, B. McGuinness, T. Wijeratne, T. G. Phan, W. Chong, R. V. Chandra, C. F. Bladin, M. Badve, H. Rice, L. de Villiers, H. Ma, P. M. Desmond, G. A. Donnan, S. M. Davis, N Engl J Med 2015, 372, 1009; (c) L. A. van den Berg, M. G. Dijkgraaf, O. A. Berkhemer, P. S. Fransen, D. Beumer, H. F. Lingsma, C. B. Majoie, D. W. Dippel, A. van der Lugt, R. J. van Oostenbrugge, W. H. van Zwam, Y. B. Roos, N Engl J Med 2017, 376, 1341.

[151] (a) R. G. Nogueira, A. P. Jadhav, D. C. Haussen, A. Bonafe, R. F. Budzik, P. Bhuva, D. R. Yavagal, M. Ribo, C. Cognard, R. A. Hanel, C. A. Sila, A. E. Hassan, M. Millan, E. I. Levy, P. Mitchell, M. Chen, J. D. English, Q. A. Shah, F. L. Silver, V. M. Pereira, B. P. Mehta, B. W. Baxter, M. G. Abraham, P. Cardona, E. Veznedaroglu, F. R. Hellinger, L. Feng, J. F. Kirmani, D. K. Lopes, B. T. Jankowitz, M. R. Frankel, V. Costalat, N. A. Vora, A. J. Yoo, A. M. Malik, A. J. Furlan, M. Rubiera, A. Aghaebrahim, J. M. Olivot, W. G. Tekle, R. Shields, T. Graves, R. J. Lewis, W. S. Smith, D. S. Liebeskind, J. L. Saver, T. G. Jovin, D. T. Investigators, $N$ Engl J Med 2018, 378, 11; (b) G. W. Albers, M. P. Marks, S. Kemp, S. Christensen, J. P. Tsai, S. Ortega-Gutierrez, R. A. McTaggart, M. T. Torbey, M. Kim-Tenser, T. LeslieMazwi, A. Sarraj, S. E. Kasner, S. A. Ansari, S. D. Yeatts, S. Hamilton, M. Mlynash, J. J. Heit, G. Zaharchuk, S. Kim, J. Carrozzella, Y. Y. Palesch, A. M. Demchuk, R. Bammer, P. W. Lavori, J. P. Broderick, M. G. Lansberg, D. Investigators, N Engl J Med 2018, 378, 708.

[152] T. Simard, B. Hibbert, F. D. Ramirez, M. Froeschl, Y. X. Chen, E. R. O'Brien, Can J Cardiol 2014, 


\section{Submitted to

$30,35$.

[153] (a) N. F. Kassell, T. Sasaki, A. R. Colohan, G. Nazar, Stroke 1985, 16, 562; (b) N. M. Alotaibi, G.

Lanzino, J Neurointerv Surg 2013, 5, 413; (c) B. A. Gross, R. Du, World Neurosurg 2012, 78, 300.

[154] N. W. Dorsch, M. T. King, J Clin Neurosci 1994, 1, 19.

[155] B. Weir, M. Grace, J. Hansen, C. Rothberg, J Neurosurg 1978, 48, 173.

[156] P. M. Rist, M. C. Jimenez, S. S. Tworoger, F. B. Hu, J. E. Manson, Q. Sun, K. M. Rexrode, J Stroke Cerebrovasc Dis 2018, 27, 68.

[157] A. Dilraj, J. H. Botha, V. Rambiritch, R. Miller, J. R. van Dellen, Neurosurgery 1992, 31, 42.

[158] M. Sabri, J. Ai, B. Knight, A. Tariq, H. Jeon, X. Shang, P. A. Marsden, R. Loch Macdonald, J Cereb Blood Flow Metab 2011, 31, 190.

[159] M. J. McGirt, J. R. Lynch, R. Blessing, D. S. Warner, A. H. Friedman, D. T. Laskowitz, Neurosurgery 2002, 51, 1128.

[160] I. Siasios, E. Z. Kapsalaki, K. N. Fountas, Neurol Res Int 2013, 2013, 571328.

[161] (a) J. C. Durrant, H. E. Hinson, Curr Neurol Neurosci Rep 2015, 15, 521; (b) G. Dabus, R. G. Nogueira, Interv Neurol 2013, 2, 30.

[162] I. Iakovou, T. Schmidt, E. Bonizzoni, L. Ge, G. M. Sangiorgi, G. Stankovic, F. Airoldi, A. Chieffo,

M. Montorfano, M. Carlino, I. Michev, N. Corvaja, C. Briguori, U. Gerckens, E. Grube, A. Colombo, JAMA 2005, 293, 2126.

[163] G. Lemesle, C. Delhaye, L. Bonello, A. de Labriolle, R. Waksman, A. Pichard, Arch Cardiovasc Dis 2008, 101, 769.

[164] (a) M. Awata, J. Kotani, M. Uematsu, T. Morozumi, T. Watanabe, T. Onishi, O. Iida, F. Sera, S. Nanto, M. Hori, S. Nagata, Circulation 2007, 116, 910; (b) D. E. Cutlip, D. S. Baim, K. K. Ho, J. J. Popma, A. J. Lansky, D. J. Cohen, J. P. Carrozza, Jr., M. S. Chauhan, O. Rodriguez, R. E. Kuntz, Circulation 2001, 103, 1967.

[165] A. V. Finn, M. Joner, G. Nakazawa, F. Kolodgie, J. Newell, M. C. John, H. K. Gold, R. Virmani, Circulation 2007, 115, 2435.

[166] D. R. Holmes, Jr., D. J. Kereiakes, S. Garg, P. W. Serruys, G. J. Dehmer, S. G. Ellis, D. O. Williams,

T. Kimura, D. J. Moliterno, J Am Coll Cardiol 2010, 56, 1357.

[167] D. J. Kereiakes, J. K. Choo, J. J. Young, T. M. Broderick, Rev Cardiovasc Med 2004, 5, 9.

[168] A. Chieffo, E. Bonizzoni, D. Orlic, G. Stankovic, R. Rogacka, F. Airoldi, G. W. Mikhail, M. Montorfano, I. Michev, M. Carlino, A. Colombo, Circulation 2004, 109, 2732.

[169] M. H. Jeong, W. G. Owen, M. E. Staab, S. S. Srivatsa, G. Sangiorgi, M. Stewart, D. R. Holmes, Jr.,

R. S. Schwartz, Cathet Cardiovasc Diagn 1996, 38, 38.

[170] (a) S. Rinfret, D. E. Cutlip, P. T. Katsiyiannis, K. K. Ho, D. J. Cohen, J. P. Carrozza, Jr., R. J. Laham,

Catheter Cardiovasc Interv 2002, 57, 24; (b) D. Hasdai, K. N. Garratt, D. R. Holmes, Jr., P. B. Berger, R. S. Schwartz, M. R. Bell, J Am Coll Cardiol 1996, 28, 361.

[171] P. Wenaweser, C. Rey, F. R. Eberli, M. Togni, D. Tuller, S. Locher, A. Remondino, C. Seiler, O. M.

Hess, B. Meier, S. Windecker, Eur Heart J 2005, 26, 1180.

[172] M. L. Adix, I. A. Kaminsky, I. S. Choi, J Neurointerv Surg 2017, 9, 686.

[173] L. Rangel-Castilla, S. A. Munich, N. Jaleel, M. C. Cress, C. Krishna, A. Sonig, K. V. Snyder, A. H. Siddiqui, E. I. Levy, J Neurosurg 2017, 126, 1064. 


\section{Submitted to \\ ADVANCEDS}

[174] (a) S. Kawaguchi, T. Sakaki, H. Iwahashi, K. Fujimoto, J. Iida, H. Mishima, N. Nishikawa, Cerebrovasc Dis 2006, 22, 402; (b) R. M. Hupperts, J. Lodder, E. P. Heuts-van Raak, F. Kessels, Brain 1994, 117 ( Pt 4), 825; (c) J. H. Yang, H. Y. Choi, H. S. Nam, S. H. Kim, S. W. Han, J. H. Heo, Cerebrovasc Dis 2007, 24, 445.

[175] Y. Q. Zhu, M. H. Li, C. Fang, H. Q. Tan, W. Wang, P. L. Zhang, Y. S. Cheng, J. B. Wang, L. T. Ma, J Endovasc Ther 2010, 17, 55.

[176] S. Fuke, K. Maekawa, K. Kawamoto, H. Saito, T. Sato, T. Hioka, T. Ohe, Circ J 2007, 71, 220.

[177] P. R. Moreno, I. F. Palacios, M. N. Leon, J. Rhodes, V. Fuster, J. T. Fallon, Am J Cardiol 1999, 84, 462.

[178] (a) A. Farb, D. K. Weber, F. D. Kolodgie, A. P. Burke, R. Virmani, Circulation 2002, 105, 2974; (b) M. A. Costa, D. I. Simon, Circulation 2005, 111, 2257.

[179] H. C. Lowe, S. N. Oesterle, L. M. Khachigian, J Am Coll Cardiol 2002, 39, 183.

[180] C. Indolfi, G. Esposito, E. Di Lorenzo, A. Rapacciuolo, A. Feliciello, A. Porcellini, V. E. Avvedimento, M. Condorelli, M. Chiariello, Circulation 1995, 92, 1230.

[181] F. G. Welt, C. Rogers, Arterioscl Throm Vas 2002, 22, 1769.

[182] V. Evangelista, S. Manarini, S. Rotondo, N. Martelli, R. Polischuk, J. L. McGregor, G. de Gaetano,

C. Cerletti, Blood 1996, 88, 4183.

[183] D. I. Simon, Z. Chen, H. Xu, C. Q. Li, J. Dong, L. V. McIntire, C. M. Ballantyne, L. Zhang, M. I.

Furman, M. C. Berndt, J. A. Lopez, J Exp Med 2000, 192, 193.

[184] T. G. Diacovo, S. J. Roth, J. M. Buccola, D. F. Bainton, T. A. Springer, Blood 1996, 88, 146.

[185] D. I. Simon, Z. Dhen, P. Seifert, E. R. Edelman, C. M. Ballantyne, C. Rogers, J Clin Invest 2000, 105, 293.

[186] N. A. Scott, Adv Drug Deliv Rev 2006, 58, 358.

[187] (a) P. Libby, S. J. Warner, R. N. Salomon, L. K. Birinyi, N Engl J Med 1988, 318, 1493; (b) N. A. Scott, G. D. Cipolla, C. E. Ross, B. Dunn, F. H. Martin, L. Simonet, J. N. Wilcox, Circulation 1996, 93 , 2178.

[188] (a) A. Abizaid, R. Kornowski, G. S. Mintz, M. K. Hong, A. S. Abizaid, R. Mehran, A. D. Pichard, K.

M. Kent, L. F. Satler, H. Wu, J. J. Popma, M. B. Leon, J Am Coll Cardiol 1998, 32, 584; (b) S. Mittal,

D. L. Weiss, J. W. Hirshfeld, Jr., D. M. Kolansky, H. C. Herrmann, Am J Cardiol 1997, 80, 711.

[189] H. Narita, S. Chen, K. Komori, K. Kadomatsu, J Vasc Surg 2008, 47, 1322.

[190] (a) J. H. Martin, B. D. Yahata, J. M. Hundley, J. A. Mayer, T. A. Schaedler, T. M. Pollock, Nature 2017, 549, 365; (b) C. M. Campos, T. Muramatsu, J. Iqbal, Y. J. Zhang, Y. Onuma, H. M. Garcia-Garcia, M. Haude, P. A. Lemos, B. Warnack, P. W. Serruys, Int J Mol Sci 2013, 14, 24492; (c) M. J. Patel, S. S. Patel, N. S. Patel, N. M. Patel, Acta Pharm 2012, 62, 473; (d) H. Li, T. Liu, M. Wang, D. Zhao, A. Qiao, X. Wang, J. Gu, Z. Li, B. Zhu, Biomed Eng Online 2017, 16, 13; (e) K. M. Lekshmi, H. L. Che, C. S. Cho, I. K. Park, Chonnam Med J 2017, 53, 14; (f) R. Waksman, R. Erbel, C. Di Mario, J. Bartunek, B. de Bruyne, F. R. Eberli, P. Erne, M. Haude, M. Horrigan, C. Ilsley, D. Bose, H. Bonnier, J. Koolen, T. F. Luscher, N. J. Weissman, P.-A. Investigators, JACC Cardiovasc Interv 2009, 2, 312; (g) I. Larrabide, A. J. Geers, H. G. Morales, M. L. Aguilar, D. A. Rufenacht, J Neurointerv Surg 2015, 7, 272; (h) J. M. Jimenez, P. F. Davies, Ann Biomed Eng 2009, 37, 1483; (i) Q. Lin, X. Ding, F. Qiu, X. Song, G. Fu, J. Ji, Biomaterials 2010, 31, 4017; (j) Q. K. Guo, Z. Q. Lu, J. Y. Wang, T. Li, J Mater Sci Mater Med 2011, 


\section{Submitted to \\ ADVANCED}

22, 1615; (k) W. Lin, L. Qin, H. Qi, D. Zhang, G. Zhang, R. Gao, H. Qiu, Y. Xia, P. Cao, X. Wang, W. Zheng, Acta Biomater 2017, 54, 454; (1) T. Koppara, K. Sakakura, E. Pacheco, Q. Cheng, X. Zhao, E. Acampado, A. V. Finn, M. Barakat, L. Maillard, J. Ren, M. Deshpande, F. D. Kolodgie, M. Joner, R. Virmani, Int J Cardiol 2016, 222, 217; (m) T. J. Gundert, S. C. Shadden, A. R. Williams, B. K. Koo, J. A. Feinstein, J. F. Ladisa, Jr., Ann Biomed Eng 2011, 39, 1423; (n) R. Erbel, C. Di Mario, J. Bartunek, J. Bonnier, B. de Bruyne, F. R. Eberli, P. Erne, M. Haude, B. Heublein, M. Horrigan, C. Ilsley, D. Bose, J. Koolen, T. F. Luscher, N. Weissman, R. Waksman, P.-A. Investigators, Lancet 2007, 369, 1869; (o) M. W. Hagen, G. Girdhar, J. Wainwright, M. T. Hinds, J Neurointerv Surg 2017, 9, 1006.

[191] S. Morlacchi, F. Migliavacca, Ann Biomed Eng 2013, 41, 1428.

[192] C. Indolfi, E. V. Avvedimento, E. Di Lorenzo, G. Esposito, A. Rapacciuolo, P. Giuliano, D. Grieco,

L. Cavuto, A. M. Stingone, I. Ciullo, G. Condorelli, M. Chiariello, Nat Med 1997, 3, 775.

[193] C. Indolfi, E. Stabile, C. Coppola, A. Gallo, C. Perrino, G. Allevato, L. Cavuto, D. Torella, E. Di Lorenzo, G. Troncone, A. Feliciello, E. Avvedimento, M. Chiariello, Circ Res 2001, 88, 319.

[194] C. Indolfi, E. V. Avvedimento, A. Rapacciuolo, E. Di Lorenzo, G. Esposito, E. Stabile, A. Feliciello,

E. Mele, P. Giuliano, G. Condorelli, et al., Nat Med 1995, 1, 541.

[195] A. Curcio, D. Torella, C. Indolfi, Circ J 2011, 75, 1287.

[196] R. Wessely, A. Schomig, A. Kastrati, J Am Coll Cardiol 2006, 47, 708.

[197] C. Gareri, S. De Rosa, C. Indolfi, Circ Res 2016, 118, 1170.

[198] (a) R. Ji, Y. Cheng, J. Yue, J. Yang, X. Liu, H. Chen, D. B. Dean, C. Zhang, Circ Res 2007, 100, 1579;

(b) E. Raitoharju, L. P. Lyytikainen, M. Levula, N. Oksala, A. Mennander, M. Tarkka, N. Klopp, T. Illig,

M. Kahonen, P. J. Karhunen, R. Laaksonen, T. Lehtimaki, Atherosclerosis 2011, 219, 211.

[199] K. E. King, V. P. Iyemere, P. L. Weissberg, C. M. Shanahan, J Biol Chem 2003, 278, 11661.

[200] X. Liu, Y. Cheng, J. Yang, L. Xu, C. Zhang, J Mol Cell Cardiol 2012, 52, 245.

[201] X. Liu, Y. Cheng, S. Zhang, Y. Lin, J. Yang, C. Zhang, Circ Res 2009, 104, 476.

[202] E. Merlet, F. Atassi, R. K. Motiani, N. Mougenot, A. Jacquet, S. Nadaud, T. Capiod, M. Trebak, A.

M. Lompre, A. Marchand, Cardiovasc Res 2013, 98, 458.

[203] Y. Cheng, X. Liu, J. Yang, Y. Lin, D. Z. Xu, Q. Lu, E. A. Deitch, Y. Huo, E. S. Delphin, C. Zhang, Circ Res 2009, 105, 158.

[204] (a) K. R. Cordes, N. T. Sheehy, M. P. White, E. C. Berry, S. U. Morton, A. N. Muth, T. H. Lee, J. M. Miano, K. N. Ivey, D. Srivastava, Nature 2009, 460, 705; (b) J. M. Boucher, S. M. Peterson, S. Urs, C. Zhang, L. Liaw, J Biol Chem 2011, 286, 28312.

[205] L. Elia, M. Quintavalle, J. Zhang, R. Contu, L. Cossu, M. V. Latronico, K. L. Peterson, C. Indolfi, D. Catalucci, J. Chen, S. A. Courtneidge, G. Condorelli, Cell Death Differ 2009, 16, 1590.

[206] M. Xin, E. M. Small, L. B. Sutherland, X. Qi, J. McAnally, C. F. Plato, J. A. Richardson, R. BasselDuby, E. N. Olson, Genes Dev 2009, 23, 2166.

[207] (a) Q. Liu, H. Fu, F. Sun, H. Zhang, Y. Tie, J. Zhu, R. Xing, Z. Sun, X. Zheng, Nucleic Acids Res 2008, 36, 5391; (b) Y. S. Wang, H. Y. Wang, Y. C. Liao, P. C. Tsai, K. C. Chen, H. Y. Cheng, R. T. Lin, S. H. Juo, Cardiovasc Res 2012, 95, 517.

[208] R. Bakhshi, A. Darbyshire, J. E. Evans, Z. You, J. Lu, A. M. Seifalian, Colloids Surf B Biointerfaces 2011, 86, 93.

[209] D. Giacoppo, G. Gargiulo, P. Aruta, P. Capranzano, C. Tamburino, D. Capodanno, BMJ 2015, 351, 


\section{Submitted to \\ ADVANCEDS
MATERIALS}

h5392.

[210] Y. Zhu, K. Yang, R. Cheng, Y. Xiang, T. Yuan, Y. Cheng, B. Sarmento, W. Cui, Mater Today 2017, $20,516$.

[211] G. La Torre, U. Romeo, G. Iarocci, O. Brugnoletti, L. Semyonov, A. Galanakis, E. Barbato, Ann Stomatol (Roma) 2015, 5, 131.

[212] E. Barbato, W. Wijns, JACC Cardiovasc Interv 2015, 8, 280.

[213] (a) K. Tsuji-Takayama, T. Inoue, Y. Ijiri, T. Otani, R. Motoda, S. Nakamura, K. Orita, Biochem Biophys Res Commun 2004, 323, 86; (b) G. G. Toth, A. Ntalianis, Y. Ntarladimas, M. de Booij, O. De Winter, E. Barbato, B. Pilet, C. Van Mieghem, W. Wijns, B. De Bruyne, Catheter Cardiovasc Interv 2015, 85, 1173.

[214] (a) C. Di Mario, H. Griffiths, O. Goktekin, N. Peeters, J. Verbist, M. Bosiers, K. Deloose, B. Heublein, R. Rohde, V. Kasese, C. Ilsley, R. Erbel, J Interv Cardiol 2004, 17, 391; (b) P. Zartner, R. Cesnjevar, H. Singer, M. Weyand, Catheter Cardiovasc Interv 2005, 66, 590; (c) D. Schranz, P. Zartner, I. MichelBehnke, H. Akinturk, Catheter Cardiovasc Interv 2006, 67, 671; (d) R. Erbel, C. Di Mario, J. Bartunek, J. Bonnier, B. de Bruyne, F. R. Eberli, P. Erne, M. Haude, B. Heublein, M. Horrigan, C. Ilsley, D. Bose, J. Koolen, T. F. Luscher, N. Weissman, R. Waksman, P.-A. Investigators, Lancet 2007, 369, 1869; (e) A. Schomig, A. Dibra, S. Windecker, J. Mehilli, J. Suarez de Lezo, C. Kaiser, S. J. Park, J. J. Goy, J. H. Lee, E. Di Lorenzo, J. Wu, P. Juni, M. E. Pfisterer, B. Meier, A. Kastrati, J Am Coll Cardiol 2007, 50, 1373; (f) M. Haude, H. Ince, A. Abizaid, R. Toelg, P. A. Lemos, C. von Birgelen, E. H. Christiansen, W. Wijns, F. J. Neumann, C. Kaiser, E. Eeckhout, S. T. Lim, J. Escaned, H. M. Garcia-Garcia, R. Waksman, Lancet 2016, 387, 31.

[215] (a) J. Wang, Y. He, M. F. Maitz, B. Collins, K. Xiong, L. Guo, Y. Yun, G. Wan, N. Huang, Acta Biomater 2013, 9, 8678; (b) E. Zhang, F. Shen, Mater Sci Eng C Mater Biol Appl 2015, 52, 37.

[216] (a) S. F. Fischerauer, T. Kraus, X. Wu, S. Tangl, E. Sorantin, A. C. Hanzi, J. F. Loffler, P. J. Uggowitzer,

A. M. Weinberg, Acta Biomater 2013, 9, 5411; (b) P. Lu, L. Cao, Y. Liu, X. Xu, X. Wu, J Biomed Mater Res B Appl Biomater 2011, 96, 101.

[217] E. Mostaed, M. Hashempour, A. Fabrizi, D. Dellasega, M. Bestetti, F. Bonollo, M. Vedani, J Mech Behav Biomed Mater 2014, 37, 307.

[218] M. Greger, R. Kocich, L. Cizek, J Achievements Mat M 2007, $20,447$.

[219] Y. Li, C. Wen, D. Mushahary, R. Sravanthi, N. Harishankar, G. Pande, P. Hodgson, Acta Biomater 2012, 8, 3177.

[220] G. Song, A. Atrens, X. Wu, B. Zhang, Corros Sci 1998, 40, 1769.

[221] B. Ratna Sunil, T. S. Sampath Kumar, U. Chakkingal, V. Nandakumar, M. Doble, V. Devi Prasad, M. Raghunath, Mater Sci Eng C Mater Biol Appl 2016, 59, 356.

[222] (a) M. Peuster, P. Wohlsein, M. Brugmann, M. Ehlerding, K. Seidler, C. Fink, H. Brauer, A. Fischer,

G. Hausdorf, Heart 2001, 86, 563; (b) C. Wu, H. Qiu, X. Y. Hu, Y. M. Ruan, Y. Tian, Y. Chu, X. L. Xu,

L. Xu, Y. Tang, R. L. Gao, Chin Med J (Engl) 2013, 126, 4752.

[223] P. K. Bowen, J. Drelich, J. Goldman, Adv Mater 2013, 25, 2577.

[224] E. Mostaed, M. Sikora-Jasinska, A. Mostaed, S. Loffredo, A. G. Demir, B. Previtali, D. Mantovani,

R. Beanland, M. Vedani, J Mech Behav Biomed Mater 2016, 60, 581.

[225] (a) H. Takatsuki, S. Komatsu, R. Sano, Y. Takada, T. Tsuji, Cancer Res 2004, 64, 6065; (b) E. 


\section{Submitted to \\ ADNAMEED
MAATERAAS}

Tenekecioglu, C. Bourantas, M. Abdelghani, Y. Zeng, R. C. Silva, H. Tateishi, Y. Sotomi, Y. Onuma, M. Yilmaz, P. W. Serruys, Expert Rev Med Devices 2016, 13, 271.

[226] (a) X. Zhu, R. D. Braatz, J Biomed Mater Res A 2015, 103, 2269; (b) J. B. McClain, W. C. Carlyle,

D. J. Donohoe, J. A. Ormiston, Minerva Cardioangiol 2016.

[227] K. Nishimiya, Y. Matsumoto, H. Uzuka, T. Ogata, M. Hirano, T. Shindo, Y. Hasebe, R. Tsuburaya, T.

Shiroto, J. Takahashi, K. Ito, H. Shimokawa, JACC Cardiovasc Interv 2016, 9, 281.

[228] C. S. Yang, H. C. Wu, J. S. Sun, H. M. Hsiao, T. W. Wang, ACS Appl Mater Interfaces 2013, 5, 10985.

[229] U. Westedt, M. Wittmar, M. Hellwig, P. Hanefeld, A. Greiner, A. K. Schaper, T. Kissel, J Control Release 2006, 111, 235.

[230] T. Tsuji, H. Nakamura, A. Hirata, T. Yamamoto, Anat Rec A Discov Mol Cell Evol Biol 2004, 279, 729.

[231] T. Tsuji, M. Yoshinaga, S. Togami, T. Douchi, Y. Nagata, Acta Obstet Gynecol Scand 2004, 83, 586. [232] M. Joner, G. Nakazawa, A. V. Finn, S. C. Quee, L. Coleman, E. Acampado, P. S. Wilson, K. Skorija,

Q. Cheng, X. Xu, H. K. Gold, F. D. Kolodgie, R. Virmani, J Am Coll Cardiol 2008, 52, 333.

[233] G. G. Stefanini, P. W. Serruys, S. Silber, A. A. Khattab, R. J. van Geuns, G. Richardt, P. E. Buszman,

H. Kelbaek, A. J. van Boven, S. H. Hofma, A. Linke, V. Klauss, W. Wijns, C. Macaya, P. Garot, C. Di Mario, G. Manoharan, R. Kornowski, T. Ischinger, A. L. Bartorelli, P. Gobbens, S. Windecker, J Am Coll Cardiol 2011, 57, 2221.

[234] G. J. Wilson, B. A. Huibregtse, D. E. Pennington, K. D. Dawkins, EuroIntervention 2012, 8, 250.

[235] J. Iqbal, S. Verheye, A. Abizaid, J. Ormiston, T. de Vries, L. Morrison, S. Toyloy, P. Fitzgerald, S.

Windecker, P. W. Serruys, EuroIntervention 2015, 11.

[236] S. Banerjee, Cardiol Ther 2013, 2, 17.

[237] Y. Zhang, F. Chen, T. Muramatsu, B. Xu, Z. Li, J. Ge, Q. He, Z. Yang, S. Li, L. Wang, H. Wang, B.

He, K. Li, G. Qi, T. Li, H. Zeng, J. Peng, T. Jiang, Q. Zeng, J. Zhu, G. Fu, C. V. Bourantas, P. W. Serruys, Y. Huo, Chin Med J (Engl) 2014, 127, 2153.

[238] D. J. Kereiakes, L. A. Cannon, J. A. Ormiston, M. A. Turco, T. Mann, G. J. Mishkel, T. McGarry, H.

Wang, P. Underwood, K. D. Dawkins, Am J Cardiol 2011, 108, 828.

[239] M. Chen, X. G. Wang, B. Zheng, H. Y. Peng, X. Y. Zhang, B. Zhang, Y. Huo, Chin Med J (Engl) 2012, 125, 4083 .

[240] B. Xu, K. Dou, Y. Yang, S. Lv, L. Wang, H. Wang, Z. Li, L. Wang, Y. Chen, Y. Huo, W. Li, A. J. Kirtane, R. Gao, EuroIntervention 2012, 8, 796.

[241] B. Chevalier, P. W. Serruys, S. Silber, E. Garcia, H. Suryapranata, K. Hauptmann, W. Wijns, G. Schuler, F. Fath-Ordoubadi, S. Worthley, L. Thuesen, I. Meredith, M. Bressers, H. Nagai, D. Paunovic, EuroIntervention 2007, 2, 426.

[242] N. Reifart, K. E. Hauptmann, A. Rabe, D. Enayat, K. Giokoglu, EuroIntervention 2010, 6, 356.

[243] S. Oikawa, M. Minegishi, K. Endo, W. Kawashima, K. Suzuki, H. Shimizu, Vox Sang 2016, 111, 437.

[244] G. B. Danzi, B. Chevalier, P. Urban, F. Fath-Ordoubadi, D. Carrie, M. Wiemer, A. Serra, W. Wijns,

P. Kala, A. Stabile, J. G. Ruigomez, D. Sagic, P. Laanmets, G. Strupp, N. West, D. Paunovic, N. Investigators, EuroIntervention 2012, 8, 109.

[245] I. Buysschaert, E. Sanidas, T. Hasegawa, B. K. Koo, Y. Honda, P. J. Fitzgerald, S. Verheye, Catheter Cardiovasc Interv 2014, 84, 1062. 


\section{Submitted to \\ ADVANCEDS}

[246] J. Waltenberger, J. Brachmann, J. van der Heyden, G. Richardt, O. Frobert, M. Seige, A. Erglis, W.

Dewilde, M. Winkens, C. Hegeler-Molkewehrum, N. Klein, S. Hoffmann, B.-I. Investigators, EuroIntervention 2016, 11, 1106.

[247] G. F. Attizzani, H. G. Bezerra, D. Chamie, Y. Fujino, A. M. Spognardi, J. R. Stanley, H. Yamamoto, E. Mehanna, W. Wang, W. C. Carlyle, J. B. McClain, M. A. Costa, J Invasive Cardiol 2012, 24, 560.

[248] L. Zhang, J. Yuan, G. Liu, J. P. Zhong, Y. H. Yin, Q. She, L. Su, Z. Y. Ling, Y. Q. Chen, J Interv Cardiol 2012, 25, 604.

[249] R. Diletti, H. M. Garcia-Garcia, C. V. Bourantas, R. J. van Geuns, N. M. Van Mieghem, P. Agostoni,

T. Muramatsu, V. Farooq, R. Spencer, J. De Schepper, M. Pomeranz, P. Stella, P. W. Serruys, EuroIntervention 2013, 9, 125.

[250] E. Barbato, S. Salinger-Martinovic, D. Sagic, B. Beleslin, M. Vrolix, A. N. Neskovic, N. Jagic, S.

Verheye, Z. Mehmedbegovic, W. Wijns, EuroIntervention 2015, 11, 541.

[251] P. Urban, A. Abizaid, B. Chevalier, S. Greene, I. Meredith, M. C. Morice, S. Pocock, Am Heart J 2013, 165, 704.

[252] C. Moretti, V. Lolli, G. Perona, M. C. Vignolini, K. Cabiale, M. Falzone, M. Galloni, EuroIntervention 2012, 7, 1087.

[253] L. O. Jensen, M. Maeng, A. Kaltoft, P. Thayssen, H. H. Hansen, M. Bottcher, J. F. Lassen, L. R.

Krussel, K. Rasmussen, K. N. Hansen, L. Pedersen, S. P. Johnsen, H. T. Soerensen, L. Thuesen, J Am Coll Cardiol 2007, 50, 463.

[254] (a) H. K. Kim, M. H. Jeong, Chonnam Med J 2012, 48, 141; (b) J. Pache, A. Kastrati, J. Mehilli, H. Schuhlen, F. Dotzer, J. Hausleiter, M. Fleckenstein, F. J. Neumann, U. Sattelberger, C. Schmitt, M. Muller, J. Dirschinger, A. Schomig, J Am Coll Cardiol 2003, 41, 1283; (c) A. Kastrati, J. Mehilli, J. Dirschinger, F. Dotzer, H. Schuhlen, F. J. Neumann, M. Fleckenstein, C. Pfafferott, M. Seyfarth, A. Schomig, Circulation 2001, 103, 2816; (d) K. Kolandaivelu, R. Swaminathan, W. J. Gibson, V. B. Kolachalama, K. L. Nguyen-Ehrenreich, V. L. Giddings, L. Coleman, G. K. Wong, E. R. Edelman, Circulation 2011, 123, 1400.

[255] D. Sun, Y. Zheng, T. Yin, C. Tang, Q. Yu, G. Wang, J Biomed Mater Res A 2014, 102, 1625.

[256] B. Chevalier, S. Silber, S. J. Park, E. Garcia, G. Schuler, H. Suryapranata, J. Koolen, K. E. Hauptmann,

W. Wijns, M. C. Morice, D. Carrie, G. A. van Es, H. Nagai, D. Detiege, D. Paunovic, P. W. Serruys, N. C. Investigators, Circ Cardiovasc Interv 2009, 2, 188.

[257] (a) J. Legutko, W. Zasada, G. L. Kaluza, G. Heba, L. Rzeszutko, J. Jakala, J. Dragan, A. Klecha, D. Giszterowicz, W. Dobrowolski, L. Partyka, S. Jayaraman, D. Dudek, Indian Heart J 2013, 65, 388; (b)

Q. Dang, Y. J. Li, L. Gao, Z. Jin, L. X. Gou, Chin Med J (Engl) 2012, 125, 3393.

[258] Y. Onuma, P. W. Serruys, L. E. Perkins, T. Okamura, N. Gonzalo, H. M. Garcia-Garcia, E. Regar, M.

Kamberi, J. C. Powers, R. Rapoza, H. van Beusekom, W. van der Giessen, R. Virmani, Circulation 2010, $122,2288$.

[259] S. Brugaletta, J. H. Heo, H. M. Garcia-Garcia, V. Farooq, R. J. van Geuns, B. de Bruyne, D. Dudek,

P. C. Smits, J. Koolen, D. McClean, C. Dorange, S. Veldhof, R. Rapoza, Y. Onuma, N. Bruining, J. A. Ormiston, P. W. Serruys, Eur Heart J 2012, 33, 1325.

[260] R. J. Cottone, G. L. Thatcher, S. P. Parker, L. Hanks, D. A. Kujawa, S. M. Rowland, M. Costa, R. S. Schwartz, Y. Onuma, EuroIntervention 2009, 5 Suppl F, F65. 


\section{Submitted to \\ ADNANEE
MAATERALS}

[261] (a) W. Kurre, M. Aguilar-Perez, S. Fischer, G. Arnold, E. Schmid, H. Bazner, H. Henkes, Cardiovasc Intervent Radiol 2015, 38, 583; (b) J. H. Lee, S. M. Jo, K. D. Jo, M. K. Kim, S. Y. Lee, S. H. You, J Cerebrovasc Endovasc Neurosurg 2013, 15, 85; (c) S. Park, D. G. Lee, W. J. Chung, D. H. Lee, D. C. Suh, Neurointervention 2013, 8, 9.

[262] M. Marosfoi, F. Clarencon, E. T. Langan, R. M. King, O. W. Brooks, T. Tamura, J. M. Wainwright, M. J. Gounis, S. Vedantham, A. S. Puri, J Neurointerv Surg 2018, 10, 406.

[263] (a) S. Bailey, P. Seifert, B. Huibregtse, B. Poff, Cardiovascular Revascularization Medicine 2006, 7 , 90; (b) A. C. Strang, M. L. Knetsch, L. H. Koole, R. J. de Winter, A. C. van der Wal, C. J. de Vries, P. P. Tak, R. J. Bisoendial, E. S. Stroes, J. I. Rotmans, PLoS One 2015, 10, e0122836.

[264] (a) P. Tack, J. Victor, P. Gemmel, L. Annemans, Biomed Eng Online 2016, 15, 115; (b) U. Jammalamadaka, K. Tappa, J Funct Biomater 2018, 9, pii: E22.

[265] J. J. Lewandowski, M. Seifi, Annu Rev Mater Res 2016, 46.

[266] K. V. Venkatesh, V. V. Nandini, J Indian Prosthodont Soc 2013, 13, 389.

[267] D. Mitsouras, P. Liacouras, A. Imanzadeh, A. A. Giannopoulos, T. Cai, K. K. Kumamaru, E. George, N. Wake, E. J. Caterson, B. Pomahac, V. B. Ho, G. T. Grant, F. J. Rybicki, Radiographics 2015, 35, 1965.

[268] H. W. Kang, S. J. Lee, I. K. Ko, C. Kengla, J. J. Yoo, A. Atala, Nat Biotechnol 2016, 34, 312.

[269] S. S. G. Kaplas, Munish, Adv Manufacturing Pr 2009, 24, 1405.

[270] E. MacDonald, R. Wicker, Science 2016, 353, aaf2093. 


\section{Click here to access/download \\ Supporting Information 20180919-Review Paper - clear version.docx}


Click here to access/download

\section{Supporting Information All License.zip}


Click here to access/download
Production Data
Fig 1.tif

Click here to access/download
Production Data
Fig 1.tif Click here to access/download
Production Data
Fig 1.tif

Fig. 1

.

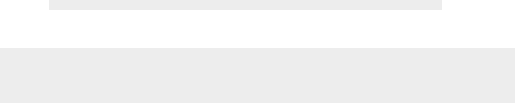

.

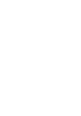

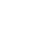


Click here to access/download
Production Data
Fig 3.tif

Click here to access/download
Production Data
Fig 3.tif Click here to access/download
Production Data
Fig 3.tif

Fig. 3
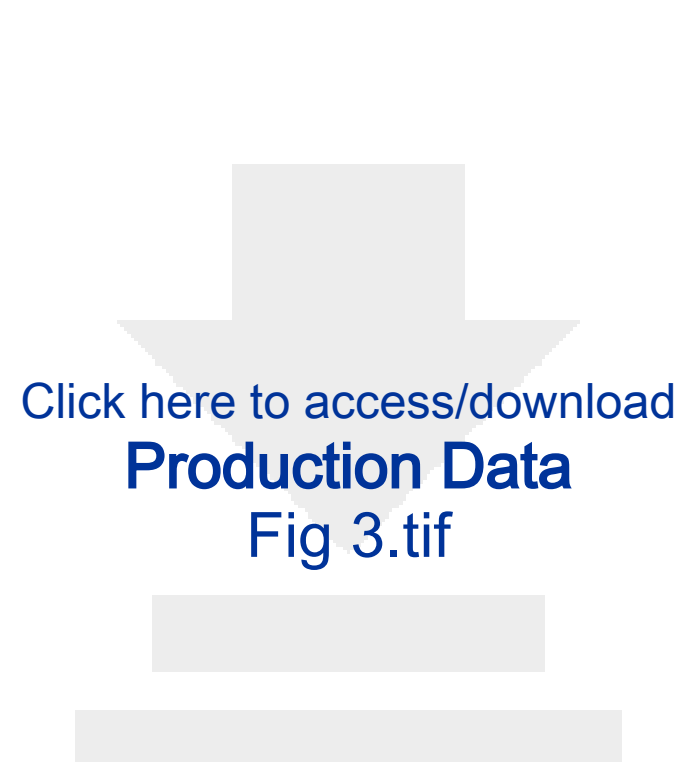

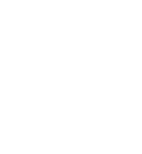

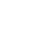

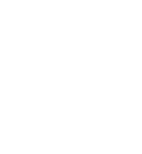

.


Click here to access/download
Production Data

Click here to access/download
Production Data

Fig. 4

\section{Fig 4.tif

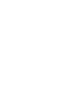

F. 4

.

-

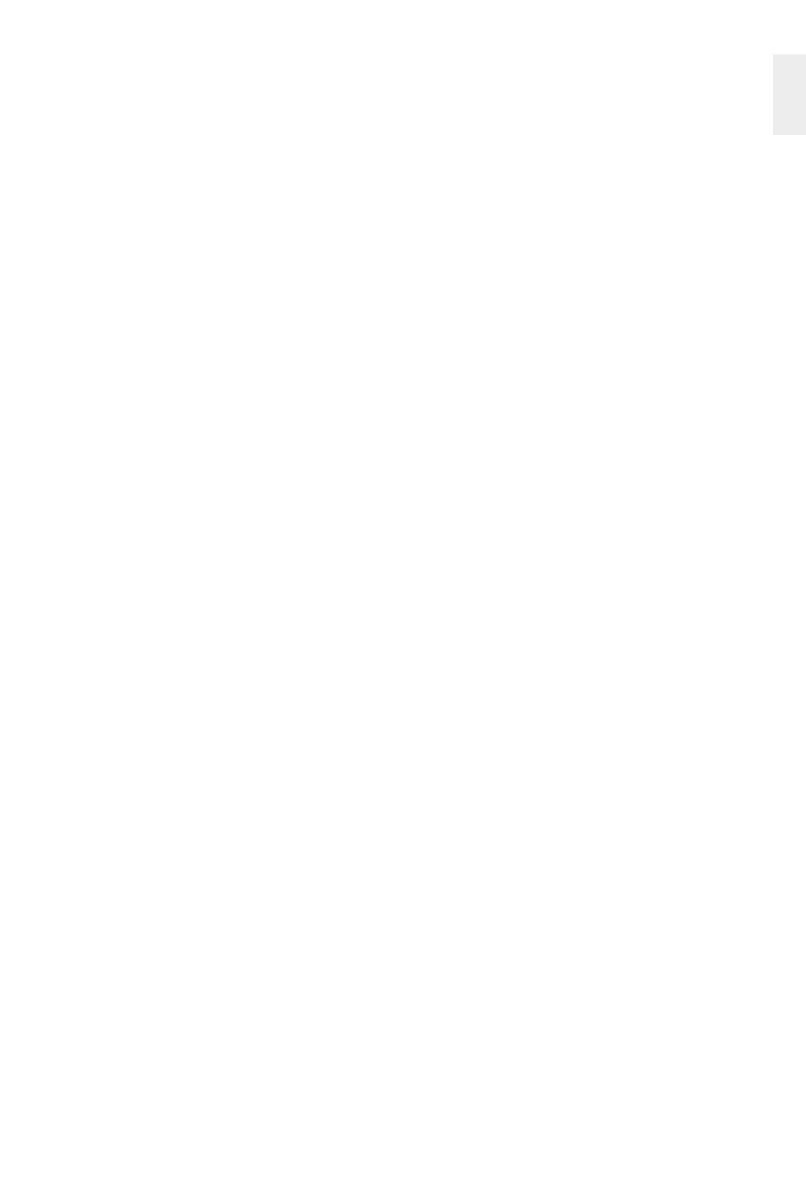

.


Fig. 5

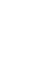
Click here to access/download
Production Data
Fig 5.tif

\section{Click here to access/download
Production Data
Fig 5.tif Click here to access/download
Production Data
Fig 5.tif \\ Click here to access/download
Production Data
Fig 5.tif \\ Click here to access/download
Production Data
Fig 5.tif

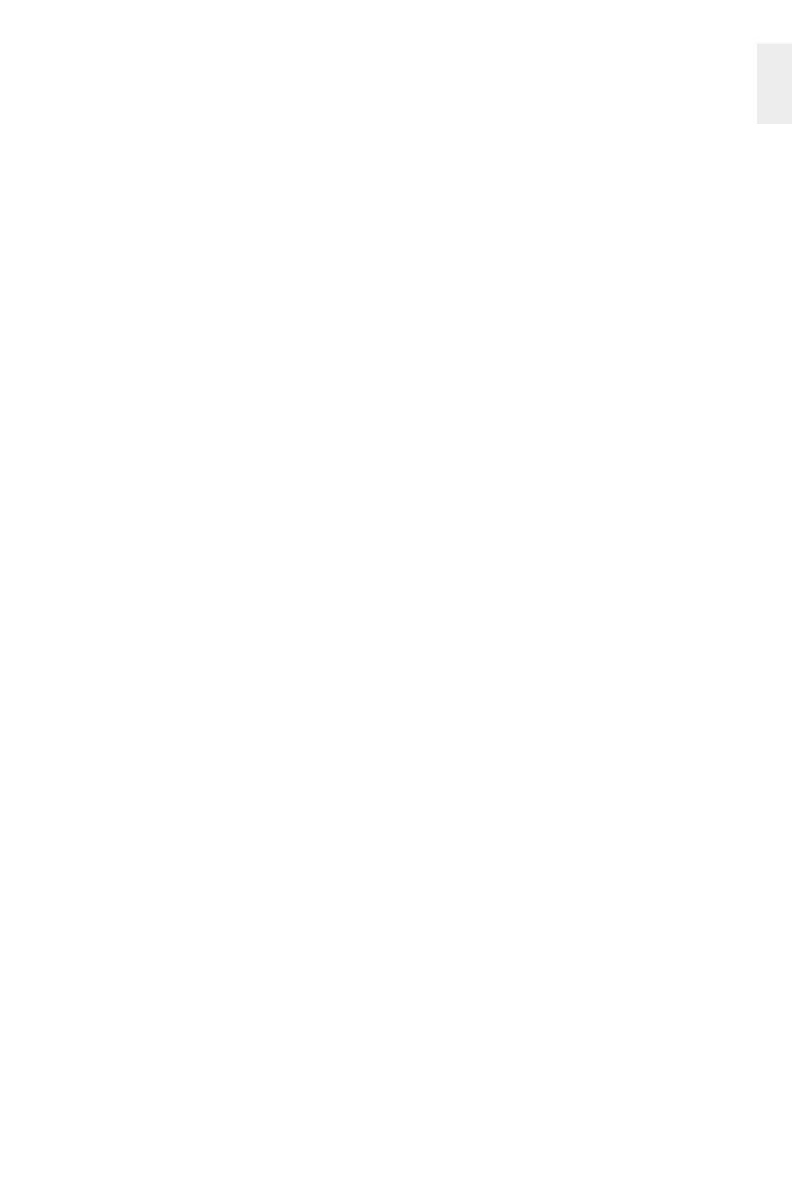


Fig. 6

\section{Click here to access/download
Production Data
Fig 6.tif \\ Click here to access/download
Production Data
Fig 6.tif Click here to access/download
Production Data
Fig 6.tif \\ Click here to access/download
Production Data
Fig 6.tif \\ Click here to access/download
Production Data
Fig 6.tif \\ Click here to access/download
Production Data
Fig 6.tif}

.

6

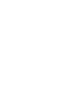

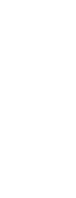

Click here to access/download
Production Data
Fig 6.tif . 
Fig. 7

\title{
Click here to access/download
Production Data \\ Click here to access/download
Production Data
Fig 7.tif Click here to access/download
Production Data
Fig 7.tif \\ Click here to access/download
Production Data
Fig 7.tif \\ Click here to access/download
Production Data
Fig 7.tif
}

.

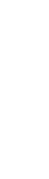

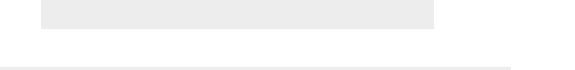

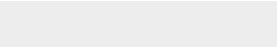

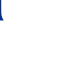

.

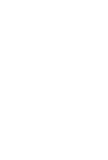


Graphical Abstract

Click here to access/download Production Data Graphic abstract.tif 